National Highway Traffic Safety Administration

\title{
Evaluation of Oregon's Graduated Driver Lieensing Program
}

Final Report 


\section{ACKNOWLEDGEMENTS}

We gratefully acknowledge Barnie Jones and Robert Edgar of the Oregon Department of Transportation for their assistance and support in this investigation.

Our Advisory Panel provided ongoing guidance and suggestions, and we thank them for the time and effort offered by Iris Key, National Council of Juvenile \& Family Court Judges; Dan Mayhew, Kathy Desmond, and Ward Vanlaar of Traffic Injury Research Foundation; Ruth Shults, Centers for Disease Control and Prevention; and Troy Costales, Mary Garcia, John Harvey, Barnie Jones, Susan Riehl, and Rodney Rosenkranz of the Oregon Department of Transportation.

We also appreciate the support provided by Patty Ellison-Potter and Linda Cosgrove of the Office of Behavioral Safety Research, National Highway Traffic Safety Administration. 


\begin{tabular}{|c|c|c|c|}
\hline $\begin{array}{l}\text { 1. Report No. } \\
\text { DOT HS } 810830\end{array}$ & 2. Government Accession No. & \multicolumn{2}{|c|}{ 3. Recipient's Catalog No. } \\
\hline \multicolumn{2}{|l|}{ 4. Title and Subtitle } & \multicolumn{2}{|l|}{ 5. Report Date } \\
\hline \multirow{2}{*}{\multicolumn{2}{|c|}{ Evaluation of Oregon's Graduated Driver Licensing Program }} & \multicolumn{2}{|c|}{ September 2007} \\
\hline & & \multicolumn{2}{|c|}{ 6. Performing Organization Code } \\
\hline \multicolumn{2}{|c|}{$\begin{array}{l}\text { 7. Author(s) } \\
\text { Paula Raymond, Michael Johns, Gary Golembiewski, Rita Furst Seifert, } \\
\text { James Nichols, and Richard Knoblauch }\end{array}$} & \multicolumn{2}{|c|}{ 8. Performing Organization Report No. } \\
\hline \multirow{3}{*}{\multicolumn{2}{|c|}{$\begin{array}{l}\text { 9. Performing Organization Name and Address } \\
\text { Center for Applied Research, Inc. } \\
\text { 9661 Fringe Tree Road } \\
\text { Great Falls, VA 22066-1901 }\end{array}$}} & \multirow{2}{*}{\multicolumn{2}{|c|}{ 10. Work Unit No. (TRAIS) }} \\
\hline & & & \\
\hline & & \multicolumn{2}{|c|}{$\begin{array}{l}\text { 11. Contract or Grant No. } \\
\text { DTNH22-02-D-35121 }\end{array}$} \\
\hline \multirow{3}{*}{\multicolumn{2}{|c|}{$\begin{array}{l}\text { 12. Sponsoring Agency Name and Address } \\
\text { U.S. Department of Transportation } \\
\text { National Highway Traffic Safety Administration } \\
1200 \text { New Jersey Avenue SE. } \\
\text { Washington, DC } 20590\end{array}$}} & \multirow{2}{*}{\multicolumn{2}{|c|}{$\begin{array}{l}\text { 13. Type of Report and Period Covered } \\
\text { Final Report } \\
\text { October } 2005 \text { - November } 2006\end{array}$}} \\
\hline & & & \\
\hline & & \multicolumn{2}{|c|}{ 14. Sponsoring Agency Code } \\
\hline \multicolumn{4}{|l|}{$\begin{array}{l}\text { 15. Supplementary Notes } \\
\text { Dr. Patricia Ellison-Potter s }\end{array}$} \\
\hline \multicolumn{4}{|c|}{$\begin{array}{l}\text { 18. Distribution Statement } \\
\text { This report is available from the National Technical Services } \\
\text { (NTIS), Springfield, VA 22161, 703-605-6000. It is also } \\
\text { available, free of charge, on the NHTSA Web site at } \\
\text { www.nhtsa.dot.gov. }\end{array}$} \\
\hline $\begin{array}{l}\text { 19. Security Classif.(of this report) } \\
\text { Unclassified }\end{array}$ & $\begin{array}{l}\text { 20. Security Classif.(of this page) } \\
\text { Unclassified }\end{array}$ & $\begin{array}{l}\text { 21. No. of Pages } \\
138\end{array}$ & 22. Price \\
\hline
\end{tabular}




\section{TABLE OF CONTENTS}

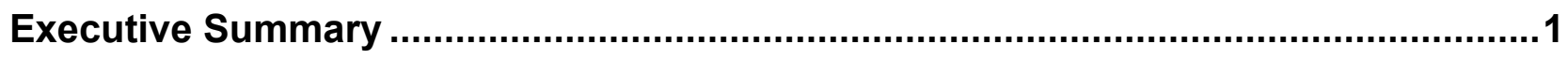

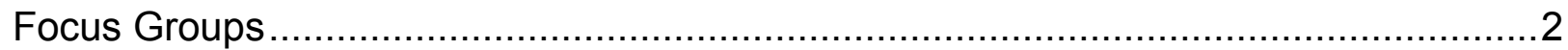

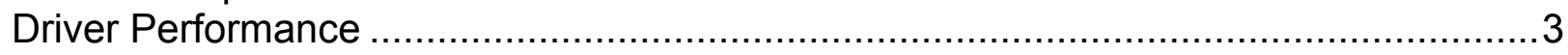

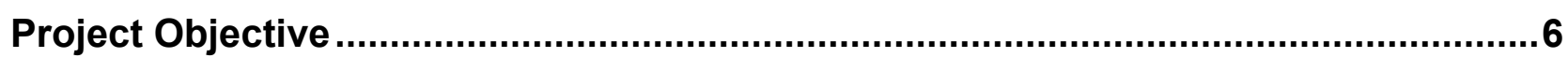

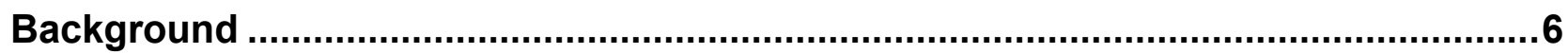

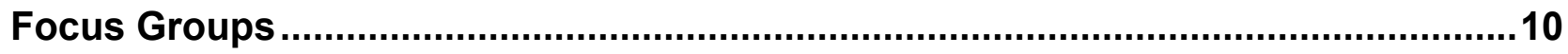

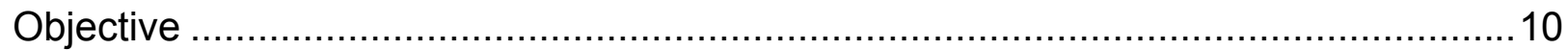

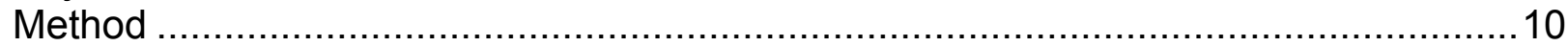

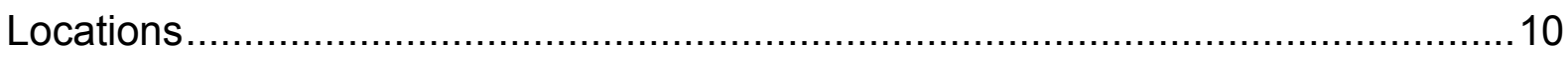

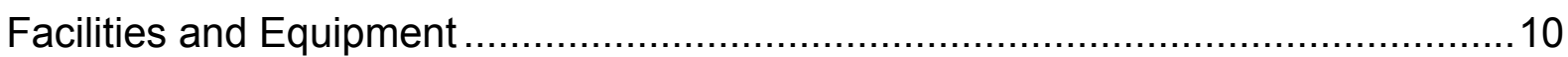

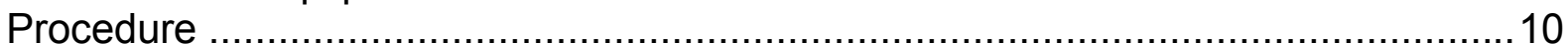

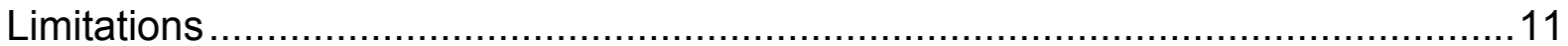

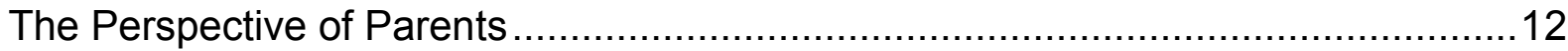

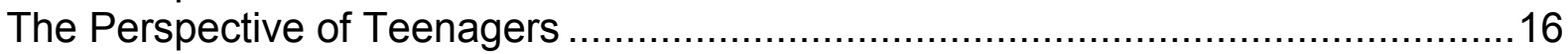

The Perspective of Law Enforcement Officers ................................................ 18

The Perspective of DMV Driving Test Administrators .......................................20

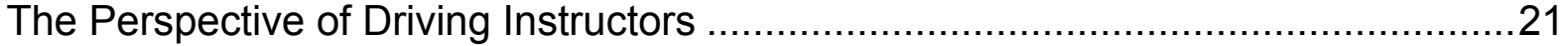

The Perspective of High School Administrators ................................................22

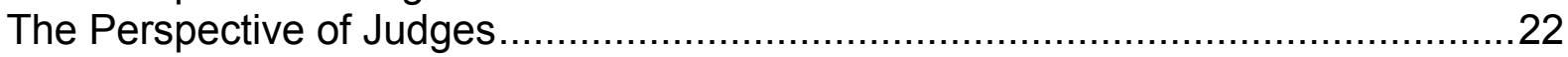

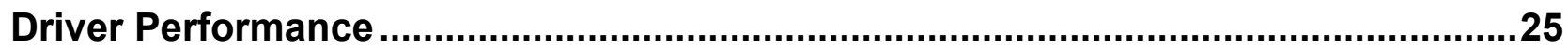

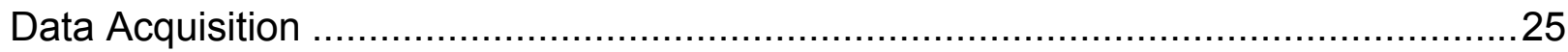

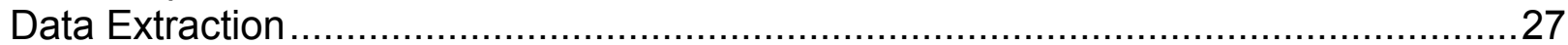

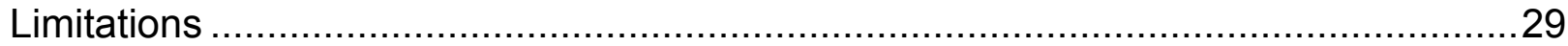

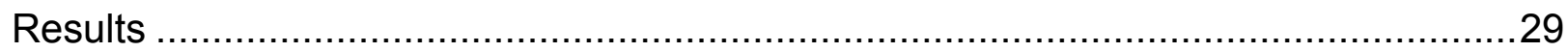

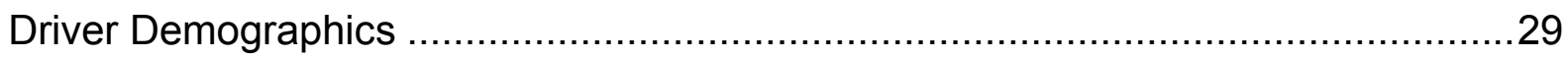

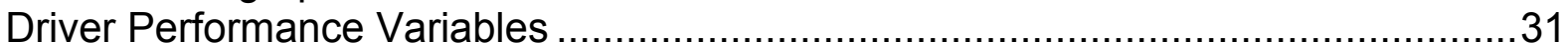

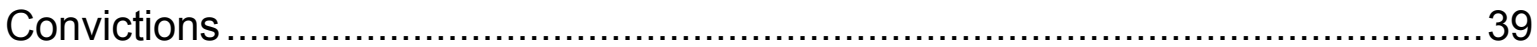

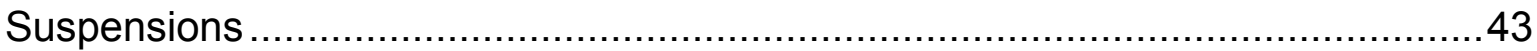

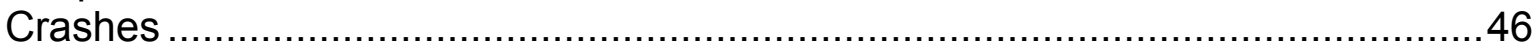

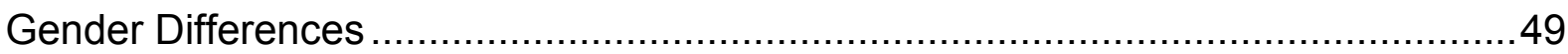

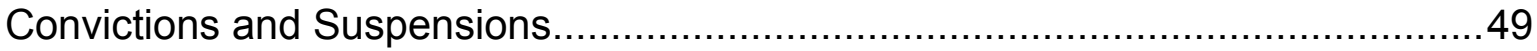

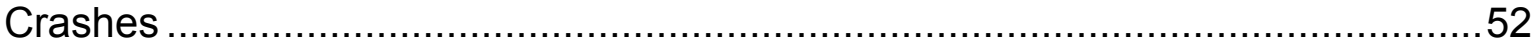

Driving Performance Related to Education and Training Options .........................56

Conclusions and Summary Discussion .................................................................59

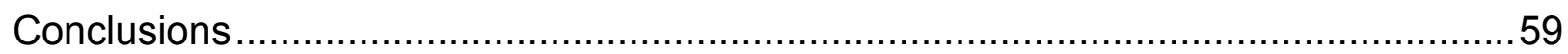




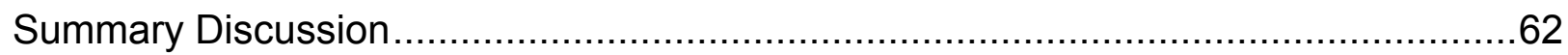

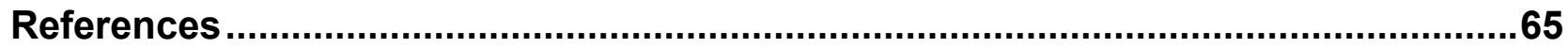

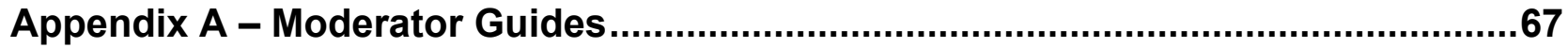

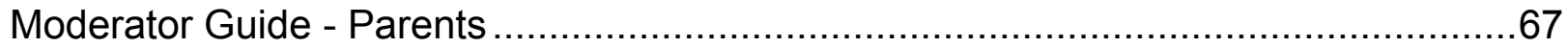

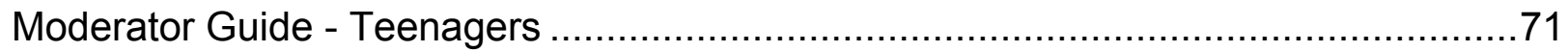

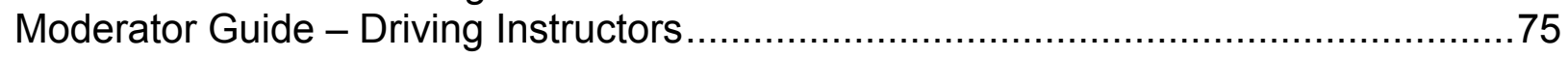

Moderator Guide - DMV Road Test Administrators ........................................... 79

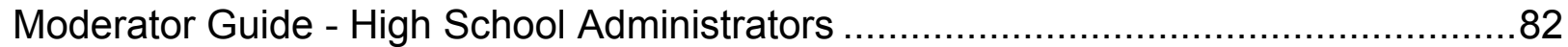

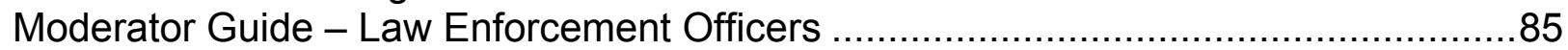

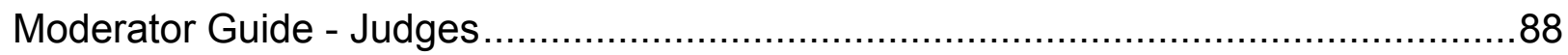

Appendix B - Oregon Teen Driving Laws Fact Sheet ...............................................91

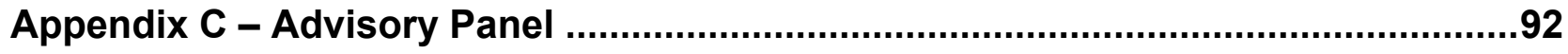

Appendix D - Driving Performance Related to Education and Training Options.....94

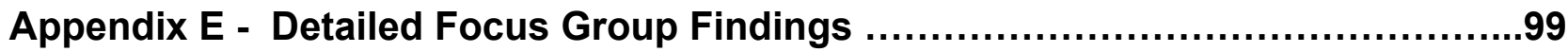

Appendix F - Oregon Statutes Related to Youth Driver Licensing ....................132 


\section{LIST OF TABLES}

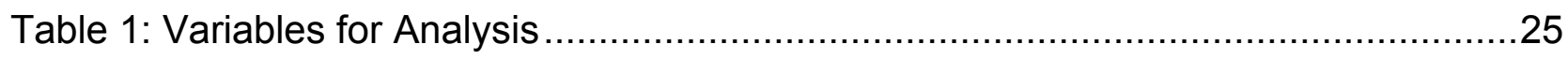

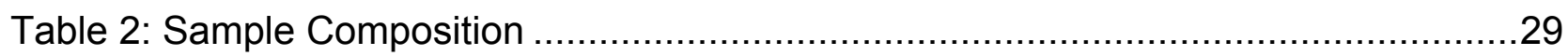

Table 3: Convictions, Suspensions and Crashes by Age Group and Year, 1999-2002 ..32

Table 4: Suspensions by Age (16 \& 17-year Olds) per 1,000 .....................................33

Table 5: Suspensions by Age (18 \& 19-Year Olds) per 1,000 ....................................34

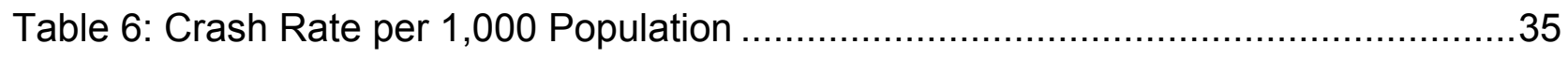

Table 7: Crash Rates per 1,000 Population 18 and Older ............................................3

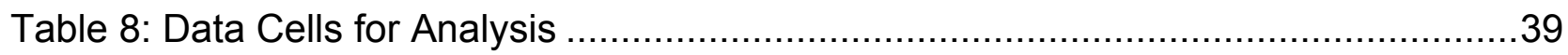

Table 9: Conviction Rate - Summary of Analyses by Months and Comparison Groups...41

Table 10: Suspension Rate - Summary of Analyses by Months and Comparison Groups

Table 11: Crash Rate - Summary of Analyses by Months and Comparison Groups

Table 12: Conviction Rate - Summary of Analyses by Months, Gender, and Comparison Groups

Table 13: Suspension Rate - Summary of Analyses by Months, Gender, and Comparison Groups

Table 14: Crash Rate - Summary of Analyses by Months, Gender, and Comparison Groups

Table 15: Characteristics of Drivers Who Chose Driver Education versus Additional Practice.....

Table 16: Conviction Rate - Summary of Analyses by Months, Training Option, and Comparison Groups

Table 17: Suspension Rate - Summary of Analyses by Months, Training Option, and Comparison Groups

Table 18: Crash Rate - Summary of Analyses by Months, Training Option, and Comparison Groups 


\section{LIST OF FIGURES}

Figure 1: Number of New Drivers by Age at Licensure by Year ....................................30

Figure 2: New Drivers by Age and Gender at Licensure by Year ..................................30

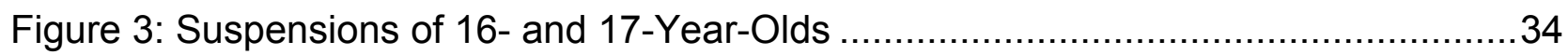

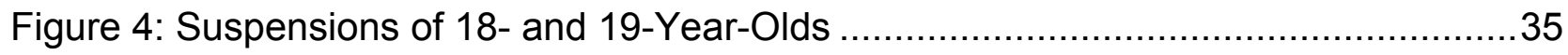

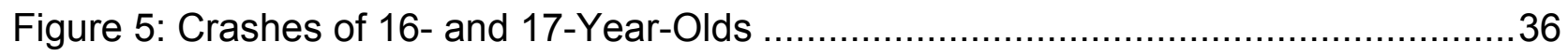

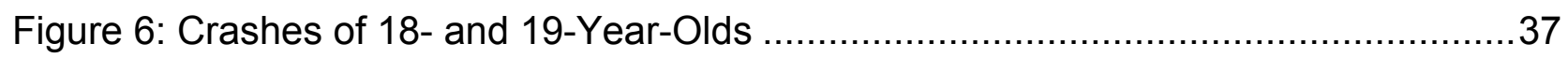

Figure 7: Monthly Convictions per 1,000 Drivers in the First 6 Months of Licensure

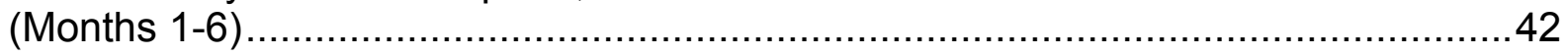

Figure 8: Monthly Convictions per 1,000 Drivers in the Second 6 Months of Licensure

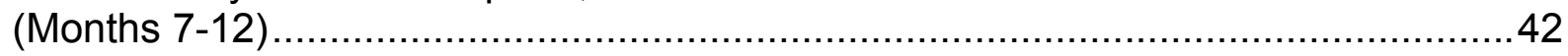

Figure 9: Monthly Convictions per 1,000 Drivers in the Second Year of Licensure (Months 13-24)

Figure 10: Monthly Suspensions per 1,000 Drivers in the First Two Years of Licensure..45

Figure 11: Monthly Crashes per 1,000 Drivers in First 2 Years of Licensure ...................48

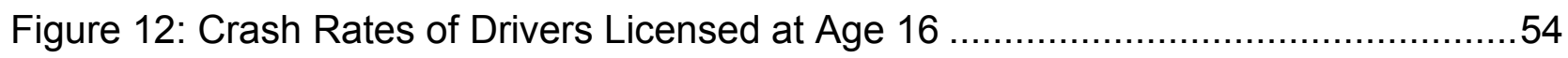

Figure 13: Crash Rates of Drivers Licensed at Age 17 .................................................54

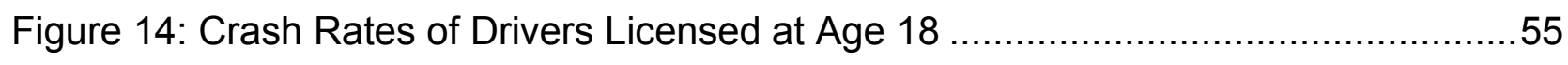

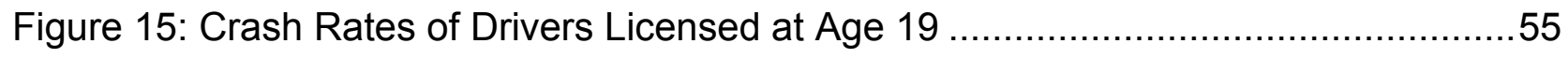

Figure 16: Conviction Rates - 16- and 17-Year-Olds (GDL) by Type of Driver Training ..98

Figure 17: Suspension Rates - 16- and 17-Year Olds (GDL) by Type of Driver Training

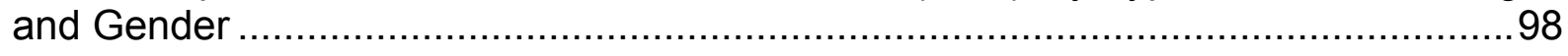

Figure 18: Crash Rates - 16- and 17-Year-Olds (GDL) by Type of Driver Training .........98 



\section{EXECUTIVE SUMMARY}

The crash involvement rate for young drivers is much higher than that for older adults. Most States have recently revised or expanded different elements of their driver's license requirements for young novice drivers (ages 15-20). More stringent requirements include extending the length of time a novice driver must have a learner's permit before earning full driving privileges, restricting the number of teenage passengers, or by restricting nighttime driving. Another approach is to lower the age at which a young driver can obtain a learner's permit.

The State of Oregon enacted its Graduated Driver's License (GDL) program in March 2000. Oregon's GDL program includes the following requirements and restrictions for novice drivers under 18 years old:

Drivers must hold an Oregon instruction permit for 6 months prior to applying for a driver's license.

During the first $\mathbf{6}$ months a driver may not carry any passenger younger than 20 years of age who is not a member of the driver's immediate family.

During the second six months a driver may not carry more than three passengers who are under 20 years of age who are not members of the driver's immediate family.

During the first year a driver cannot drive between the hours of midnight and 5am, except a) driving from home and place of employment; b) driving between home and a school event for which no other transportation is available; c) driving for employment purposes; or d) driving with a passenger who is at least 25 years of age.

Parental verification that a person has had at least 50 hours of driving experience while being supervised by a licensed driver who is at least 21 years of age and has had a valid license for at least three years, and one of the following:

- Completion of a traffic safety course that meets standards developed by the Oregon Department of Transportation (ODOT) with 50 hours of supervised driving experience; or

- Teen drivers may waive the traffic safety course and opt for an additional 50 hours of driving experience for a total of 100 hours of supervised driving with a licensed driver.

An evaluation of this program was conducted to help determine if the new law had an impact on novice driver performance. Information was obtained through two methods: Focus Groups and Driver Performance, including crashes, convictions, and suspensions. 


\section{FOCUS GROUPS}

Fourteen focus groups were conducted in Oregon. Five focus groups were comprised of teenage drivers and 5 groups were composed of parents of teenage drivers. The remaining 4 focus groups were composed as follows: 1 group of 10 DMV road test administrators; 1 group of 10 driving instructors, 1 group of 6 law enforcement officers, and 1 group of 5 high school administrators. In addition, two Oregon judges who preside over traffic adjudications involving teenagers were interviewed by telephone.

All groups discussed their perceptions and opinions regarding Oregon's Graduated Driver Licensing (GDL) program. They discussed their awareness and perceptions of the GDL program, the program's implementation and enforcement, and the perceived impact of the program on safety. Each group contributed their own perspective and knowledge of the program and its effects.

Strong support for GDL requirements and restrictions was exhibited across the board, by all groups who participated. Although many of the teenagers disliked the restrictions, even the teens felt the GDL program enhanced their safety. The GDL rules and restrictions were strongly believed to positively affect safety, both for teen drivers and for those they encounter on the road.

The requirements for driver education and/or supervised practice before licensure were well understood, as were the restrictions placed on the first 6 months of licensure. The restrictions placed on the second 6 months of licensure, however, were not well understood. Simplifying the GDL law to apply all restrictions for the first year and eliminating the distinction between the first 6 months and the second 6 months may help with this confusion. The parents, teens, law enforcement, and driving instructors believed that teens became overconfident after approximately 6 months of licensure, and were therefore prone to making mistakes after the first 6 months.

All groups considered parents to be the front line for both implementation and enforcement of the GDL program. Educating the public on the importance of parental monitoring and enforcing their teen's progress through the GDL would highlight this crucial component. Providing parents with guidelines and direction for this monitoring may be beneficial.

All groups cited peer pressure as a factor for noncompliance. Strong enforcement was believed to mitigate the influence of peers.

The DMV was perceived as weak when enforcing the practice requirements for the GDL program. Most respondents wanted the DMV to require use of the practice log and wanted the DMV to collect it. Additionally, law enforcement was perceived by others to enforce the restrictions unevenly. Most parents and teens were unaware that law enforcement officers could not make traffic stops solely for GDL violations. There was strong support for GDL to become subject to primary enforcement. 
Parents felt empowered by the GDL program. Many of the adult participants saw the GDL program serving a wider purpose of gradually ushering a teen into adult responsibilities. They expected the GDL program's implementation and enforcement to have a long-lasting effect on individuals' broader attitudes toward the law.

\section{DRIVER PERFORMANCE}

Databases were acquired from the Oregon Driver and Motor Vehicle Services. These data included anonymously coded driver records and information on driver performance, such as suspensions, driving violations, and crashes. The project sample database included information for drivers ages 16 to 24 who had received their driver's licenses from January 1, 1998, through November 2003. The data chosen represented drivers who were not subject to the GDL requirements due to age (over 18 or who received their licenses before GDL was enacted) and those who were subject to the requirements.

The program was evaluated by performing analyses on driver performance variables (convictions, suspensions, and crashes) comparing drivers:

- Who were and were not licensed under the GDL requirements;

- To adults both before and after GDL implementation; and

- By level of experience after receiving their licenses.

Suspension rates for 16- and 17-year-old drivers, when standardized to adult rates, were lower after implementation of Oregon's new GDL program, as were crash rates for 16-yearold drivers in the first 6 months of licensure.

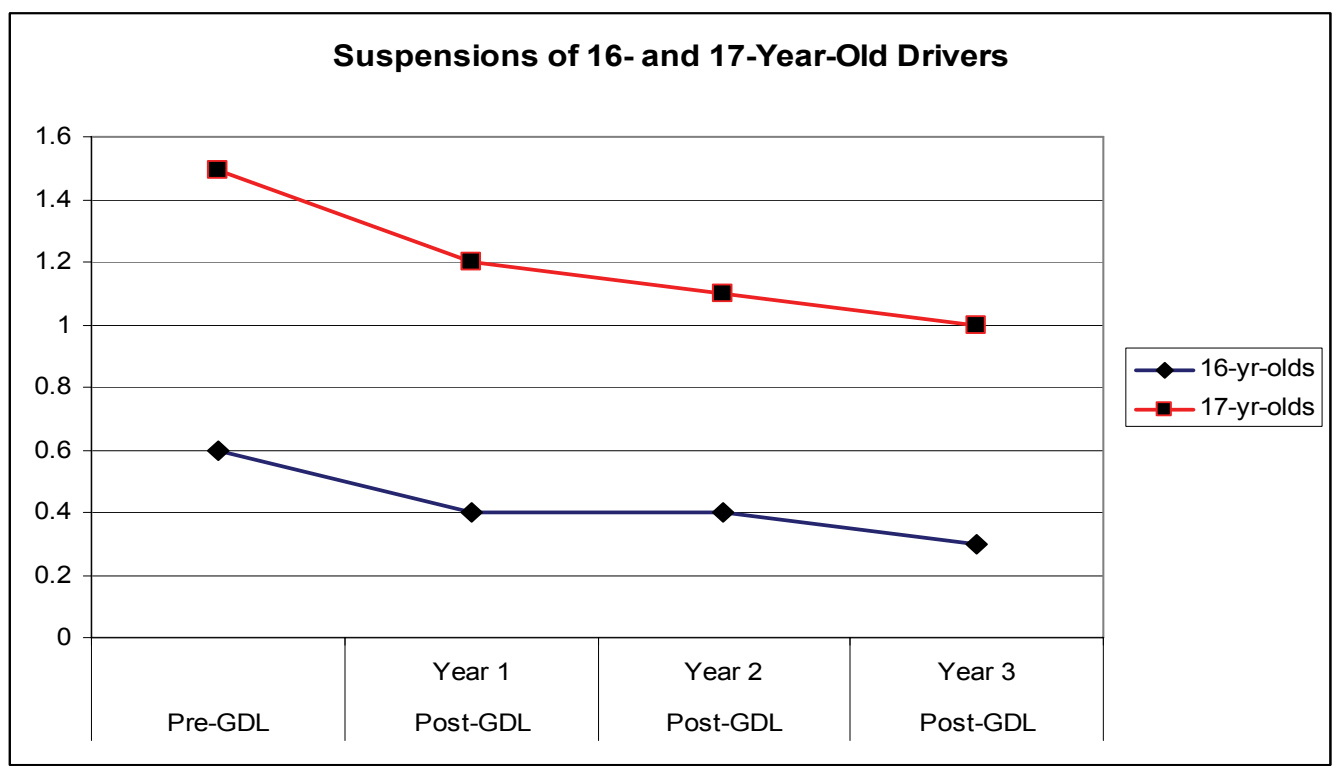

Ratios Standardized to Adult Rates 
After GDL implementation, conviction and suspension rates were lower for all age groups, even among the unrestricted 18- and 19-year-old novice drivers. Also, a few more Oregon teenagers seemed to wait until they turned 18 to acquire their driver's licenses. Males seemed to be more likely to wait. Older novice teens exhibited higher conviction and suspension rates than younger teens, perhaps due to greater exposure.

Note that for drivers initially licensed at age 16, crash rates did not seem to drop as quickly over time as they did for other age groups. In particular, the second full year of driving (months 13-24) still showed high crash rates for both pre-GDL and GDL drivers (almost 12 monthly crashes per 1,000 drivers) for those drivers licensed at 16. For the second year of driving, pre-GDL novices initially licensed at 16 crashed more often than pre-GDL novices licensed at age 18 - even though 18-year-olds' higher conviction and suspension rates (Tables 9 and 10) might suggest more infractions and/or greater exposure among the older novices. Perhaps this finding simply highlights the importance of the interaction of experience and maturity in producing a driver with sound judgment, decision-making, and hazard perception skills.

In every age group, in every time period, for either GDL status, males had significantly higher conviction and suspension rates than females. After GDL implementation, however, males' rates generally dropped closer to the female crash rates.

Teen drivers who opted to take an approved ODOT driver education course, in lieu of an additional 50 hours of supervised practice, had fewer crashes, traffic convictions, and suspensions. It is not possible to determine if the better outcomes are a result of the ODOT-approved training courses, or if they are due to selection bias. For example, parents who had teens take driver education may have placed greater restrictions on their teenage drivers. It is also important to note that there was no way to verify that the teen drivers who opted for 100 hours of supervised practice actually completed 100 hours of practice. Focus group participants reported that many parents may have simply signed the ODOT form verifying the 100 hours of practice regardless of how many, or how few, hours their teen driver actually completed.

The analysis of convictions, suspensions, and crashes offers strong support for GDL programs. It seems clear that Oregon's GDL program is associated with improved safety. Particularly for 16-year-old drivers, suspensions and crashes dropped by the second year of GDL implementation, even when controlled for adult suspension and crash rates. The drivers who show the most improved safety are those who were most affected by the law, though enhanced safety is seen even in older teens (18- to 19-year-old drivers) who are not restricted by GDL regulations. In combination with the support shown by all participants of the focus groups, it appears the GDL is a strong and feasible legislative countermeasure that can be implemented in the States to reduce teen novice driver crashes.

The gender effects seen in this study are consistent with those seen in the literature: males are at higher risk of infractions and crashes than females. It is promising that after GDL implementation, male crash rates dropped to levels approximating female crash rates. 
GDL implementation was associated with a pattern of better outcome rates overall. Sixteen-year-old drivers exhibited lower crash rates in their first 6 months of licensure. When controlled for adult suspension and crash rates, 16- and 17-year-old drivers had reduced suspension and crash rates. When examined over the course of their early licensure, teen drivers generally showed lower conviction and suspension rates after GDL implementation. 


\section{PROJECT OBJECTIVE}

The objective for this project was to evaluate the Graduated Licensing Program in the State of Oregon. This report summarizes the project tasks, the methods used to acquire and analyze the data, and the major results and conclusions of this evaluation. The project conducted two major types of data collection procedures: (1) database development and analyses of driver performance and (2) focus group information from a number of stakeholder groups including teens; parents; and representatives of law enforcement, educational, and judicial organizations. This report presents findings from both methods.

\section{BACKGROUND}

Driving a motor vehicle is a complex task —one that requires knowledge, specific motor skills, specific perceptual skills, judgment, and maturity. Traditional driver licensing systems expose young drivers to many of the most difficult driving tasks very early in their learning process. Young, inexperienced drivers exhibit an unfortunate number of deaths and injuries. Sixteen-year-old drivers, for example, have almost four times the crash involvement ( 35 crashes versus 9 crashes per million vehicle miles) rate of those drivers who are 20 to 24 years of age (Williams, 2003).

Young drivers' crashes occur more frequently under certain conditions; specifically, young drivers are vulnerable to greater risk when they carry passengers (Preusser, Ferguson, \& Williams, 1998; Chen, Baker, Braver, \& Li, 2000), when they drive at night (Williams \& Preusser, 1997) and when alcohol is involved (Williams, 2003). Efforts to define the causes of the problem have primarily focused on the effects of youth and inexperience (e.g., McKnight and McKnight, 2003). Though the two issues have been difficult to isolate, youth is believed to be associated with higher risk-taking, impulsivity, overconfidence, and peer pressure. Inexperience, in contrast, affects all novices regardless of their age and involves the ability to control the vehicle, perceive hazards, and make accurate judgments and quick decisions.

Debate continues about the contributions of youth and inexperience to the problem of young driver crashes. However, it is now generally acknowledged that both factors contribute to young drivers' high crash rates (McKnight and McKnight, 2003; Engstrom, Gregersen, Hernetkoski, Keskinen, \& Nyberg, 2003).

The challenge, then, is that young novices need to gain experience without increasing their exposure. Most efforts to reduce the crash risk of teenage drivers have concentrated on pragmatic attempts to reduce young drivers' risk by delaying licensure, limiting exposure during high-risk conditions (e.g., nighttime) and by suspending young drivers' licenses when they commit infractions (Preusser, 1995). These varying attempts have gradually contributed knowledge toward the development of a more codified system intended to reduce young drivers' crash risk. 
Graduated Driver Licensing (GDL) systems provide an approach that permits younger drivers to learn safe driving in a more controlled way. The goal of GDL is to limit new drivers' exposure to the highest-risk situations, while allowing them to accumulate experience in lower-risk conditions.

\section{GRADUATED DRIVER LICENSING}

NHTSA's recommended GDL system has three stages, each with specific core components:

$$
\begin{aligned}
& \text { Stage } 1 \text { - The Learner's Permit } \\
& \text { Stage } 2 \text { - The Intermediate License } \\
& \text { Stage } 3 \text { - Full License }
\end{aligned}
$$

Stage 1 allows beginning drivers to practice basic driving skills under supervision. The Intermediate stage allows unsupervised driving but includes restrictions (e.g., no unsupervised nighttime driving). This allows young drivers to use acquired skills and develop new skills for more demanding situations, but restricts driving under high-risk conditions (e.g., driving at night and driving with passengers). Stage 3 permits full privileges to the drivers. Unlike traditional driver licensing, GDL allows young drivers to practice over an extended period of time, increases the amount of supervised training (especially during higher-risk, e.g., nighttime hours, and rewards safe driving by allowing those with good driving records to graduate to a full and unconditional driver's license.

While differences in State regulations are evident, recent evaluation summaries (Shope and Molnar, 2002; Combs, 2003) have indicated initiation of these programs has been associated with decreases in crash rates among teen drivers.

As of July 2006, a total of 45 States plus the District of Columbia and Puerto Rico have enacted legislation that contains the recommended three-stage GDL system (NHTSA, 2006). In a recent (July 2006) review of graduated licensing laws the Insurance Institute for Highway Safety evaluated the GDL laws in all the States and the District of Columbia. Twenty-six States were rated "good" while 9 were rated "fair;" 11 were rated "marginal," or as "poor." Clearly GDL laws vary greatly, but the basic tenets are increasingly implemented.

Many preliminary evaluations have demonstrated the potential safety benefits of GDL. Florida, for example, reported a $9 \%$ reduction in fatal and injury crashes the first full year that graduated licensing was in effect (Ulmer, Preusser, Williams, Ferguson, \& Farmer, 1999). Kentucky reported a $31 \%$ reduction in crashes among 16-year-olds (Agent, Pigman, Steenbergen, Pollack, Kidd, \& McCoy, 2000)

Evaluations of support for GDL laws have repeatedly revealed widespread approval for GDL programs among parents, and have even demonstrated that teens are fairly accepting of GDL components (Williams, Nelson, \& Leaf; 2001). Parental support and implementation of restrictions can be increased through educational efforts (Simons-Morton 
\& Hartos, 2003). Acceptance by both parents and teens is critical, since people tend to ignore restrictions which are perceived as overly extreme (Foss \& Goodwin, 2003).

Supervised driving is seen as an important factor in reducing teen crash rates because supervised practice provides a low-risk way for teens to gain experience. Parents appear to be supportive of requirements for supervised driving (Waller, Olk, and Shope, 2000).

\section{OREGON'S GRADUATED DRIVER LICENSE PROGRAM}

The State of Oregon implemented its GDL law in March, 2000. Oregon's GDL program stipulates that drivers under the age of 18 are issued licenses with the following requirements and restrictions:

\section{$\underline{\text { Requirements before receiving license }}$}

1. Drivers must hold an instruction permit for 6 months.

2. Parents must certify 50 hours of supervised driving experience.

3. Drivers must complete an ODOT-approved driver education course.

$$
\text { -OR- }
$$

Certify an additional 50 hours of supervised driving experience.

\section{$\underline{\text { Restrictions after license is issued }}$}

1. For the first 6 months after issuance, drivers cannot drive with a passenger under age 20 who is not a member of their immediate family. ${ }^{*}$

2. For the second 6 months after issuance, drivers cannot drive with more than three passengers who are under age 20 who are not members of their immediate family. (Passenger restrictions do not apply while provisional drivers are driving with an instructor as part of a certified traffic safety education course or with a parent or stepparent, who has valid driving privileges.)

1. For the first year after issuance of their licenses, drivers cannot drive between midnight and 5 a.m. unless they are:

- Driving between home and work;

- Driving between home and a school event for which there is no other transportation available;

- Driving for employment purposes; or

- Accompanied by a licensed driver who is at least 25 years old.

These restrictions only apply until the driver is 18 or has had the provisional license for one year, whichever comes first. 
Violations of the passenger or night driving restrictions are Class B traffic violations and are subject to a fine of $\$ 175$.

The "provisional license" phrasing may be misleading. The current phrasing sounds as if Oregon teens receive a different type of driver's license card until they have been licensed for a year or have turned 18, and turn it in for a "full" license. In fact, Oregon 16-year-olds receive the same physical driver's license as Oregon 18-year-olds. Oregon teens under age 18 spend a provisional period of time during which they do not have full, unrestricted driving privileges. The card in their wallets, however, is simply an Oregon driver's license. The date of issue on the license, along with the driver's age, determines the stage of driving privilege.

Oregon's new 2000 law modified an earlier provisional licensing program which had been enacted in 1989. The 1989 program required new drivers younger than 18 to pass a "safe driving practices" knowledge test in addition to the standard knowledge test. Young drivers who failed the road test were required to wait 28 days before a new attempt, and were required to obtain an instruction permit if they had not already done so. In addition, the 1989 program placed stricter sanctions on young drivers. Drivers under 18 faced suspension for any measurable blood alcohol level; could be suspended until age 18 for a major traffic conviction; and upon a single traffic conviction, were subject to a four-stage driver improvement program which levied successively greater sanctions for each additional infraction. 


\section{FOCUS GROUPS}

\section{OBJECTIVE}

The objective of this task was to evaluate perception and awareness of the Graduated Driver Licensing (GDL) Program in the State of Oregon. Focus groups were conducted in Oregon to investigate perceptions of various components of the GDL program including pre-licensure practice requirements, post-licensure driving restrictions, parental involvement, driver education, law enforcement, and implementation at the DMV.

\section{METHOD}

\section{LOCATIONS}

Fourteen focus groups were held between November 10 and 20 of 2003 in five cities in Oregon: Portland, Pendleton, Grants Pass, Eugene, and Bend. These five sites represent each of the five Oregon DOT regions. The sites span the State and represent a wide variety of geography, city population, availability of commercial driving instruction, and socioeconomic resources. In each of the five cities, a focus group was conducted with a group of Parents of Teenage Drivers and a group of Teenage Drivers. Additional focus groups were conducted in Portland and Eugene, and were composed as follows:

\section{Portland}

One group of $10 \mathrm{DMV}$ personnel who administer driving examinations

One group of 10 driving instructors

\section{Eugene}

One group of 6 law enforcement officers

One group of 5 high school administrators

In addition, two telephone interviews were conducted with Oregon judges who handle traffic cases.

\section{FACILITIES AND EQUIPMENT}

All groups took place either in specialized focus group facilities or in hotel meeting rooms. Focus groups were audiotaped and videotaped.

\section{PROCEDURE}

All participants were welcomed and thanked for their participation. They were informed that their participation would be videotaped and audiotaped, and were told that their identities would be kept confidential. 
In all discussion groups, participants began by introducing themselves and describing their household composition, plus relevant background information (for example, parents gave the ages of their children, while law enforcement officers gave the length of their service in law enforcement). For details, please see the Moderator Guides (Appendix A).

Discussion was guided among many points, as seen in the Moderator Guides. In all discussion groups, participants were asked to describe their understanding of the Oregon GDL program's requirements and restrictions. After respondents had done so, they were provided with a Fact Sheet (Appendix B) which summarized each aspect of the law. Discussion then continued, as shown in the Moderator Guides.

Focus group sessions lasted approximately 2 hours. At the conclusion, participants were thanked again for their time and were paid for their participation.

\section{LIMITATIONS}

The information generated by this methodology is limited in three ways. First, the data are qualitative and cannot be analyzed using quantitative techniques. Second, the participants were not a randomly selected, statistically representative sample of Oregon drivers. Third, the reported views are participants' perceptions, not objectively verified facts.

Like all focus groups methodologies, the data generated are qualitative in nature and cannot be quantified. Conclusions and recommendations were generated by overall consensus of the groups and by the assimilation of participants' input by the research team. The information generated by focus groups should not be treated as quantitative data.

In addition, focus group discussants could not be randomly selected from the Oregon population. Participants were those who filled the basic requirements (e.g., were parents of teenage drivers), were willing to attend a group, were able to pass a brief articulation drill, and arrived at the facility for participation. The participants were not, could not be, and were not intended to be a statistically representative sample.

Finally, the views expressed by participants are their perceptions, not statements of facts. Participants, for example, tended to believe that the GDL restrictions were unevenly enforced in different regions of Oregon. This report does not address the accuracy of this impression or of other perceptions. This report merely presents information on what those perceptions were. 


\section{FOCUS GROUP SUMMARY}

Following is a summary of the overall focus group findings. For a complete and detailed summary, please see Appendix E.

\section{A. PARENTS}

\section{- Parental Concerns}

\section{Acquisition of a driver license for one's teen was a traumatic experience for the} parents.

Parents described the pursuit of their teenagers' driver licenses as a bittersweet milestone. The parents shared their children's joy and excitement with this rite of passage, as it not only marked a significant point in the lives of their children, but also added a significant amount of convenience and flexibility to the lives of the parents. Carpooling and chauffeuring duties were significantly reduced, if not totally eliminated.

Another major apprehension of many of the parents was the reduction in the amount of control they could maintain over their children after they got their driver's licenses. Given access to an automotive vehicle, their children had the ability to go almost anyplace they wanted, be with whomever they wanted, and do what they wanted; all without parental knowledge or consent. The driver's license gave their teenagers more freedom and independence than they had ever had before in their lives.

Immaturity, insurance costs, and lack of experience were the major factors driving the fears of the parents.

Even after their teenagers had mastered the basic skills to operate an automotive vehicle, immaturity and lack of experience continued to be the parents' greatest concerns. The parents believed that any driver was probably at highest risk when inexperienced.

Parents felt the teens suffered from a sense of invincibility. Teens did not expect bad things to happen to them. Thus, they were not cautious enough. Further, they had a tendency to show off for their peers. They were more likely to do dangerous things when with friends than if they were alone. Thus, their peers were not only a distraction, but also a liability because of the influence they had on each other.

The cost of auto insurance was a major consideration for both the parents and their children. Many of the parents passed this cost on to their teenagers not only to defray the expense, but also to heighten the teens' awareness of the responsibility and exposure. Parents indicated that the attempt to reduce the insurance costs was a major motivation for the teens to pursue driver safety training. 


\section{- Awareness and Perceptions of the GDL Program}

Most parents were more aware of the requirements to get the license than of the later restrictions.

Parents showed more knowledge of licensing requirements than of restrictions placed on new drivers. They felt this was probably because the teens knew more about the regulations than their parents, and the teens were more concerned about informing their parents about the requirements to obtain the license than telling their parents about the restrictions that kept them from doing what they wanted.

Most of the parents were very aware of a restriction on passengers for the first 6 months. However, many were not aware of the restrictions on driving between midnight and 5 a.m., a stipulation for both the first and second 6 months.

\section{Available resources were not widely utilized.}

Most of the parents were unfamiliar with the Tuning Up manual, a pre-licensing guide intended by ODOT for distribution to parents and teens when the learning permit is obtained. The Tuning Up manual offers suggestions on teaching and learning to drive. Of the parents who had obtained and used the manual, most considered it to be useful.

For information about the GDL program, parents wished for a single fact sheet that summarized the major GDL requirements and restrictions. They felt they could have posted something like this on their refrigerators as a reminder.

The parents felt the GDL program empowered them to enhance the safety of their teenage drivers.

Many of the parents felt they would have imposed many of the same regulations had the GDL program not existed, especially those for the first 6 months of licensure. However, without the GDL program, the parents felt they would have had much more difficulty trying to enforce them.

Many parents did not consider the requirements to be tough enough.

Many of the parents, especially the fathers, were leery about the level of maturity and responsibility of teenagers relative to driving. Some felt the existing GDL restrictions were giving the teenagers too much, too fast. Some of the parents felt the age at which one could get a driver's license was too young. They felt a teenager should not be allowed to get a license until the age of 18 .

Others thought the age of eligibility should be linked to grades in, and references from, school, and/or other sources regarding maturity and responsibility. Some thought the restrictions should last until age 18, regardless of how long the license had been held. However, there were parents who felt the GDL restrictions were sufficient. Although they 
felt there were some teenagers who were not mature and responsible enough to drive at any age, most - including theirs - were. These parents felt it was the responsibility of the parents to determine if their teenager was responsible and mature enough to manage what could become a dangerous weapon.

Caravanning and an incentive for dishonesty were perceived to be the two major cons of the GDL program.

Often, because of the restrictions on passengers, individual teens drove separately in caravans. Many of the parents felt this caused more exposure to danger than having them ride together. On occasions like these, some wished there was more flexibility with the restrictions.

Some parents felt awkward because they expected their children to break the rules with respect to the passenger restriction and lie to maintain the driving privilege.

\section{- Implementation and Enforcement}

Enforcement of the GDL regulations was very important to the parents.

Enforcement of the rules and regulations of the GDL program was very important to most of the parents for several reasons. The most obvious was that these rules were perceived to be effective in saving the lives of teenage drivers. In addition, many of the parents, especially those in the smaller cities, felt these rules should have been enforced if for no other reason than that they were the law.

Many of the parents were disappointed by the implementation and enforcement of the regulations.

Many of the parents felt the regulations were not monitored and enforced seriously enough by law enforcement and/or the Department of Motor Vehicles (DMV).

Several indicated that even before the driver's license was issued, they felt that the program was not being diligently enforced. For example, several of the parents were very disappointed that the DMV had not required documentation to substantiate the supervised driving experience.

Many of the parents were also very critical of the level of enforcement provided by police officers. They felt the law enforcement officers were not aggressive enough in stopping violators. Many of these parents were not aware that GDL violations were not subject to primary enforcement. They did not realize that a traffic stop could not be made solely for a GDL violation.

\section{- Parental Involvement}

Parents recognized that they were the foundation of the program. 
Most parents, when made fully aware of how the GDL regulations were written, recognized that they, themselves, were the focal point for the implementation and enforcement of the program.

However, to be effective catalysts for this program, the parents said they must be well armed with knowledge regarding how the program works and steps they could take to effectively promote and monitor compliance. Many of the parents felt unsure of their role with respect to GDL and their teen drivers.

\section{Parents were very involved in teaching their teenagers during the instructional period.}

Most of the parents indicated they drove with their teenagers very frequently during the instructional period, some almost every day. This was especially true in the less urban areas. Their concerns were more related to making sure their children learned to drive than about the fulfillment of the supervised driving requirement. The parents did not want their teenagers driving until they felt comfortable about the teens' skills.

Most felt they spent far more than the required hours of supervised driving experience. However, very few of them kept an accurate accounting of the time. Further, some who did admitted that the accounting was not accurate.

Parents were very committed to compliance during the first 6 months of restrictions.

Most parents reported they were initially very diligent about trying to monitor and enforce the restrictions during the first 6 months, especially the passenger limitation. This was the rule parents considered to be the most important. It was also the rule they perceived to be the most difficult to monitor and most likely to be violated. However, many of the parents said they became less diligent as time passed. Some became less concerned about compliance because they felt more comfortable with their teenagers' driving skills, but most did so simply because they got worn down.

\section{Parents often added their own rules and restrictions.}

Many of the more responsible parents, in addition to close monitoring and enforcing the GDL regulations, had taken steps above and beyond the program. Some of the parents had their teenagers sign contracts or statements of understanding of expectations, regulations and consequences.

\section{Parents perceived the traffic safety training courses as beneficial.}

The most popular benefits of the traffic training courses were that they reduced the insurance rate and the number of hours of supervised driving experience for the teenage drivers. 
Most of the parents firmly believed that having a trained professional teach their teenagers how to drive resulted in safer drivers. They felt the professional instructor was current with techniques and procedures and had access to teaching aids, including a curriculum. For example, some parents learned to drive before airbags were popular and felt the hand positioning they were taught was not correct for today's vehicle equipped with airbags. Further, they felt that an instructor who did not instruct on a regular basis (e.g., a parent or a history teacher) could easily have forgotten important information.

\section{B. TEENAGERS}

\section{- Teenage Concerns}

The driver's license was one of the most exciting milestones in a teenager's young life.

The teenage drivers in Oregon said they placed a high priority on the privilege of driving. For these teenagers, the driver's license was a rite of passage. The privilege was a means of freedom, flexibility, and independence; it was new and exciting; and it enhanced their social status. They no longer had to wait until it was convenient for someone else to take them places. They could do things on their own and stay out later. They felt independent of their parents.

\section{Some of the major concerns of the teenagers included liability and costs.}

The teenagers recognized that the driver license was a big responsibility. Many of the teenagers indicated that they were initially very fearful of hitting people when driving. They also worried about the safety of their passengers.

The costs of driving were also major concerns for the teenagers. These costs included insurance, gasoline, and in some instances, the costs of buying and maintaining a vehicle. Insurance costs were one of the greatest concerns.

However, the biggest concern of all was the "6-month rule", which restricts carrying unrelated passengers for the first 6 months of licensure. Much of the anticipation and excitement of getting their driver's license was perceived to be severely dampened by this rule. The teens said they were under extreme pressure to break the GDL restrictions. All of their friends were going to want rides, and encouraged them to break the rules and lie to their parents.

\section{Many of the teenagers indicated that overconfidence became a problem.}

After driving for several months, many of the teenagers felt their fear and caution faded into a dangerous overconfidence. They began to feel they were much better drivers than they actually were. They became more careless and took greater risks. In many cases, it was 
not until they had a crash, they had been cited for a violation, or their parents reined them back that they reassessed their skills, responsibility, and consequences.

\section{- Awareness and Perception of the GDL Program}

\section{Most teens were very well versed on the "6-month rule."}

The teens were not familiar with the program as the "Graduated Driver License" or "GDL" program. Like almost all participants, they referred to it as the "6-Month Rule" or the "Provisionals." The teens were much more aware of the provisions of the program than the parents. They were most familiar with the restrictions for the first 6 months, and, much more so than the parents, very aware of the fact that violations were a secondary offense.

Most of the teens were much less aware of the second 6 months' restrictions. In fact, a few were not even aware that there were restrictions for the second 6 months.

\section{Most teens recognized the objectives of GDL.}

Although they were reluctant to admit it, most of the teens said that GDL was implemented to enhance their safety and to save their lives, and they recognized that most of these regulations were helpful for their initial level of driving experience and skills.

However, there were some teens who were skeptical of the motivations for GDL. They thought it was discriminating against teenagers and/or just a way to make money. They felt there was no good reason to establish a threshold of age 18 for the restrictions. They felt the restrictions should apply to all new drivers, not just teenage drivers. A few also felt that recent changes to the mandatory fines were an indication that money was a prime motivation.

\section{- Perceptions of Implementation and Enforcement}

\section{Enforcement of GDL restrictions was perceived as weak and inconsistent.}

The general perception among focus group participants was that GDL restrictions were not seriously enforced. Many of the teens indicated that even before they got their driver's licenses, they did not expect serious enforcement by the police. Many of their friends had had encounters with police officers while in violation of GDL and were not cited. Some had even been told, by persons they considered to be knowledgeable authority figures, that the GDL restrictions were not seriously enforced.

The courts were also perceived to be soft on the enforcement. Teens who had been before the court for traffic violations bragged about how lenient the adjudication was in general and specifically how they were not punished at all for the GDL violations. They indicated that this not only dilutes the anticipated consequences for those involved, but also for the many friends to whom they brag. 


\section{Parents were central to GDL enforcement.}

Most of the teenage respondents were more concerned about their parents catching them breaking the GDL laws than the law enforcement officers. For many, this was because they knew the consequences were guaranteed and would be severe.

The teens whose parents were most conscientious about enforcement and monitoring were those who were most likely to comply. There were some parents who were strict right from the beginning.

\section{Pressure and practicality wore down compliance.}

Most of the parents and teens said they were much more conscientious about compliance in the beginning. However, as time passed and teens gained experience, both the parents and the teens tended to be less concerned about compliance. As the parents and teens felt more confident about the teens' capabilities, external pressures more easily wore both down. Both became more likely to trade off compliance for practicality and convenience.

The teenagers were constantly pressured by peers to give them rides. As they gained confidence and realized they probably would not get caught, they gave in to the pressure and broke the rule that was the most difficult for them to uphold, the passenger restrictions.

Driver Education was perceived to be useful, but could be more effective in making teenagers safer, more experienced drivers.

Most of the teenagers took the course to lower their insurance costs and to reduce the required number of hours of supervised instruction. As anticipated, most found driver education to be boring and "remedial," but felt there were direct benefits. In addition to the benefits enumerated earlier by the parents, the teens appreciated an objective third party perspective rather than "having mom or dad telling me what to do." They also felt they benefited from the hours on the road, the informational and sometimes graphic videos, and guest speakers such as police officers.

The administration of driver education had a big impact on its effectiveness. Lengthy, continuous classroom sessions appeared to be ineffective. Teenagers felt the need for more hours on the road to increase their driving experience. They felt shorter and more interactive classroom sessions would be more effective.

\section{LAW ENFORCEMENT OFFICERS}

\section{- Perceptions of Teenage Drivers}

\section{Teenager overconfidence was a major concern to law enforcement.}

The police officers observed that after about 6 months to a year, teenage drivers tend to feel more comfortable and confident about their capabilities and skills. It was at that point 
many of the police officers thought the teens were vulnerable as they began to take more risks.

The officers felt many of the teenagers were not properly prepared to drive.

The law enforcement officers felt that the level of driver training provided to teenagers was inconsistent and inadequate. They thought, however, that driver education courses should be mandatory because parents were not qualified to adequately teach their kids how to drive. They felt in some cases the parents did not know how to drive themselves, much less how to teach. Further, they felt DMV testing was so basic that the inadequacies of the teenager would go undetected. Thus, some of the officers felt that many teenagers who passed the DMV test were grossly unprepared to drive in real world situations.

\section{- Awareness and Perception of GDL by Law Enforcement}

\section{Many of the officers felt GDL laws were more complicated than necessary.}

The officers felt "semi-well-versed" on the GDL laws. However, as a result of there being one set of restrictions for the first 6 months, and another set for the second 6 months, the officers had to calculate one time frame for one set, and another timeframe for the other. To make sure they did not get confused, many of the officers felt the need to keep a copy of the restrictions with them to ensure accurate execution of the laws.

\section{Police officers said they were very serious about enforcement of GDL.}

Although there appeared to be a slight difference in tolerance of GDL violations, most of the officers indicated they cut very little slack. They insisted that they ticketed almost everyone they encountered who was in violation of the GDL laws. The slight distinction was that the traffic officers stated they granted zero tolerance, while the State troopers ticketed about $90 \%$ of the violators.

These officers said they did not enforce this law with enthusiasm just because it was the law. They were strict with this law because they felt they were doing something for the kids, not to them. They were not out to punish the kids. They felt they were saving their lives. These officers wished the GDL violations were subject to primary enforcement, which would have made enforcement easier.

\section{Law enforcement officers said that teens did not appear to be aware of the consequences of GDL violations.}

The officers felt GDL compliance would be higher if the teens were more aware of the consequences. Most of the teens they encountered were very unaware of the consequences of the GDL violations they committed. 
Law enforcement officers perceived the judiciary to be weak relative to GDL.

Many of the police officers felt the courts sent the wrong messages to teenage drivers by reducing the consequences of violating the GDL restrictions. Some also felt the actions of the courts frustrated law enforcement officers. It gave them the perception that the courts were undermining the police officers.

\section{Officers said that curfew and passenger restrictions were most frequently violated.}

The restrictions most frequently violated were the passenger restrictions and the curfew during the first 6 months. Most of the officers felt that even the parents with the best of intentions got worn down by their teens. This observation was consistent with those of the parents and the teenagers.

\section{DMV DRIVING TEST ADMINISTRATORS}

The DMV road test administrators highly recommended Driver Education courses.

DMV driving test administrators indicated they could immediately tell which candidates had been taught by professionals versus by parents. They said that those taught by professionals had better mechanics, independently made better decisions, paid attention to details, had fewer bad habits, and were generally much better prepared to be safe drivers. The candidates trained by their parents learned the bad habits of their parents. They were less likely to be taught details like checking the brakes, mirrors, and blind spots.

Although the DMV employees indicated that they could immediately detect which candidates had or had not been taught professionally, they could not tell which schools had trained them. Many felt the cutback on driver education in the public school systems had forced parents to teach their kids how to drive. They felt that the difference in the preparedness of the candidates was noticeable.

Road test administrators wished for more emphasis on the driver experience logs.

Maintaining the driver experience log was important even if the candidates inflated the time recorded. If nothing else, it made them more aware of how much time was actually expected to be invested toward becoming a safe driver.

\section{Examiners indicated that the DMV did not appear to be taking advantage of the} available resources.

In some instances, the DMV personnel did not appear to be aware of resources available to assist teenage drivers. Specific examples include their Web site and the Tuning Up manual. Only one of the $10 \mathrm{DMV}$ employees in the focus group was aware of the 
organization's Web site. Thus, they were not aware of the availability of the practice test, driver experience logs, and other resources they could have recommended to candidates.

Some of the road test examiners said that some DMV sites were not handing out the Tuning Up manual to candidates because of alleged shortages. Others said that there were manuals available, but they were not easily accessible to employees.

\section{Examiners believed that parents were not carrying their load relative to GDL.}

DMV personnel probably had more interaction with the parents of teenage drivers than most of the other respondents interviewed other than the teens themselves. They observed that most parents did not know the details of GDL, and thus were not prepared to enforce the laws. Further, they believed that the parents were not inclined to enforce the laws because they were too concerned with appeasing their teens.

They said that because the GDL restrictions were subject only to secondary enforcement, law enforcement was at a disadvantage. As a result, DMV personnel felt the parents were the most important entity affecting the enforcement and impact of the GDL program.

\section{DMV examiners said the GDL program should be simplified.}

DMV personnel suggested that the "6-month rule" be changed so that no teens under age 18 would be allowed to have passengers under age 20 who are not immediate family members. This would not only simplify the law for enforcement purposes, but also enhance safety by increasing the level of maturity at which they will be exposed to increased peer pressure and distractions.

DMV personnel also suggested making GDL violations primary to make enforcement more effective.

\section{E. DRIVING INSTRUCTORS}

The GDL program was very highly regarded by the driving instructors.

Although the instructors felt GDL has the potential to have even greater impact, they were very pleased with what has been achieved to date. They felt stricter enforcement by DMV, parents, and police could obtain even better results.

The instructors perceived there to be a discrepancy between their goals and the goals of DMV. The instructors felt that they wanted to instill higher standards than DMV was willing to require. Congruent with the comments of the DMV employees, the instructors said that DMV was more customer-service-oriented than safety-oriented. 
The instructors suggested that the submission of the driving experience log be required.

The driving instructors strongly supported the practice requirement of the GDL program. However, the DMV does not require the submission of the driving experience log for licensure. All the driving instructors felt that the submission of the log should be a requirement.

Some of the instructors felt so strongly that the log, and the practice it represented, should be taken more seriously, that they lied to their students and told them that the log will be collected and checked by the DMV.

\section{F. HIGH SCHOOL ADMINISTRATORS}

The high school administrators were no more knowledgeable than the general public regarding GDL.

With the exception of the driving instructor, these respondents were probably the least knowledgeable relative to GDL. Most of these respondents had children, but did not have experience with the GDL program, as their children were old enough to have been licensed prior to the program's implementation.

\section{High school administrators supported strong enforcement of the GDL program.}

Like many participants in other groups, the high school administrators were unaware that GDL violations were not primary offenses. They expressed frustration with the enforcement of GDL provisions. They felt that if the police were serious about enforcing GDL, they would stake out the high schools at lunch time to discourage teens piling into cars to go off-site for lunch. The high school administrators strongly supported primary enforcement of the GDL program.

The administrators felt budget cuts to driver education have hurt teenage driver safety.

The administrators felt the budget cuts have reduced the ability of the schools to provide driver education to its students. They felt this has the most impact on lower income families who cannot afford to pay the rates of commercial programs.

The high school administrators felt that driver education programs were very important for teen driver safety, and that lower income teens were particularly endangered by the lack of formal classes.

\section{G. JUDGES}

Two judges who routinely worked with traffic cases agreed to an interview. The two judges seemed to have different levels of interest in Oregon's GDL program. Judge A presided in 
urban Portland, and Judge B presided in the more suburban Eugene, Oregon. Following are additional insights from the perspective of judges who adjudicate violations committed by the teenage drivers:

\section{The judges disagreed on the level of GDL compliance.}

Judge $A$ indicated that because he does not adjudicate very many cases of teenagers who violated the GDL restrictions, this indicated to him that teens were complying with the restrictions.

Judge B said that the incidence of violations of GDL was not as high as it should be because the Sheriff's officers do not cite many of the violations they encounter. This judge indicated that police officers were stopping teenagers for other violations and only citing those violations and not the GDL laws which were also being violated.

\section{The judges disagreed on the value of strict enforcement among teenage drivers.}

The recent legislation in Oregon restricting the power of the judges to reduce fines was a defining point of difference between the two judges. Judge $A$ thought the legislation was implemented for the express purpose of raising revenue, and that it was at the expense of flexibility to order alternative remedies for teenage offenders. He felt some of the alternative remedies, corrective driving classes and programs, were more beneficial than dealing out the prescribed consequence.

However, Judge $B$ felt the legislation was necessary because judges were being too lenient with traffic adjudications. Judge B did not believe the corrective driving programs were as effective as making the perpetrator face the consequences.

Judge $B$ thought there were too many judges who were too lenient on traffic violations among teenagers in general, and specifically with GDL violations. This judge felt neither the police officers nor the judges were adequately enforcing the GDL laws in the jurisdiction of this judge.

\section{One judge felt that enforcement of GDL was very important.}

The enforcement of GDL was important to Judge B not only for safety reasons, but also because of the potentially wider-ranging impact. Judge $B$ felt that it was important that the teens learn they had a responsibility to follow the rules, especially when the rules had an impact on the greater society. They must learn that they had to face the consequences of their actions. Judge B felt that GDL violations represented the most likely opportunity to teach this lesson to teens who are on the borderline.

\section{Peer pressure was an important factor for teenagers.}

Judge $B$ indicated that most of the time when teenagers were caught violating laws, they were with other teenagers. 
Experience in dealing with teenage drivers from the bench made Judge $B$ very sensitive to the benefits of the "6-month rule" restricting passengers. Judge B considered it to be one of the most important aspects of GDL. Judge B said that from professional experience, teenagers were more prone than adults to show off and experiment with their buddies, and that immaturity justified the need to protect the teens from themselves.

\section{Parents were a major cause of compliance.}

As important as Judge $B$ thought judges and law enforcement officers were to the implementation and enforcement of GDL, the judge acknowledged the importance and responsibility of the parent. The judge felt the parents who were conscientious about raising their kids were also conscientious about enforcing GDL; compliance was a reflection and function of the parenting.

\section{More education was necessary among the ranks.}

Judge B was extremely passionate about the importance of GDL and the importance of implementing and enforcing it to the maximum. The judge felt it was crucial to stress the importance of enforcing this law (not only for traffic purposes but also to encourage a lawabiding population) more at conferences and meetings of judges and law enforcement officers. 


\section{DRIVER PERFORMANCE}

\section{DATA ACQUISITION}

The Department of Transportation for the State of Oregon provided the raw quantitative data files regarding Oregon's young drivers and their driving histories. Relevant data was extracted from these files and imported into SPSS. Information included the following:

- License Information - Basic demographic information, type of license restriction (if any), type of endorsement (if any), and license type;

- Testing Information - Driver tests and fulfillment of requirements (e.g., Road Test, Knowledge Test, Drivers Education Course) with status (Pass or Fail), and date of each;

- Crash Information - Crash records including type, date, and location;

- Conviction Information - Conviction records, including date and type; and

- Suspension Information - Suspension records, including dates when the suspension began and ended and the reason for the suspension.

The data was pulled from the Oregon database on January 13, 2004.

Each data set contained a unique driver identifier for each driver. Using this driver identifier, data sets were linked to build a record for each driver's test results and driving history. Table 1 provides a summary of the variables that were included in the analyses.

Table 1: Variables for Analysis

\begin{tabular}{|l|l|l|}
\hline Variable Name & Description & Use \\
\hline Record number & $\begin{array}{l}\text { A unique identifier generated for each } \\
\text { record (driver) }\end{array}$ & $\begin{array}{l}\text { Used to identify each } \\
\text { driver and link files }\end{array}$ \\
\hline Sex & Driver sex & $\begin{array}{l}\text { Driver demographic } \\
\text { data }\end{array}$ \\
\hline Birth date & Driver birth date & $\begin{array}{l}\text { Used to compute age } \\
\text { at licensure }\end{array}$ \\
\hline Driver's license issued & Type of license & $\begin{array}{l}\text { Used to identify } \\
\text { drivers with Class C } \\
\text { non-commercial } \\
\text { license for analysis }\end{array}$ \\
\hline
\end{tabular}


Table 1 - Variables for Analysis - Continued

\begin{tabular}{|c|c|c|}
\hline Variable Name & Description & Use \\
\hline $\begin{array}{l}\text { Test or requirement } \\
\text { for licensure }\end{array}$ & $\begin{array}{l}\text { The file was structured with a record } \\
\text { for each test type; the data to be } \\
\text { extracted include one record for each } \\
\text { of the three license tests } \\
\text { (requirements) }\end{array}$ & $\begin{array}{l}\text { 1) Road Test } \\
\text { 2) Applicant passing the GDL } \\
\text { requirement of } 50 \text { hours } \\
\text { supervised driving plus an } \\
\text { additional } 50 \text { hours } \\
\text { 3) Applicant passing the GDL } \\
\text { requirement of } 50 \text { hours } \\
\text { supervised driving plus } \\
\text { passing an ODOT } \\
\text { approved driver education } \\
\text { course }\end{array}$ \\
\hline Test result & Whether test was passed or failed & Data was subset for "Passes" \\
\hline Test date & Date test passed. & $\begin{array}{l}\text { "Pass" date for the Road Test } \\
\text { provided proxy for original } \\
\text { licensure date }\end{array}$ \\
\hline Age at licensure & Age when license issued & $\begin{array}{l}\text { Calculated by subtracting } \\
\text { Road Test Date minus birth } \\
\text { date }\end{array}$ \\
\hline $\begin{array}{l}\text { Inclusion in GDL } \\
\text { program }\end{array}$ & $\begin{array}{l}\text { Designation of driver's status at } \\
\text { licensure regarding GDL requirements }\end{array}$ & $\begin{array}{l}\text { GDL participant if the driver } \\
\text { was under } 18 \text { and was issued a } \\
\text { license after March } 1,2000 ; \\
\text { Non-GDL participant if the } \\
\text { driver was over } 18 \text { or s/he was } \\
\text { under } 18 \text { and the issue date } \\
\text { was before } \\
\text { March } 1,2000\end{array}$ \\
\hline Conviction date & Date driver convicted of offense & $\begin{array}{l}\text { Determine when offense } \\
\text { occurred }\end{array}$ \\
\hline Offense & Type of offense & Classify offense \\
\hline Date of offense & Date of offense & $\begin{array}{l}\text { Used to determine if occurred } \\
\text { within the period of } 12 \\
\text { months following licensure }\end{array}$ \\
\hline
\end{tabular}


Table 1 - Variables for Analysis - Continued

\begin{tabular}{|l|l|l|}
\hline Variable Name & Description & Use \\
\hline Conviction class & Type of conviction & Classify conviction \\
\hline Crash location & $\begin{array}{l}\text { Exact location and facility type where } \\
\text { crash occurred }\end{array}$ & $\begin{array}{l}\text { Determine crash } \\
\text { characteristics }\end{array}$ \\
\hline Crash date & $\begin{array}{l}\text { Determine if crash } \\
\text { occurred during 12 } \\
\text { month period } \\
\text { following licensure }\end{array}$ \\
\hline Crash type & Type of crash & $\begin{array}{l}\text { Determine crash type } \\
\text { (personal injury, } \\
\text { property damage, fatal, } \\
\text { etc.) }\end{array}$ \\
\hline Suspension date & When suspension ordered & $\begin{array}{l}\text { Determine if } \\
\text { Suspension offense } \\
\text { occurred during 12 } \\
\text { month period } \\
\text { following licensure }\end{array}$ \\
\hline $\begin{array}{l}\text { Date when suspension } \\
\text { began }\end{array}$ & Suspension start & $\begin{array}{l}\text { Calculate suspension } \\
\text { duration }\end{array}$ \\
\hline $\begin{array}{l}\text { Date when suspension } \\
\text { Ended }\end{array}$ & Suspension finish & $\begin{array}{l}\text { Determine Suspension } \\
\text { Type }\end{array}$ \\
\hline Reason for suspension & Suspension reason & \\
\hline
\end{tabular}

\section{DATA EXTRACTION}

Initial licensure date was operationalized as the date the Road Test was passed. This was due to the fact that Oregon's data set, for the years 1998 through 2000, contains a variable called Issue Date that was (before 2001) defined as either the initial licensure date or a license renewal date, whichever was more recent. As a result, drivers who had received their licenses before 2001 did not have a definitive original licensure date on record - most of their Issue Date information represented renewals, not initial licensure.

In order to provide a reliable benchmark for initial licensure date, Road Test date provided a proxy for the licensure date. Using this variable overcame the renewal versus initial licensure confusion of the pre-2001 records. This resulted in a working data set consistent with Oregon's new driver counts and files, supporting its use. 
A number of exclusions were made to produce a sample of representative (and valid) drivers. The following rules were applied to the data:

- Only drivers licensed in 1998 or later were included.

- Only drivers with Class C noncommercial licenses were included.

- Only drivers who were ages 16 to 19 years old at initial licensure were included.

- Only drivers who had passed the Road Test were included.

- Drivers whose Issue Date or Expire Date were listed as 01/01/0001 were excluded $(n=$ 1,389). Drivers could have dates listed as $01 / 01 / 0001$ for a variety of reasons, with no way to determine which reason applied.

- A driver whose Issue Date was listed as 2005 was excluded.

- Drivers who were listed as having passed one or more Road Tests after a license was issued, were excluded $(n=106)$.

- A driver whose sex was recorded as neither male nor female was excluded $(n=1)$.

Data on the drivers (e.g., Road Test date, sex, etc.) were available from January 1998 through November 2003. Performance data (convictions, suspensions, and crashes) were available and stable from approximately March 1999 through July 2003. Because of the short pre-GDL time period available, it was not possible to create a buffer period before and after the effective date of the GDL program.

Data were pulled from the State database on January 13, 2004. This allowed a sufficient time for the judicial system to process convictions and suspensions and for crash data to be entered through July 2003.

Drivers with less than 1 month of performance data were dropped from the sample (i.e., drivers licensed in July 2003 or later).

Drivers in the sample, then, were initially licensed between January 1998 and June 2003. Their performance data were drawn from March 1999 through July 2003. The pre-GDL group consisted of drivers who were newly licensed between January 1, 1998, and February 28,2000 . The GDL group was composed of drivers newly licensed between March 1, 2000, and June 30, 2003. Of the drivers licensed after March 1, 2000, only those who were ages 16 or 17 were subject to the GDL requirements and restrictions. 


\section{LIMITATIONS}

The information generated by these analyses were limited in the following ways. First, causality cannot be inferred with certainty. If a change is associated with an event in time, that does not guarantee that the change was caused specifically and solely by that event. Second, any study with a large sample size may generate statistically significant results even when effect sizes are small. Third, no exposure data were available, so there can be no direct evidence, for example, that 16-year-old drivers drive fewer miles than 17-year-old drivers.

\section{$\underline{\text { RESULTS }}$}

\section{DRIVER DEMOGRAPHICS}

The following charts depict various breakdowns of the sample of new drivers used for the analysis. Because of the exclusions previously discussed, the sample is slightly less than the number of newly licensed drivers for the same time period. The sample composition is shown in Table 2.

The merging/matching procedures demonstrated that the performance data, for some drivers, was not included in the driver performance database. Due to these issues, only drivers who had at least one month of performance data were included in the analysis.

Table 2: Sample Composition

\begin{tabular}{|c|c|c|c|c|c|}
\hline \multirow{2}{*}{$\begin{array}{c}\text { Year Road } \\
\text { Test Passed }\end{array}$} & \multicolumn{4}{|c|}{ Age Upon Passing the Road Test } & \\
\hline & 16 & 17 & 18 & 19 & Total \\
\hline 1998 & 18192 & 5740 & 4252 & 1499 & 29683 \\
\hline 1999 & 26107 & 7942 & 5935 & 3275 & 43259 \\
\hline 2000 & 22951 & 5435 & 6175 & 3234 & 37795 \\
\hline 2001 & 22612 & 6256 & 6643 & 3316 & 38827 \\
\hline 2002 & 20990 & 6548 & 6619 & 3188 & 37345 \\
\hline 2003 (partial year) & 9863 & 2945 & 3274 & 1741 & 17823 \\
\hline Total & 120715 & 34866 & 32898 & 16253 & 204732 \\
\hline
\end{tabular}

As shown in Table 2, the number of newly licensed drivers generally decreased from 1999 through 2002, though a slight peak is evident in 1999.

This is especially evident for the 16- and 17-year-olds. This peak could have been due to a number of factors, though, and the focus groups indicated that many younger drivers seemed to have been motivated to obtain their licenses before the GDL law was enacted in March 2000. (In fact, a proportion of the 16- and 17-year-old drivers included in the year 
2000 total were licensed in January and February of 2000, inflating the number of drivers shown in this year).

Figure 1 shows the sample composition by year of licensure and age at licensure.

Figure 1: Number of New Drivers By Age at Licensure By Year

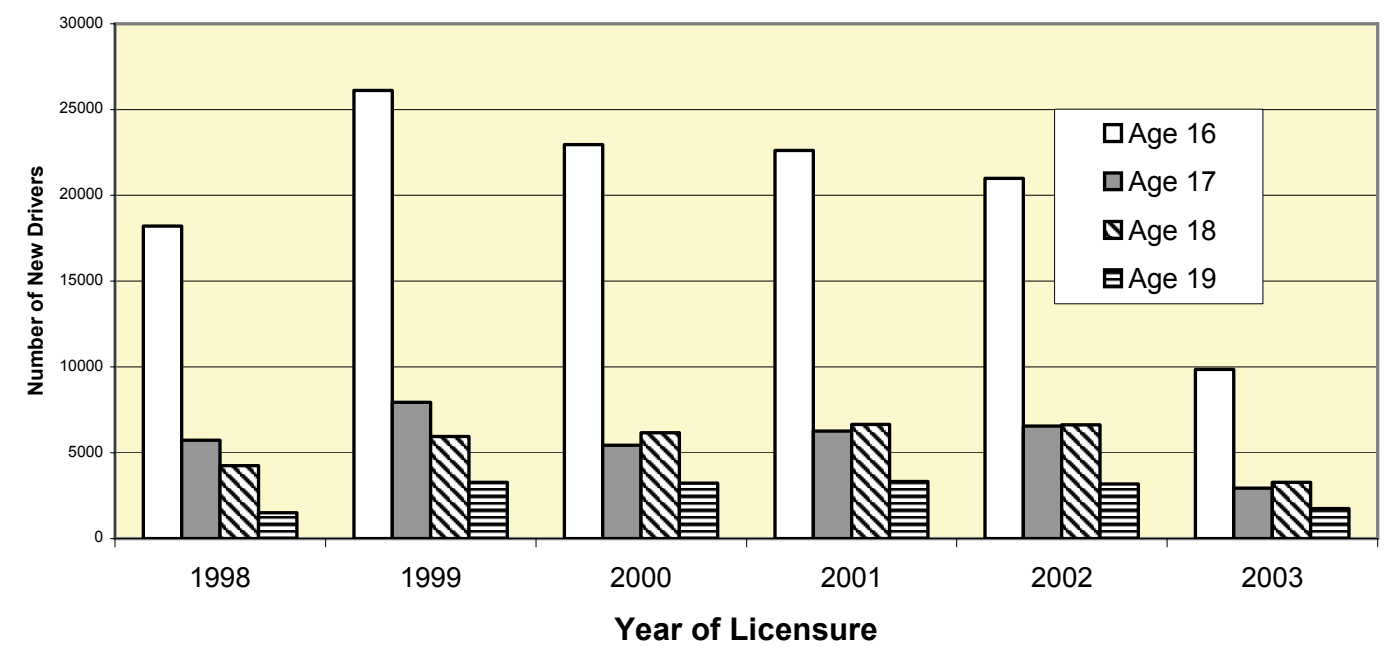

The number of males and females were approximately equal among the 16- and 17-yearold driver groups. Those who chose to obtain their licenses at ages 18 or 19 (Non-GDL Aged 18-19) and, therefore, not subject to the GDL requirements have a higher proportion of males.

This is further illuminated in Figure 2. As shown, the proportion of 16- and 17-year -olds who obtained licenses in the Post-GDL period showed a decrease and, conversely, the proportion of 18- and 19-year-olds increased. These trends were evident for both males and females, though more so for males. It appears that after GDL implementation, more Oregon teenagers waited until age 18 to obtain their licenses.

Figure 2: New Drivers By Age and Gender at Licensure By Year

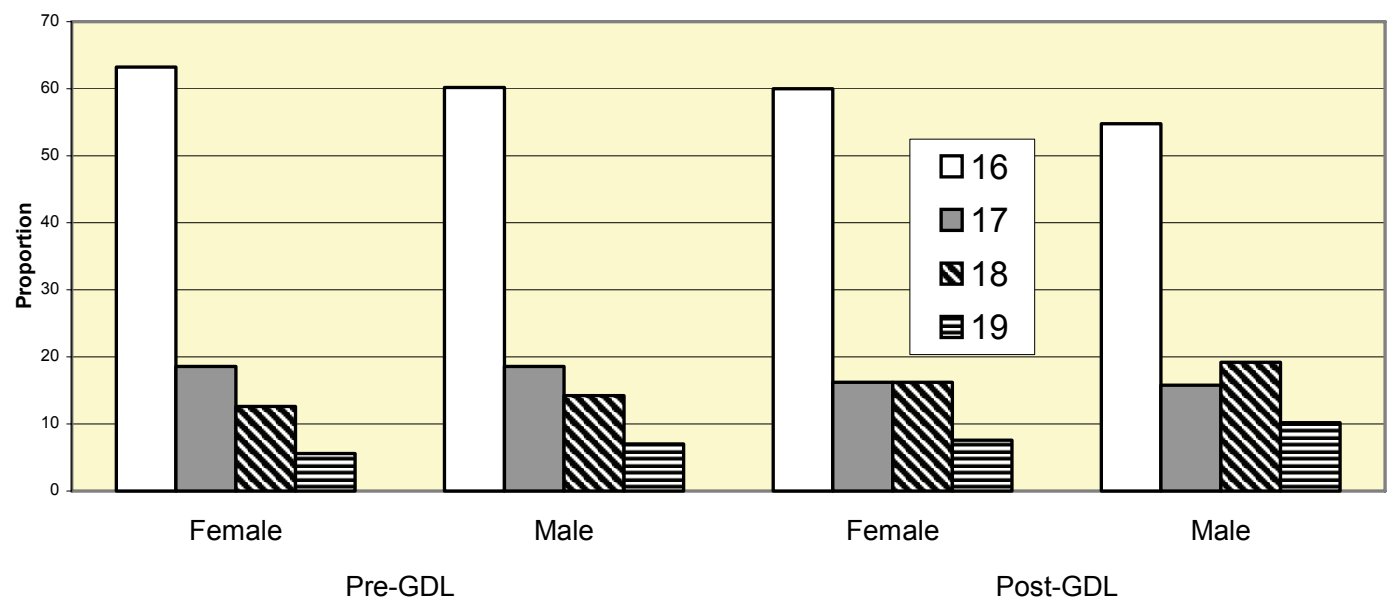

Gender / GDL Status 


\section{DRIVER PERFORMANCE VARIABLES}

Studies of GDL programs usually investigate statewide crash rates (e.g., Shope \& Molnar, 2003). This approach reveals changes in crashes associated with a new law - for example, per-capita crash rates of 16-year-olds before and after a program takes effect. This method is particularly useful for investigating teenage drivers' outcome rates during the same calendar time periods, and controlling for adult outcome rates. This approach is detailed in the first section of the Driver Performance analyses, Outcomes of Teens Relative to Adult Drivers Before and After GDL.

The current data set also permits the matching of driver records with outcomes. It is possible to determine not only the age of a driver associated with a particular outcome, but also whether the driver was licensed after the GDL program took effect, how long the driver had held the license, and what phase of the GDL program was applicable to the driver at the time. For example, the performance of GDL and non-GDL drivers can be examined during their first 6 months of licensure, during the second 6 months of licensure, and so on. Conclusions may then be drawn about crash rates during specific phases of the GDL program. These results are presented in the second section of the Driver Performance analyses, Outcomes of Teen Drivers as They Gain Experience Before and After GDL.

In addition, the current data contain information regarding driver training. Under Oregon's GDL program, new drivers licensed before age 18 are required to either complete an ODOT-approved driver education course and perform 50 hours of supervised driving practice, or the new drivers can opt out of a driver education course but are required to certify 100 hours of supervised driving practice. Specifically, some of the GDL drivers in our sample completed a formal driver's education course and claimed to have performed 50 hours of supervised practice. Others did not complete a formal driver's education course but claimed to have performed an additional 50 hours of practice for a total of 100 hours of supervised driving practice. The third section of the Results, Education and Training Options, details the analysis of this information.

\section{Outcomes of Teens Relative to Adult Drivers Before and After GDL}

Adult drivers (ages 25-65) were used as a baseline to examine whether implementation of the GDL program was associated with outcomes beyond any trend seen in the general driving public. This approach investigated teenage drivers' outcome rates controlling for adult outcome rates during the same calendar time periods.

Toward this end, conviction, suspension, and crash data were obtained for Oregon drivers age 25 and older during the targeted time period. Oregon DMV extracted the data in mid2005 and provided it for this analysis.

Suspension and crash data for the 25-65 age group looked consistent for 1999 through 2002, but convictions were not. As shown in Table 3, the number of convictions in 1999 for the 25-65 age group were far lower than those for other years. 
Table 3: Convictions, Suspensions, and Crashes by Age Group and Year, 1999-2002

\begin{tabular}{|c|c|c|c|c|}
\hline \multirow{2}{*}{$\begin{array}{l}\text { Age Group and } \\
\text { Extraction Date }\end{array}$} & \multirow[b]{2}{*}{ Year } & \multicolumn{3}{|c|}{$\mathrm{N}$} \\
\hline & & Convictions & Suspensions & Crashes \\
\hline \multirow{4}{*}{$\begin{array}{l}\text { Age } 16 \\
\text { Extracted } 2004\end{array}$} & 1999 & 7,872 & 4,159 & 4,156 \\
\hline & 2000 & 7,378 & 3,331 & 3,530 \\
\hline & 2001 & 6,897 & 3,454 & 3,450 \\
\hline & 2002 & 5,905 & 3,206 & 2,965 \\
\hline \multirow{5}{*}{$\begin{array}{l}\text { Age } 17 \\
\text { Extracted } 2004\end{array}$} & & & & \\
\hline & 1999 & 15,407 & 9,997 & 5,295 \\
\hline & 2000 & 14,737 & 9,045 & 4,816 \\
\hline & 2001 & 13,084 & 8,155 & 4,611 \\
\hline & 2002 & 12,137 & 8,003 & 4,429 \\
\hline \multirow{4}{*}{$\begin{array}{l}\text { Age } 25-65 \\
\text { Extracted } 2005\end{array}$} & 1999 & 140.308 & 248.304 & 99.551 \\
\hline & 2000 & 369,332 & 294,443 & 96,150 \\
\hline & 2001 & 360,230 & 291,478 & 97,932 \\
\hline & 2002 & 381,146 & 319,966 & 94,492 \\
\hline
\end{tabular}

Oregon periodically purges many convictions from its database after 5 years. The fact that the 1999 conviction rate for the 25-65 age group was quite different than other years might be accounted for by this and other factors. Because the data extraction for the 25-65 age group included individuals with purged conviction records, only suspensions and crashes are reported for the current analyses.

Comparisons were made of outcome rates before and after the effective date of Oregon's GDL law. Performance data from the year immediately preceding the effective date of the GDL law (March 1999 through February 2000) were compared to each of the 3 years following that date:

$\begin{array}{lr}\text { March 2000-February 2001 } & \text { (post-GDL year 1) } \\ \text { March 2001-February 2002 } & \text { (post-GDL year 2) } \\ \text { March 2002-February 2003 } & \text { (post-GDL year 3) }\end{array}$

Sixteen- and 17-year-old drivers were examined separately.

Outcome ratios were calculated to standardize the outcome rates to the adult control group. Following Ulmer et al. (1999) and Mayhew et al. (1999), each outcome rate for each young driver group was divided by the corresponding outcome rate for the adult control group. As a result, the adult control group ratios were standardized to 1.00 , and other groups obtained scores which represent their rates in relationship to the control group. Outcome ratios above 1.00 signify rates higher than the adult control group, and outcome ratios below 1.00 signify rates lower than the adult control group. 
$\underline{Z}$ statistics were used to measure significance levels. The cutoff for significance was twotailed alpha $=.01$.

It must be noted that immediately following implementation of the GDL program, only newly licensed 16- and 17-year-old drivers were subject to the GDL provisions. Only after a full year of implementation had all 16-year-old drivers been licensed under the GDL program. Only after two full years had all 17-year-old drivers been licensed under the GDL program. It is especially important to remember this when interpreting the outcomes of the first post-GDL year.

\section{Suspensions}

Table 4 shows suspension rates for each of the 4 years. Sixteen-year-olds' suspension rates ranged from 65 per thousand drivers per year, 17-year-olds' rates ranged from 162 per thousand drivers per year, and adults (25-65 years old) ranged from 141 to 168 per thousand drivers per year.

Table 4: Suspensions by Age (16- and 17-Year Olds) per 1,000

Population

As the adult suspension rates show, suspensions in the overall population rose over the time period studied. All three of the post-GDL adult suspension rates were significantly greater than the pre-GDL year (all z's $>3$, all p's $<.01$ ).

\begin{tabular}{|c|c|c|c|}
\hline \multirow{2}{*}{ Year } & \multicolumn{3}{|c|}{ Age } \\
\cline { 2 - 4 } & 16 & 17 & $25-65$ \\
\hline Pre-GDL Year & 84 & 203 & 141 \\
\hline Post-GDL Year 1 & 69 & 183 & 160 \\
\hline Post-GDL Year 2 & 70 & 168 & 156 \\
\hline Post-GDL Year 3 & 65 & 162 & 168 \\
\hline
\end{tabular}

As previously described, outcome ratios were calculated such that teenage drivers' outcomes were expressed relative to the adult rates. Sixteen-year-olds' and 17-year-olds' suspension ratios are shown in Figure 3.

Sixteen-year-olds' suspensions ratios were significantly lower from the year pre-GDL in the year immediately following GDL implementation $(\underline{z}=14.92, \underline{p}<.001)$; in the second postGDL year $(\underline{z}=13.34, \underline{p}<.0001)$; and in the third post-GDL year $(\underline{z}=19.08, \underline{p}<.0001)$. Similarly, 17-year-olds' suspension ratios were also significantly lower after the GDL law took effect. Their suspension ratios were significantly lower in the first year $(\underline{z}=17.72, \underline{p}<$ $.0001)$; in the second post-GDL year $(\underline{z}=21.63, \underline{p}<.0001)$; and in the third year $(\underline{z}=29.24$, $\underline{\mathrm{p}}<.0001)$.

Implementation of Oregon's GDL program was clearly associated with lower suspension ratios for 16- and 17-year-old drivers. 
Figure 3: Suspensions of 16- and 17-Year-Olds

(Adult Control Group Ratio Standardized to 1.0)

\section{Suspensions of 16-Year-Old Drivers}

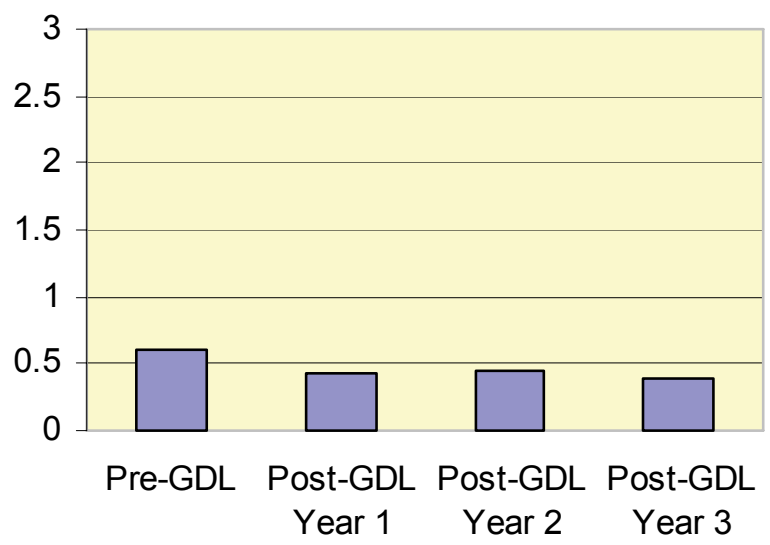

Ratios Standardized to Adult Rates

\section{Suspensions of 17-Year-Old Drivers}

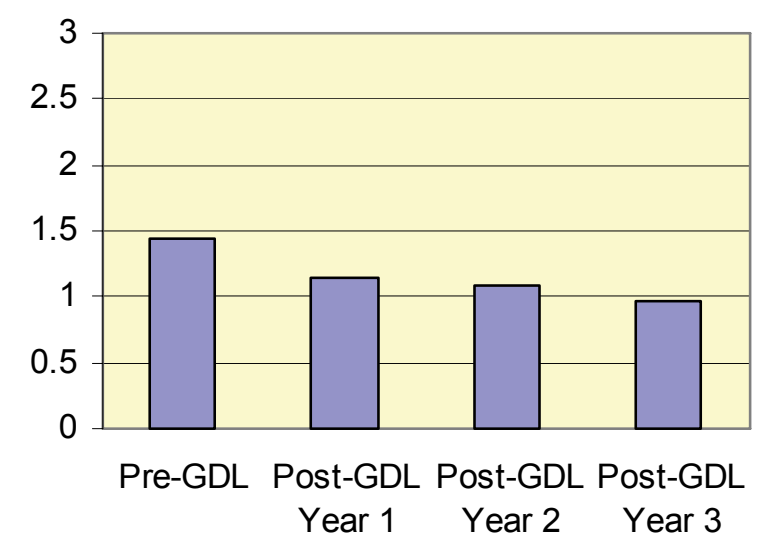

Ratios Standardized to Adult Rates

Eighteen- and 19-year-old drivers were not directly affected by the GDL program, either before or after implementation. Drivers who were licensed at age 17 were immediately exempted from the GDL restrictions when they turned 18, no matter how briefly they had been fully licensed. If the GDL program affected 18-year-old drivers at all, it would have been through the drivers having been initially licensed under the GDL requirements and restrictions.

Table 5: Suspensions by Age (18- and 19-Year-Olds) per 1,000

Eighteen- and 19-year-old drivers' suspension ratios (again, calculated relative to the adult drivers' rates) dropped significantly in post-GDL years (all z's > 3, all p's <.01) Table 5 shows raw suspension rates and Figure 4 illustrates suspension ratios Population for both age groups.

\begin{tabular}{|c|c|c|c|}
\hline \multirow{2}{*}{ Year } & \multicolumn{3}{|c|}{ Age } \\
\cline { 2 - 4 } & 18 & 19 & $25-65$ \\
\hline Pre-GDL Year & 283 & 382 & 141 \\
\hline Post-GDL Year 1 & 256 & 370 & 160 \\
\hline Post-GDL Year 2 & 252 & 375 & 156 \\
\hline Post-GDL Year 3 & 252 & 384 & 168 \\
\hline
\end{tabular}


Figure 4: Suspensions of 18- and 19-Year-Olds

(Adult Control Group Ratio Standardized to 1.0)

Suspensions of 18-Year-Old

Drivers

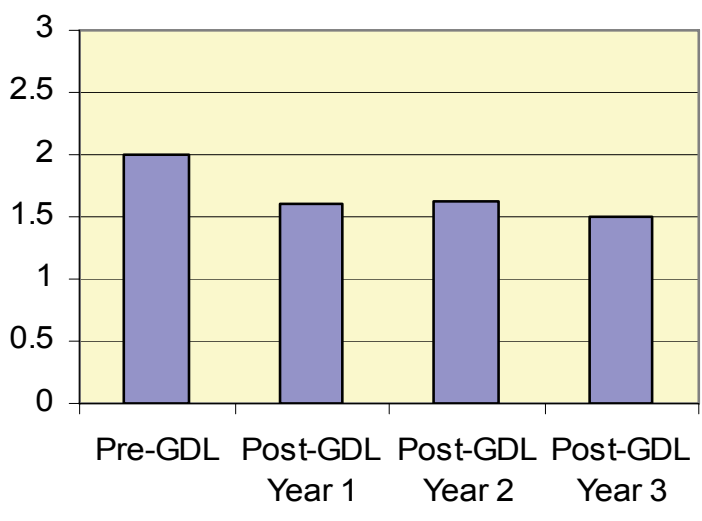

Ratios Standardized to Adult Rates

\section{Suspensions of 19-Year-Old} Drivers

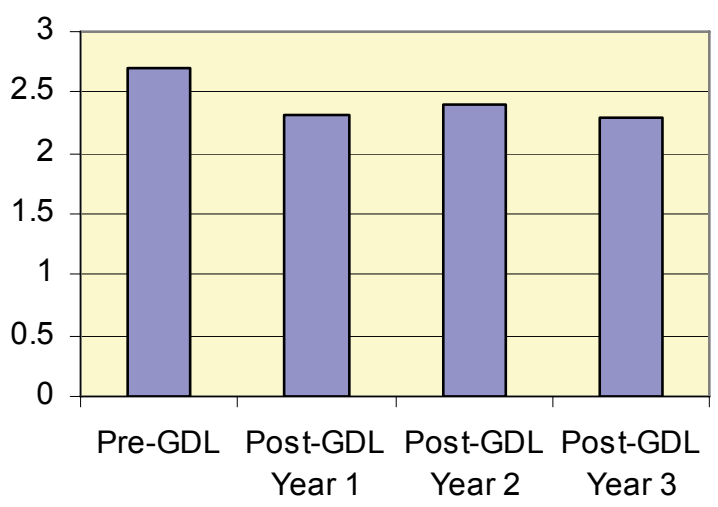

Ratios Standardized to Adult Rates

\section{Crashes}

Teenage drivers' crash rates appeared to decrease after GDL implementation, as shown in Table 6. However, the crash rates in the adult population also dropped after GDL implementation. In fact, for each of the post-GDL years, adult crash rates were lower than for the pre-GDL year (all z's > 3, all p's <.01).

Table 6: Crash Rate per 1,000 Population

\begin{tabular}{|c|c|c|c|}
\hline & \multicolumn{3}{|c|}{ Age } \\
\hline & 16 & 17 & $25-65$ \\
\hline Pre-GDL Year & 84 & 107 & 56 \\
\hline Post-GDL Year 1 & 73 & 97 & 52 \\
\hline Post-GDL Year 2 & 70 & 95 & 52 \\
\hline Post-GDL Year 3 & 60 & 90 & 50 \\
\hline
\end{tabular}

Sixteen-year-olds' crash ratios are shown in Figure 5. It is important to remember that crash ratios are standardized to the adult rate, such that teenage ratios greater than one indicate rates greater than adults demonstrated in the same year, and teenage ratios which are less than one indicate rates lower than adults. 
For 16-year-olds, all post-GDL crash ratios were significantly lower after implementation of the GDL program. Compared to the pre-GDL year, crash ratios in the first post-GDL year $(\underline{z}=3.22, \underline{p}<.01)$; the second post-GDL year $(\underline{z}=5.44, \underline{p}<.0001)$; and in the third postGDL year $(\underline{z}=9.02 ., \underline{p}<.0001)$ were all significantly lower. This represents a reduction in crashes beyond that shown by the overall adult population.

Figure 5: Crashes of 16- and 17-Year-Olds

(Adult Control Group Ratio Standardized to 1.0)

\section{Crashes of 16-Year-Old Drivers}

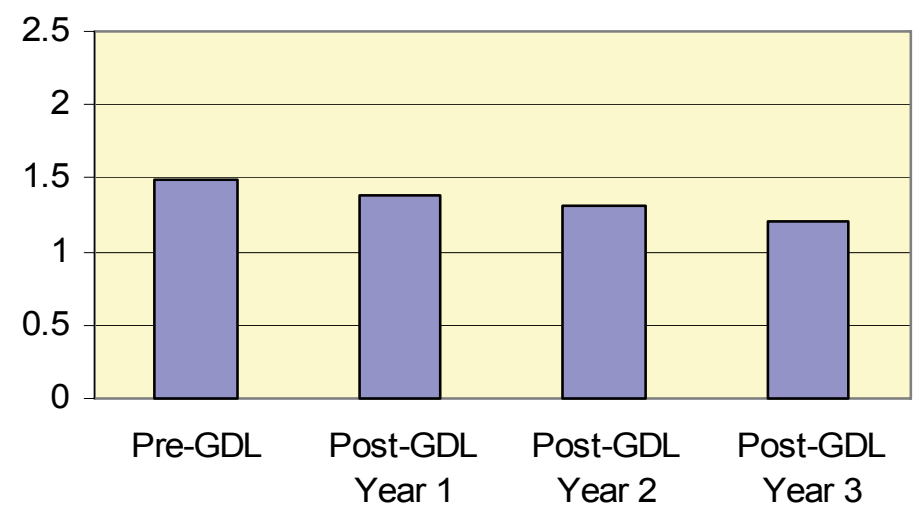

Ratios Standardized to Adult Rates
Crashes of 17-Year-Old Drivers

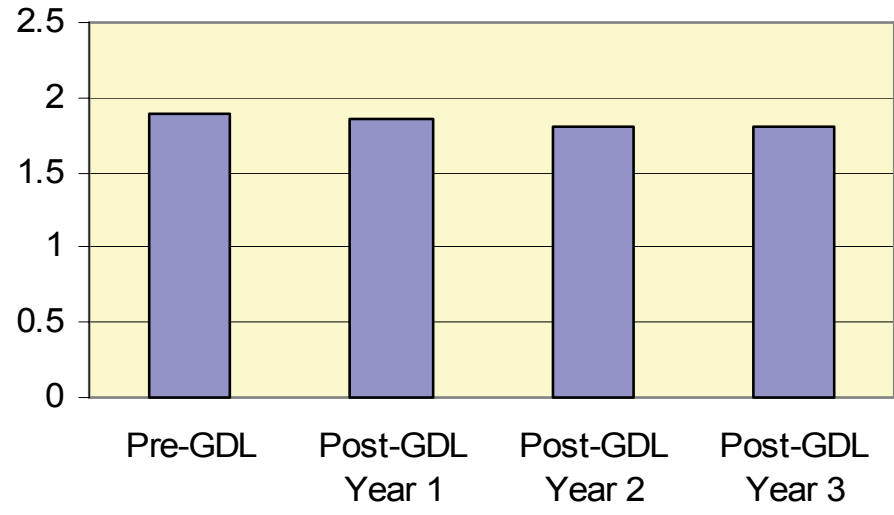

Ratios Standardized to Adult Rates

The 17-year-olds also demonstrated lower post-GDL crash ratios; though, as predicted, significant differences did not surface until the second year after the GDL program took effect and all 17-year-olds had been licensed under the GDL program. Compared to the pre-GDL year, 17-year-olds' crash ratios in the second post-GDL year $(\underline{z}=2.58, \underline{p}<.01)$ were significantly lower, and 17-year-olds' crash ratios in the third year followed the same pattern, though the third year did not achieve significance $(\underline{z}=2.57, \underline{p}>.01)$. Significantly lower crash rates represent a reduction in crashes, beyond that seen in adult drivers.

Oregon's GDL program was associated with overall lower crash ratios in the 16- and 17year-old population, especially the second year after implementation.

Eighteen- and 19-year-old drivers were not directly affected by the GDL program.

Eighteen-year-olds' crash ratios, calculated relative to adult crash rates, were significantly lower after GDL implementation only in the third post-GDL year $(\underline{z}=3.9, \underline{p}<.0001)$.

Nineteen-year-old drivers showed significantly higher crash ratios in the first and second year after the GDL program ( $\underline{z}=5.58, \underline{p}<.0001$ and $\underline{z}=3.35, \underline{p}<.001$, respectively). 
Table 7: Crash Rates per 1,000 Population 18 and Older

Note that though the 19-year-olds' raw crash rates do not appear to be dramatically higher, the ratios show an increase relative to the adult rates, which dropped in the same time period.

\begin{tabular}{|l|c|c|c|}
\hline & \multicolumn{3}{|c|}{ Age } \\
\hline & 18 & 19 & $25-65$ \\
\hline Pre-GDL Year & 122 & 100 & 56 \\
\hline Post-GDL Year 1 & 110 & 104 & 52 \\
\hline Post-GDL Year 2 & 111 & 100 & 52 \\
\hline Post-GDL Year 3 & 100 & 92 & 50 \\
\hline
\end{tabular}

Figure 6: Crashes of 18- and 19-Year-Olds

(Adult Control Group Ratio Standardized to 1.0)

Crashes of 18-Year-Old Drivers

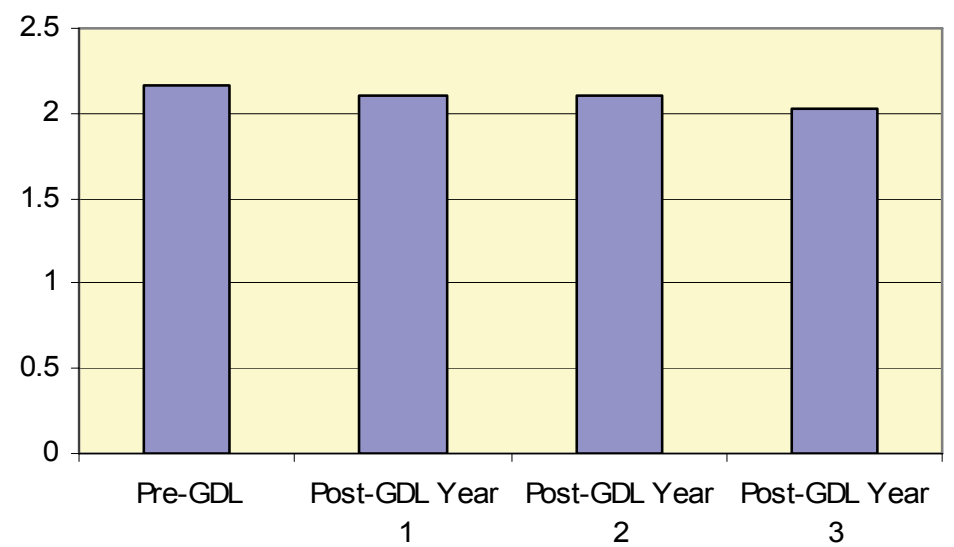

Crashes of 19-Year-Old Drivers

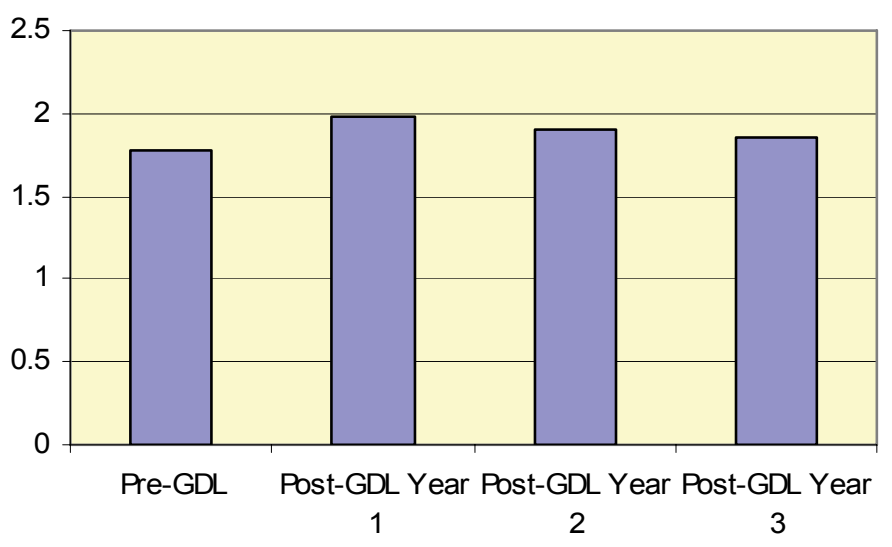




\section{Outcomes of Teen Drivers as They Gain Experience Before and After GDL.}

Performance data were drawn from March 1999 through July 2003. Each performance variable was identified and matched to the driver who committed the infraction. The driver's data was subset to yield the following information: a) license issuance date; $b$ ) number of months since licensure (1 through 24, if applicable); c) age; and d) GDL status.

Oregon's GDL program, as discussed earlier, placed restrictions on new drivers during the first year of driving, with a reduction in restrictions after the first 6 months.

Correspondingly, performance data were aggregated for the first 6 months of licensure, for the second 6 months of licensure, and for the $13^{\text {th }}-24^{\text {th }}$ months of licensure. Measures were calculated to provide a mean rate of conviction, suspension, and crash incidence per 1,000 drivers per month.

Some drivers did not have a complete performance record available for a full-time block. For example, a driver who was licensed in January 1999 would not have a performance record for the first 2 months of driving experience. Similarly, a driver who was licensed in February 2003 would have a performance record for the first 5 months of licensure but none after July 2003.

Because of these drivers with partial performance records in a time block, performance measures within time blocks were weighted by the number of months for which data was available. That is, the number of events (convictions, suspensions, crashes) for a group was divided by the number of months of data available for that group, within the time block. This provided a mean number of convictions, suspensions, and crashes per 1,000 drivers per month for each block.

If a driver had no performance data available within a time block, the driver was excluded from analysis in that block. For example, drivers who were licensed in September 1998 but had no performance data during the first 6-month time block would not be included in rates calculated for the first 6-month block.

Table 8 shows cells of data for analysis. The numbers in each cell identify the age, driving experience, and GDL status of data cells. For example, Cell 3 refers to drivers who were initially licensed when they were 16, after the GDL program took effect, during the second year of their driving experience. 
Table 8: Data Cells for Analysis

\begin{tabular}{|c|c|c|c|c|c|c|c|c|c|c|}
\hline \multirow{2}{*}{\multicolumn{2}{|c|}{\begin{tabular}{l}
\multicolumn{1}{c}{ GDL } \\
\multicolumn{1}{c}{ Status } \\
Months After \\
Licensure \\
\end{tabular}}} & \multicolumn{3}{|c|}{$\begin{array}{c}\text { Licensed under } \\
\text { GDL Program } \\
\text { Post March 2000 } \\
\end{array}$} & \multicolumn{3}{|c|}{$\begin{array}{l}\text { Never in GDL } \\
\text { Pre March } 2000\end{array}$} & \multicolumn{3}{|c|}{$\begin{array}{c}\text { Never in GDL } \\
\text { Licensed after Age } 18 \\
\text { Post March } 2000 \\
\end{array}$} \\
\hline & & $0-6 m$ & $7-12 m$ & $13-24 m$ & $0-6 m$ & $7-12 \mathrm{~m}$ & $13-24 m$ & $0-6 m$ & $7-12 m$ & $13-24 m$ \\
\hline \multirow{4}{*}{$\begin{array}{l}\text { Age at } \\
\text { Initial } \\
\text { Licensure }\end{array}$} & 16 & $1 *$ & 2 & 3 & 7 & 8 & 9 & & & \\
\hline & 17 & 4 & 5 & 6 & 10 & 11 & 12 & & & \\
\hline & 18 & & & & 13 & 14 & 15 & 19 & 20 & 21 \\
\hline & 19 & & & & 16 & 17 & 18 & 22 & 23 & 24 \\
\hline
\end{tabular}

* Numbers in each cell refer to the individual cell number indicated for analysis

Cells 1 and 2 were drivers who were initially licensed at age 16 after the GDL program took effect, so cells 1 and 2 reflected those drivers' performance under the GDL restrictions.

Cell 3, however, reflected those drivers' performance after the restrictions have been lifted.

Cells 4 and 5 were slightly more complicated. Oregon's GDL restrictions were in place for the first year of licensure. However, when a driver turns 18, all restrictions are lifted. It is important to recognize that any driver who received a license at age 17 "ages out" of the program in 364 days or fewer, and will have had the restrictions lifted before a full year of experience had been acquired. Some drivers in cell 4 have become unrestricted; all the drivers in cell 5 have become unrestricted some time before the full 12 months have elapsed. This is a characteristic of the program and is common to many GDL programs in the United States. These 17-year-olds are referred to as "GDL" drivers because they entered under the GDL program, but it is important to remember that they differ from the 16-year-olds based on the length of time the restrictions applied.

Cells 7-24 represent unrestricted driving performance. The drivers whose records are reflected in these cells were licensed before the GDL program took effect or were over 18 at licensure.

To reduce the chance of results achieving significance merely because many tests were carried out, alpha levels were set at $\underline{p}=.01$.

\section{Convictions}

Table 9, shown on the next page, summarizes the analyses conducted on the conviction rates of the sample groups. As shown, the results for all comparisons of pre-GDL groups with GDL groups are significant. That is, all groups received fewer convictions after the GDL program went into effect.

Table 9 shows the mean monthly conviction rates for drivers ages 16, 17, 18, and 19, respectively. Conviction rates pre- and post-GDL implementation are depicted for each age group. Conviction rates after GDL implementation were consistently lower compared 
to pre-GDL rates. This analysis does not directly address whether the effect is due entirely to the GDL program or other longitudinal factors such as a change in judicial leniency, enforcement funding levels, etc.

Lower conviction rates were predicted among the 16- and 17-year-olds, because these groups were directly restricted by the program. A driver who first receives a license at age 18 or 19 does not have to fulfill the same requirements as a 16- or 17-year-old, and that 18or 19-year-old driver is unrestricted. Still, it is worth noting that although both 16- and 18year-old drivers licensed in the pre-GDL period were equally unrestricted, the 18-year-old drivers show higher conviction rates. The patterns reversed as drivers gained experience: conviction rates for 18-year-old novices decreased from their first to second year of driving while the 16-year-old novices' rates increased in their second year of driving.

It is also possible that fewer convictions are occurring in the general population as a whole. Because the previously presented analyses of outcome ratios could not examine conviction rates as standardized relative to adults, this possibility cannot be assessed. If this is the case, then the reduced conviction rate may reflect a change common to the entire driving population.

Figures 7 through 9 , following Table 9 , show conviction rates changed after the GDL requirements and restrictions went into effect. In their first 6 months of licensure, teenage drivers who were initially licensed before the GDL program received more convictions than teenage drivers who were licensed afterward. After the GDL program took effect, 16-yearolds, 17-year-olds, 18-year-olds, and 19-year-olds all received fewer convictions in their first 2 years of driving. 


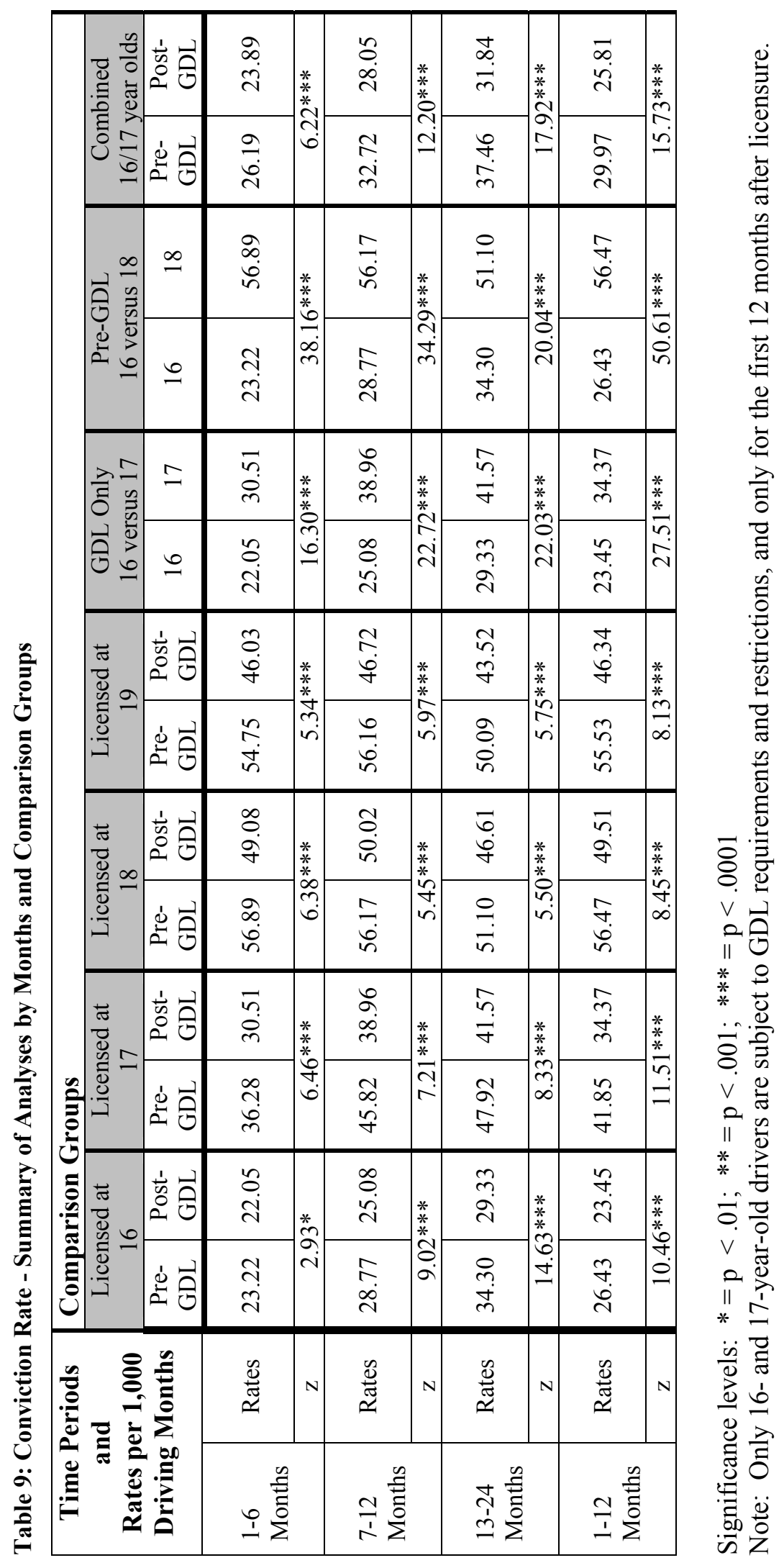


Figure 7: Monthly Convictions per 1,000 Drivers in the First 6 Months of Licensure (Months 1-6)

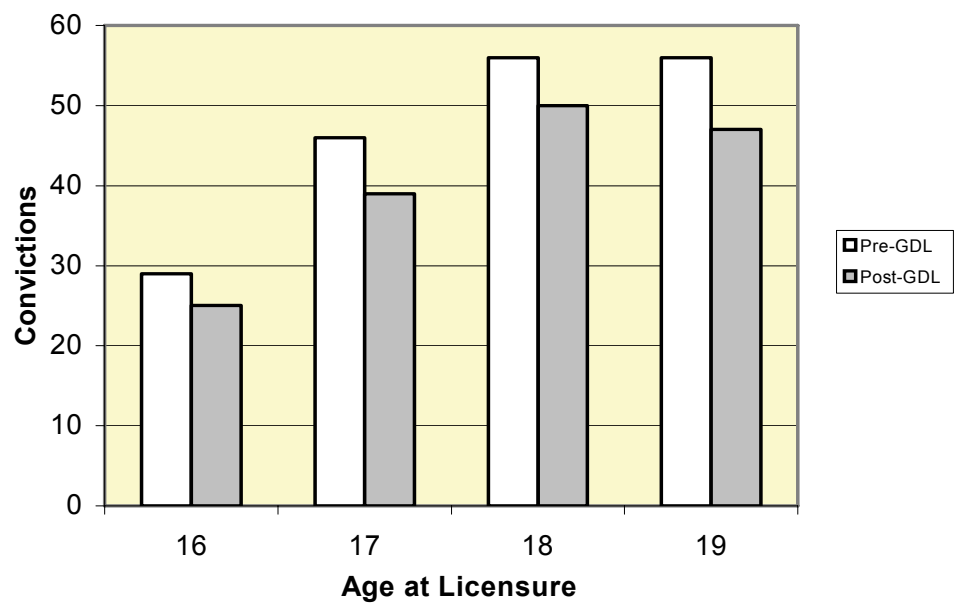

Figure 8: Monthly Convictions per 1,000 Drivers in the Second 6 Months of Licensure (Months 7-12)

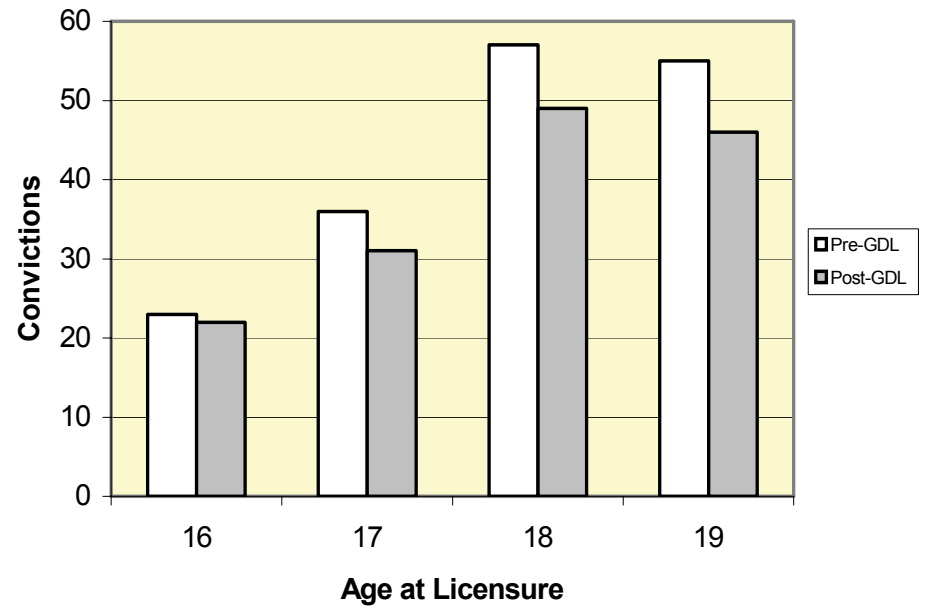

Figure 9: Monthly Convictions per 1,000 Drivers in the Second Year of Licensure (Months 13-24)

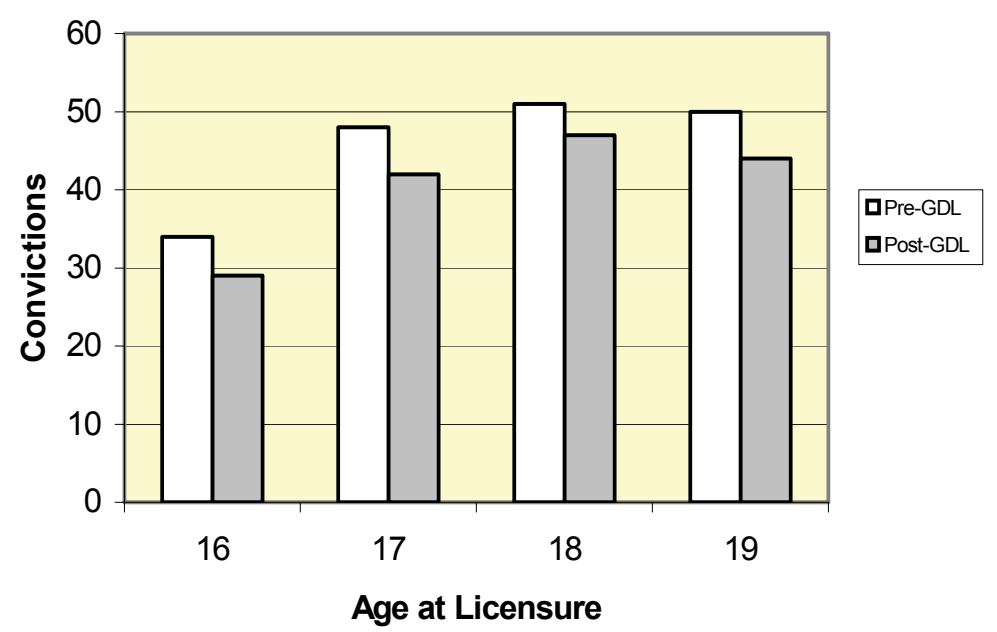




\section{Suspensions}

Suspension rates provided a rough indicator of severe offenses. Although suspensions in Oregon can result from violations that do not directly impact safety (for example, failing to appear in court) and multiple suspensions can result from a single violation (e.g., driving under the influence), they do tend to be roughly associated with more severe infractions, and are associated with lower compliance overall. Therefore, suspensions were analyzed as a rough, indirect metric of severe offenses.

As shown in Table 10 and Figure 10, young drivers who participated in the GDL program demonstrated significantly lower suspension rates than pre-GDL drivers during their first 6 months, second 6 months, and even the second year. This effect appeared to be stronger for the 16-year-olds (who are restricted for the first full year of driving) than for those who received their licenses at 17 years old (who age out of the restrictions sometime during their first year of driving).

Similar trends were also evident when comparing the pre- and post-GDL periods for 18and 19-year-olds. This finding may reinforce the hypothesis that the educational program publicizing the GDL program may have had spillover effects to novice drivers outside the GDL requirements. The population overall was not experiencing fewer suspensions during this time (see Outcomes of Teens Relative to Adult Drivers Before and After GDL, so the 16- through 19-year old drivers' reduced suspension rates do not reflect a global reduction.

It is interesting to note that slightly older novice drivers (for example, 17- and 18-yearolds) experienced higher conviction and suspension rates than younger novices (16year-olds). For example, 16- and 18-year-old novices were equally unrestricted before the GDL program, and the 18-year-old novices received more suspensions than the 16year-olds in all time periods (see "Pre-GDL 16 versus 18" column). If immaturity alone brought about higher violation rates, the opposite effect would be expected. It may be that older novices drove more miles and/or spent more time driving those miles than the younger drivers. Greater exposure could have resulted in higher conviction and suspension rates for slightly older drivers. Because exposure was not measured, this issue cannot be directly addressed. 


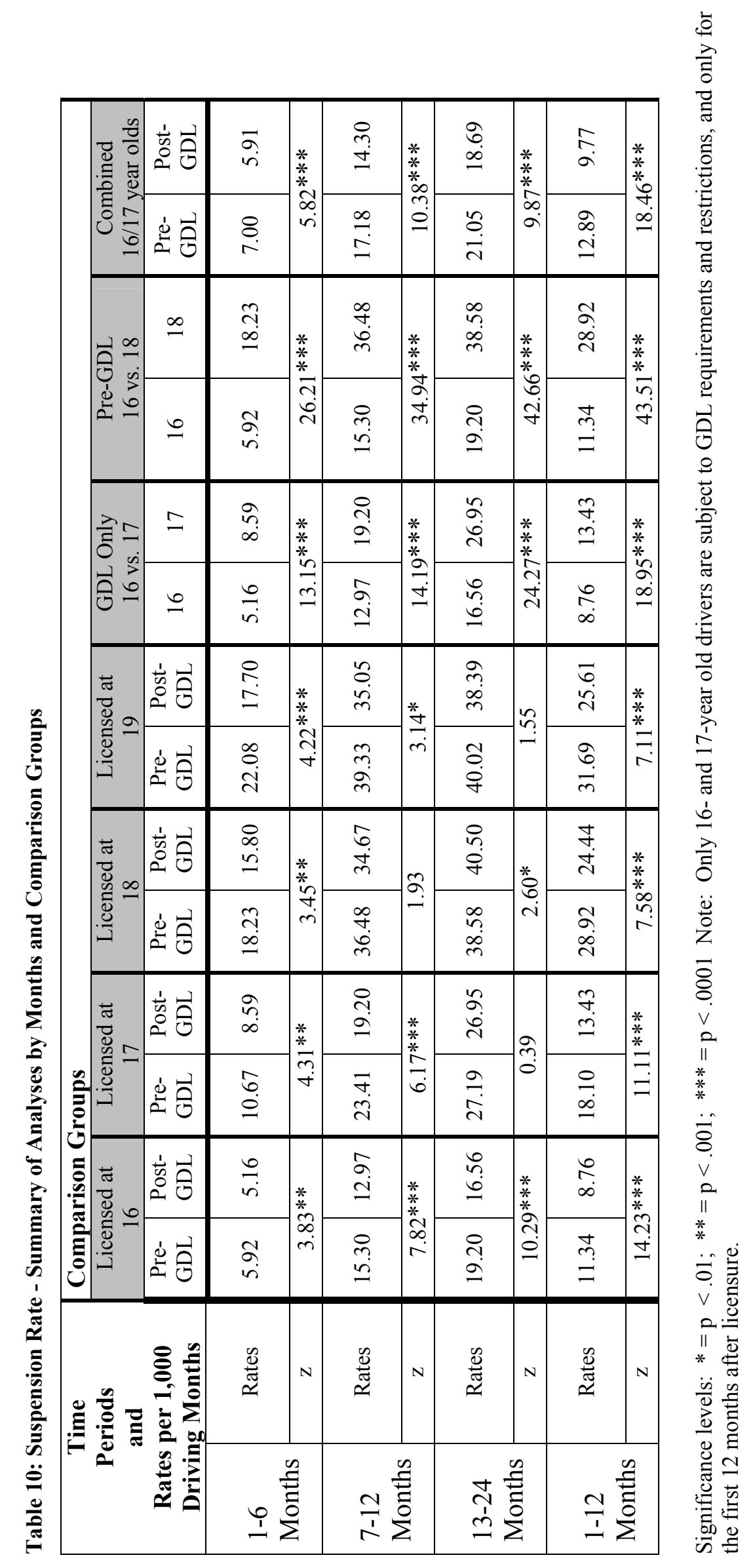


Figure 10: Monthly Suspensions per 1,000 Drivers in the First Two Years of Licensure

First 6 Months of Licensure

(Months 1-6)

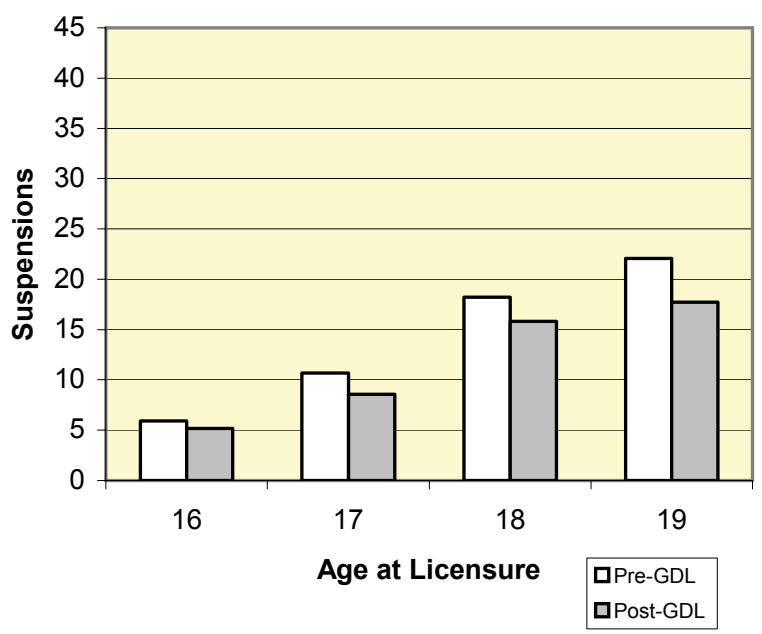

Second 6 Months of Licensure

(Months 7-12)

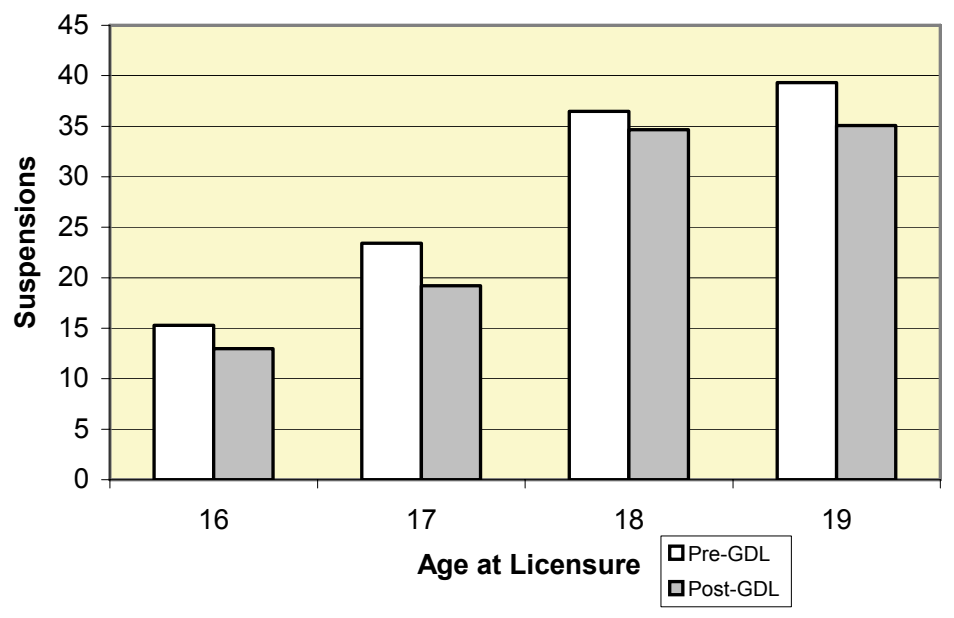

Second Year of Licensure

(Months 13-24)

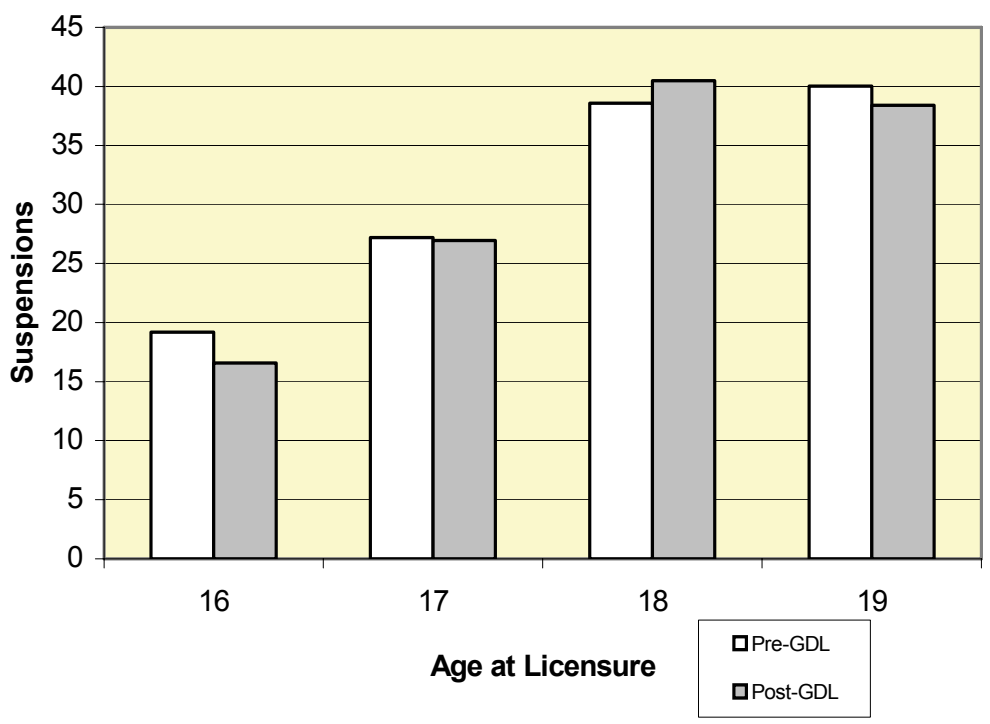




\section{Crashes}

No attempt was made to determine fault in the recorded crashes of the teenage drivers. In the current investigation, the key interest focused on safety, and a reduction of all crashes represents the ultimate goal of the GDL program. Higher crash rates, regardless of fault, demonstrate less safety; lower crash rates represent improved safety.

When examining the crash rates (Table 11), the overall trends showing lower rates for 16-year-old drivers in the GDL program, were present, though the differences between groups were not always statistically significant. The lowered crash rates were most clearly demonstrated in the first six months of driving by 16-year-old licensees. This period is when crash rates are highest, so a lowered crash rate during this time was a key finding.

For the 17-year-old drivers, no significant differences were observed. It is important to remember that drivers "age out" of the program as soon as they turn 18 , so a driver who was licensed at 17 will only be affected by the GDL restrictions until turning 18.

Note that for drivers initially licensed at age 16, crash rates did not seem to drop as quickly over time as they do for other age groups. In particular, the second full year of driving (months 13-24) still showed high crash rates for both pre-GDL and GDL drivers (almost 12 monthly crashes per 1,000 drivers) for those drivers licensed at 16 . For the second year of driving, pre-GDL novices initially licensed at 16 crashed more often than pre-GDL novices licensed at age 18 - even though 18-year-olds' higher conviction and suspension rates (Tables 9 and 10) might suggest more infractions and/or greater exposure among the older novices.

Significant differences were seen in the 19-year-old novices, who demonstrated lowered crash rates in the first year of driving, after the GDL program took effect. This does not represent a large effect size, but is consistent with the overall pattern of improved driving performance and slightly lowered crash rates following implementation of the GDL program. 18-year-old drivers, similarly, showed an overall (non-significant) trend toward a pattern of lowered crash risk after GDL implementation.

Generally, the patterns of mean outcome rates showed a lowered crash risk after the implementation of the GDL program. Particularly important is the lowered crash risk for 16-year-old drivers in the first 6 months of licensure. Though causality cannot be inferred, the lowered crash rates may be related to the stringency of GDL restrictions during the first 6 months.

The crash data represents the most powerful and direct evidence of safety after the implementation of the GDL program. 


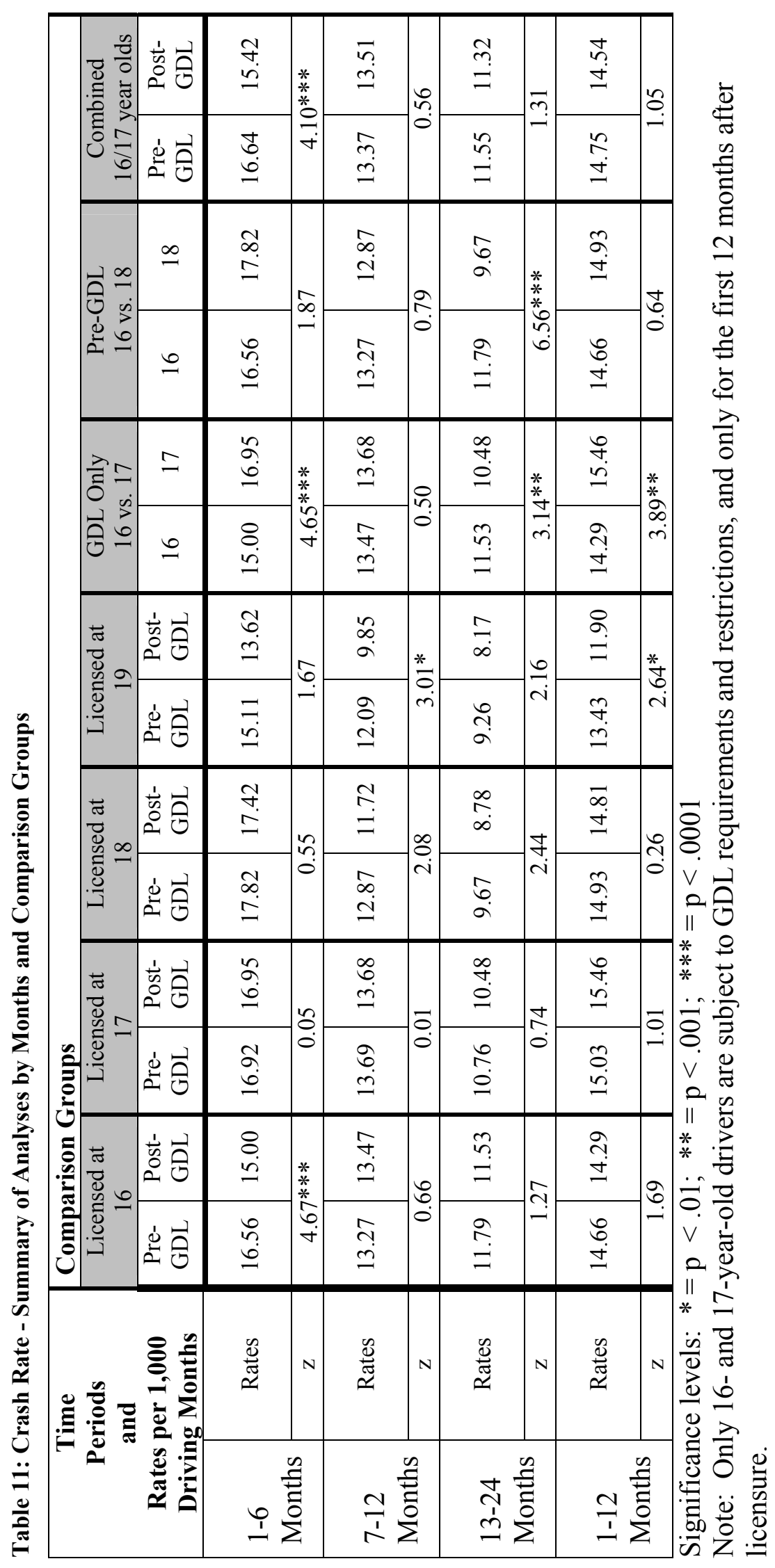


Figure 11 shows monthly crash rates per 1,000 drivers in their first 24 months of licensure.

Figure 11: Monthly Crashes per 1,000 Drivers in First 2 Years of Licensure

First 6 Months of Licensure

(Months 1-6)

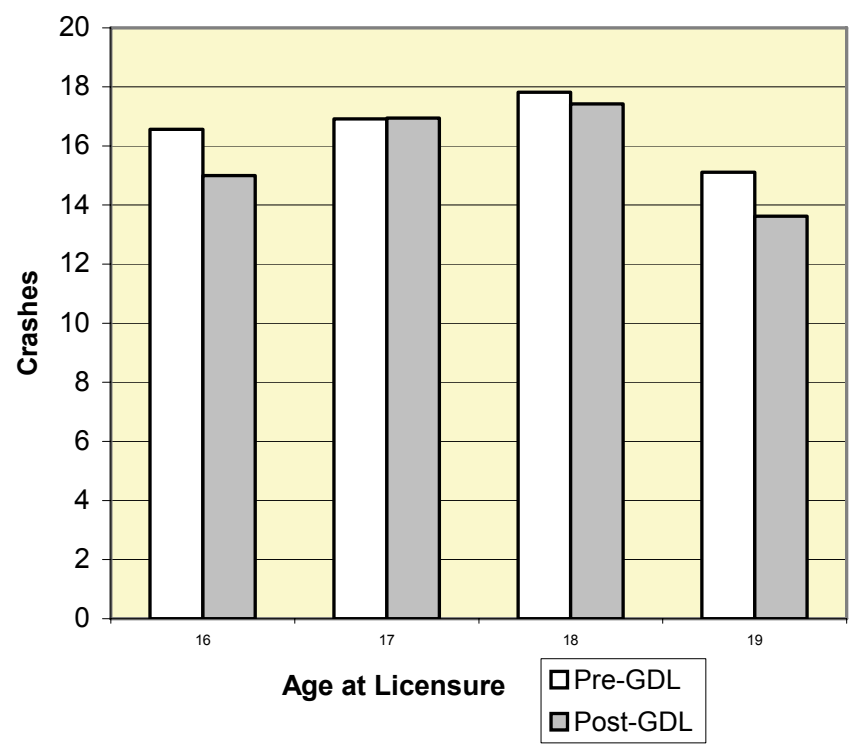

Second 6 Months of Licensure

(Months 7-12)

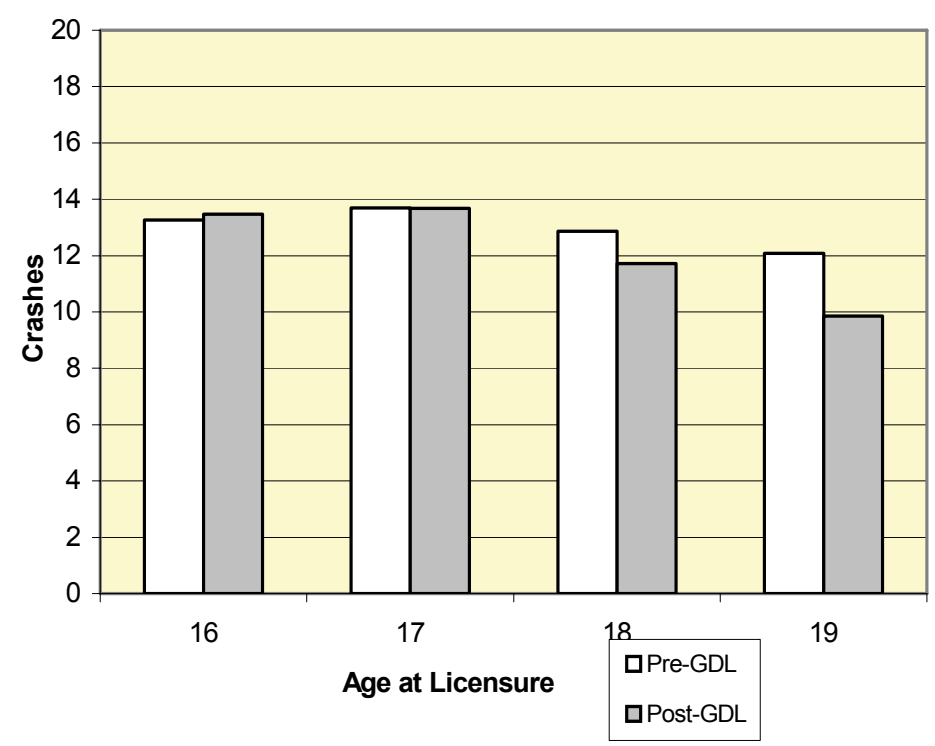

Second Year of Licensure

(Months 13-24)

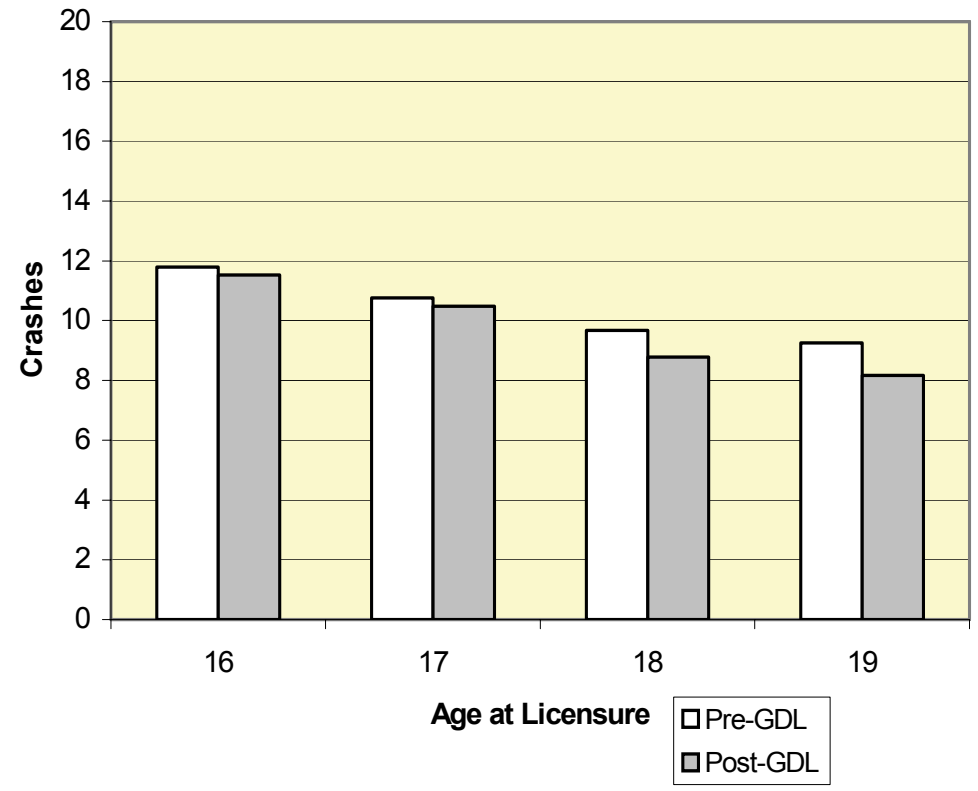




\section{GENDER DIFFERENCES}

\section{$\underline{\text { Convictions and Suspensions }}$}

Convictions and suspensions showed a strong effect for gender, as shown in summary Tables 12 and 13. For every age group, for every time period, for both GDL statuses, males had significantly higher conviction and suspension rates than females.

Within most groups, males had approximately double the conviction rates of females. For example, GDL 16-year-old males received 29.51 convictions per 1,000 drivers per month in their first 6 months of licensure. GDL 16-year-old females in the same time period received 14.46 convictions per 1,000 drivers per month. Although rates varied among cells, most male groups' rates were double the female rates.

Clearly, young male drivers were more likely to receive convictions and suspensions than corresponding female drivers. 


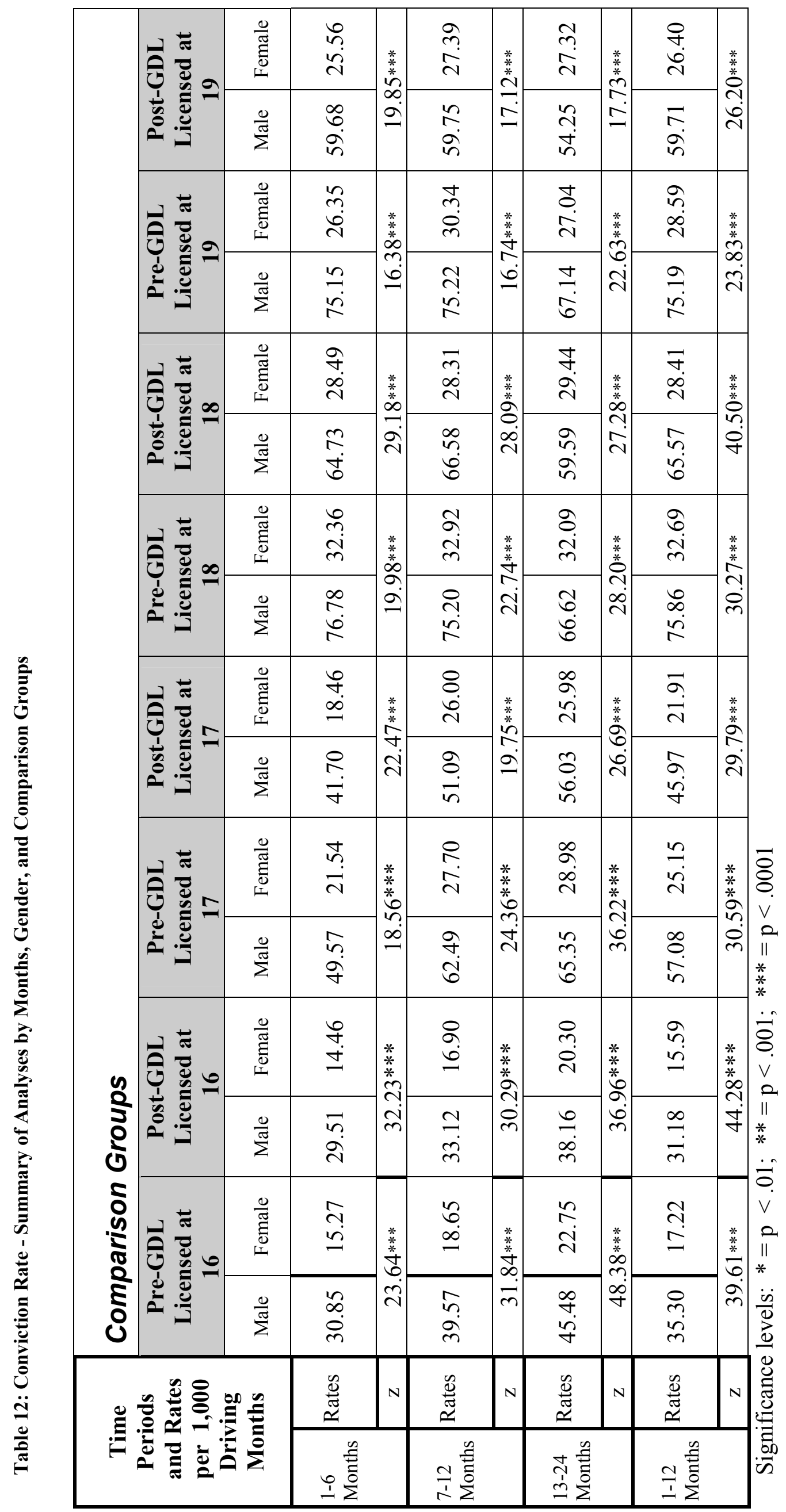




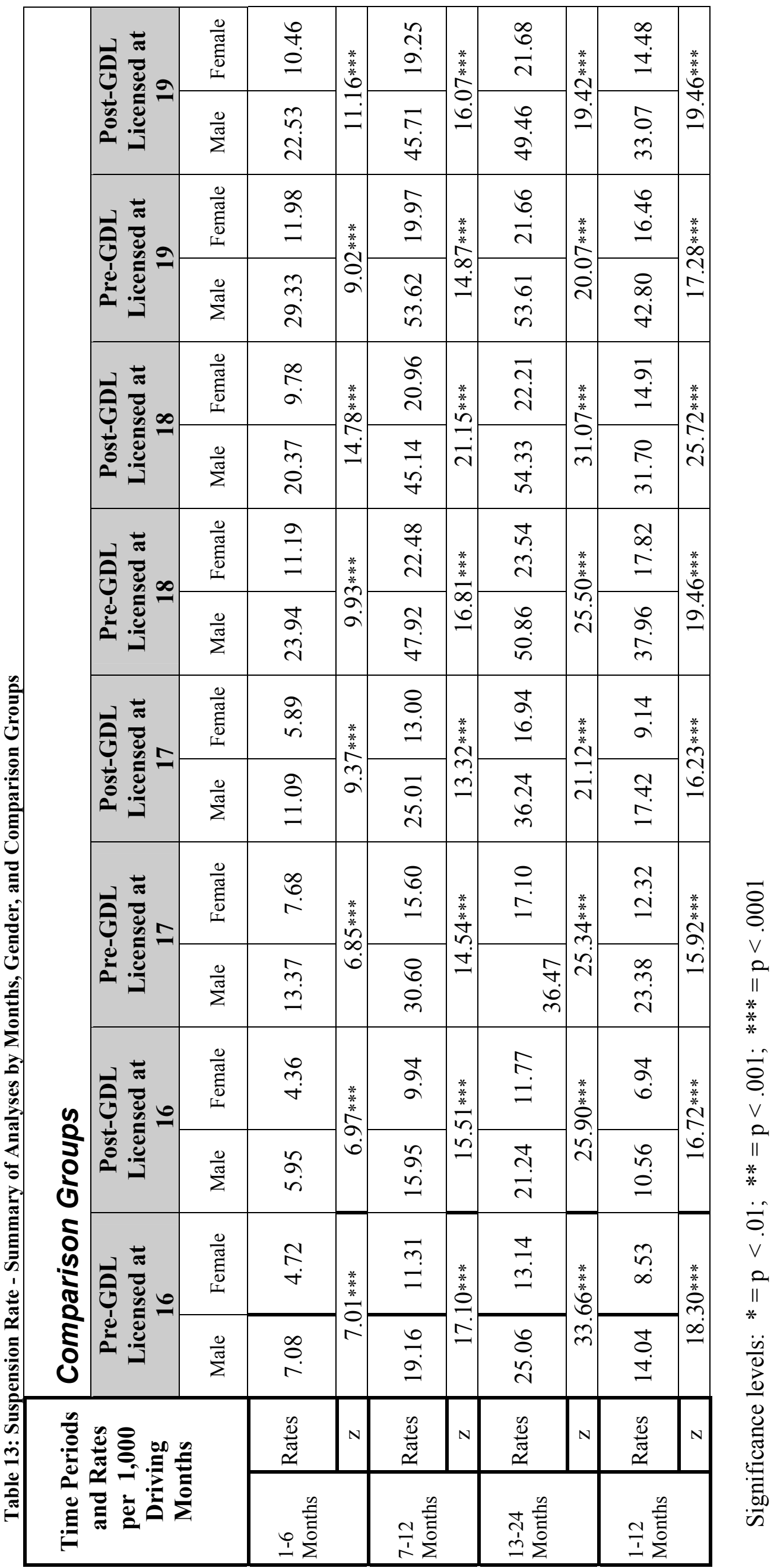




\section{$\underline{\text { Crashes }}$}

As shown in Table 14 and Figures 12 through 15, male crash rates were often significantly higher than the corresponding female crash rates. The differences between males and females, however, tended to be smaller in the GDL groups.

In fact, the pattern of significant male-female differences falls entirely in the pre-GDL comparisons between males and females. This suggests that the GDL program is associated with a reduction in male crash rates -- a reduction in which the male crash rates approximate the female rates so they are not statistically different.

Because young male crash rates are typically higher than females, a reduction in those crash rates is extremely important. 


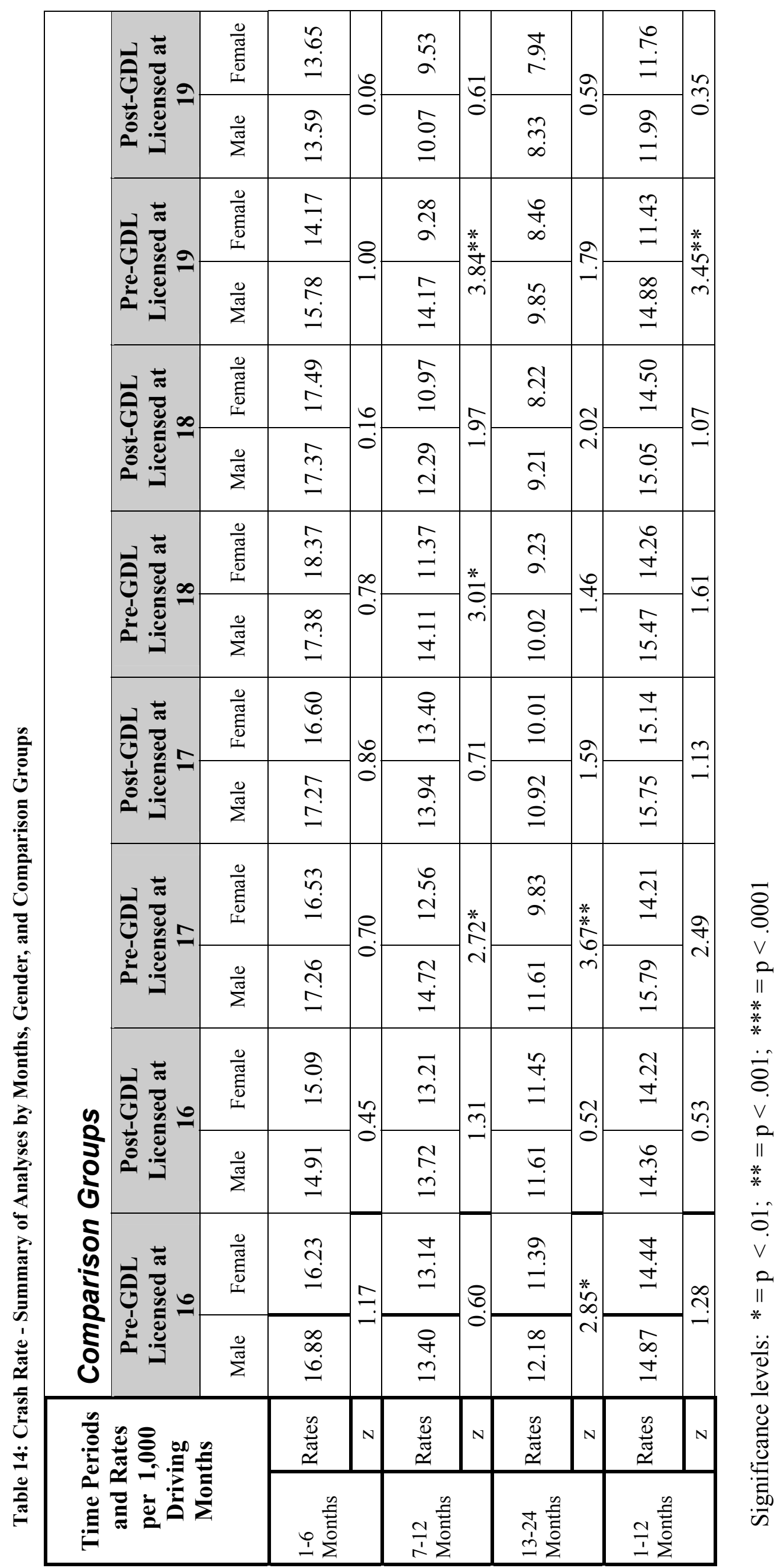


Figure 12: Crash Rates of Drivers Licensed at Age 16

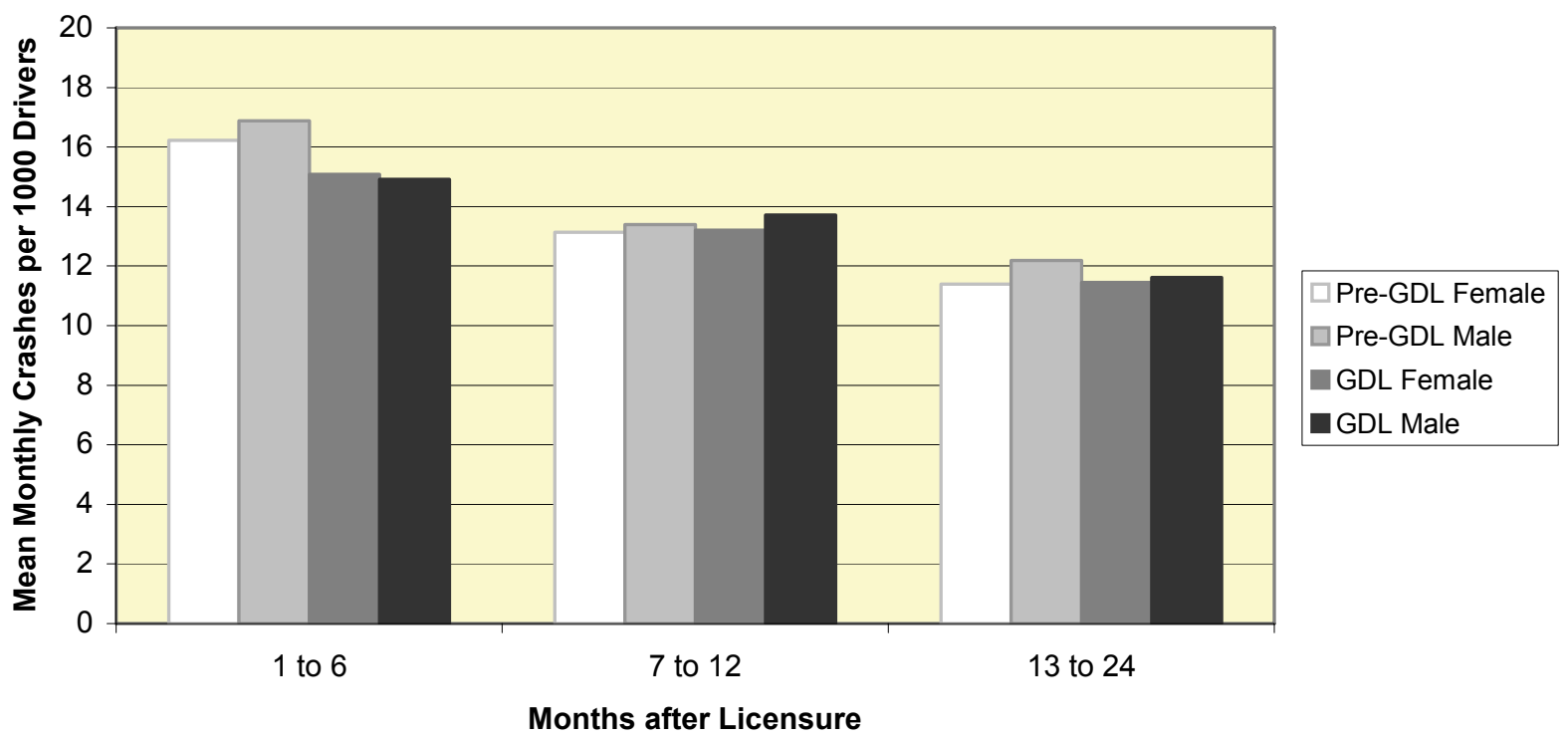

Figure 13: Crash Rates of Drivers Licensed at Age 17

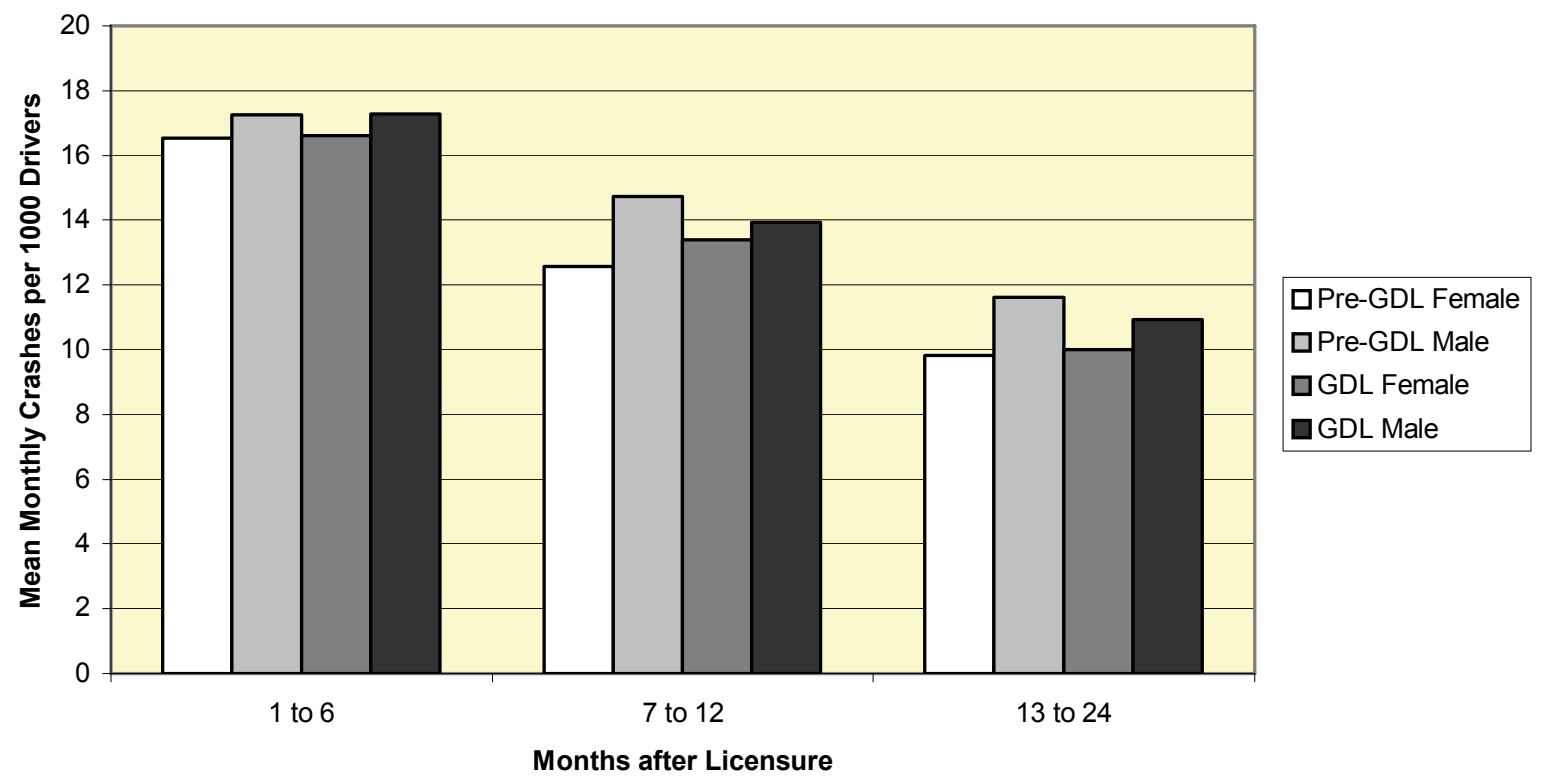


Figure 14: Crash Rates of Drivers Licensed at Age 18

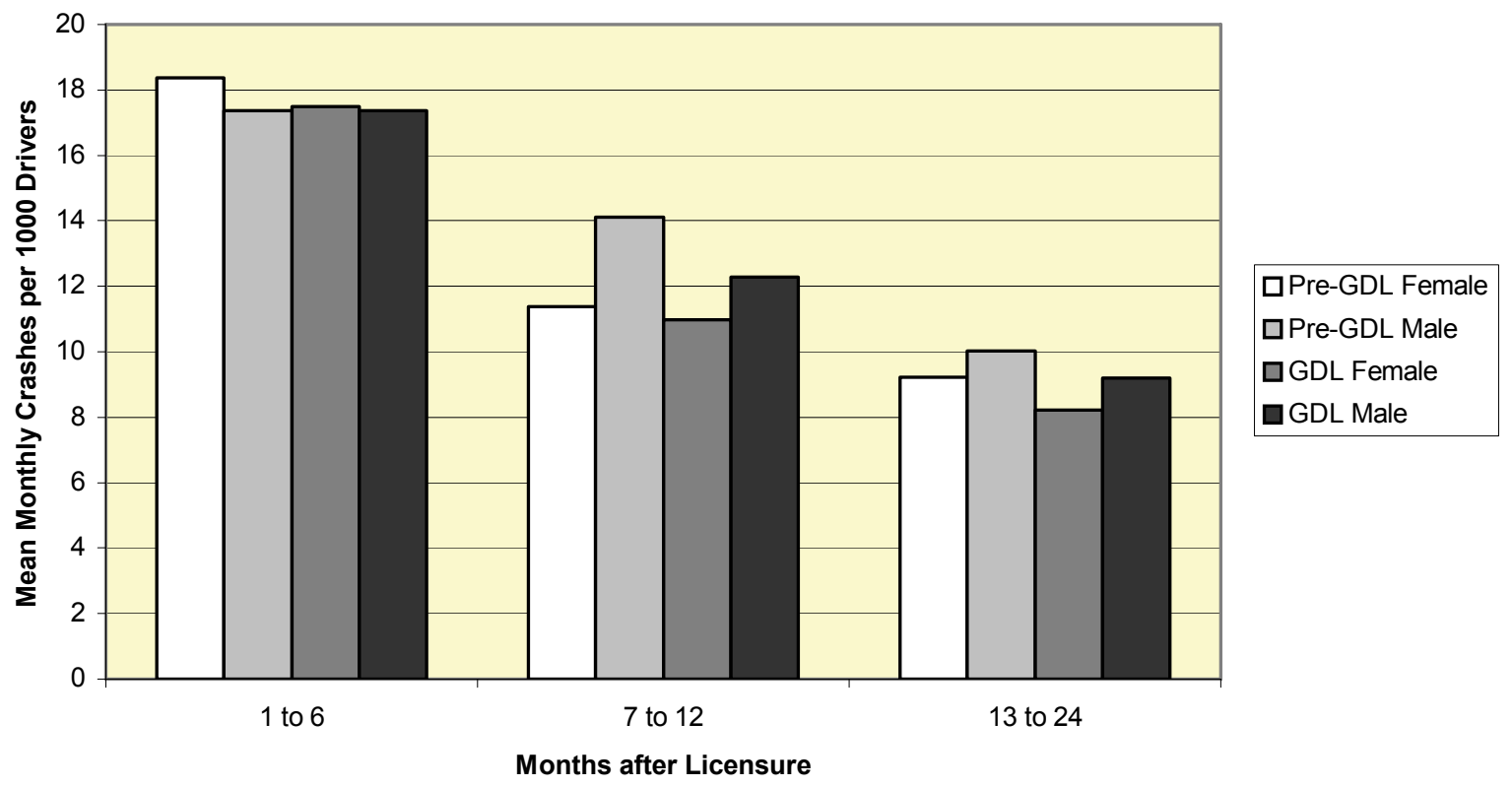

Figure 15: Crash Rates of Drivers Licensed at Age 19

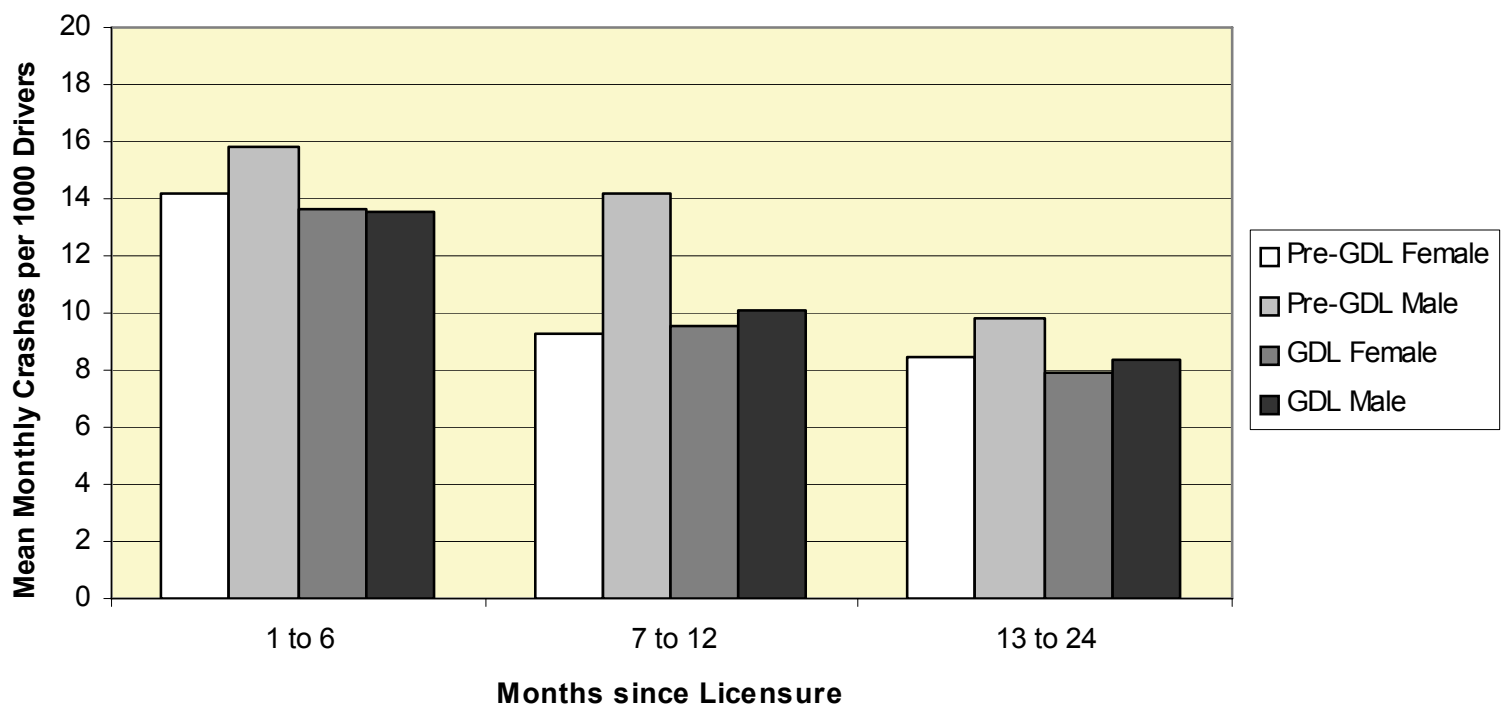




\section{DRIVING PERFORMANCE RELATED TO EDUCATION AND TRAINING OPTIONS}

In order to receive their driver's licenses, 16- and 17-year-olds under Oregon's GDL program must provide parental verification of 50 hours of supervised driving practice, plus either an additional 50 hours of supervised practice or certification of completion of an ODOT-approved driver training course.

For purposes of the analysis, drivers who submitted parental verification of 100 practice hours were compared to drivers who submitted verification of 50 hours plus the driver training course.

\section{Limitations}

The comparison of education and training options was limited in four ways. First, selection bias may have been present: Teenagers were not randomly assigned to receive formal driver education versus more supervised practice. Second, the two groups were almost certainly cross-contaminated. Third, there was no direct measurement or verification of practice time claimed. Finally, the present study was not intended to be, and was not designed to be, an evaluation of driver education and training.

The selection bias was unavoidable and insurmountable. Groups were not randomly assigned - drivers and their families made the decision which option to pursue. Many factors might have impacted that decision, and those factors may correlate with crash risk.

Focus group participants indicated that both groups were contaminated. Focus groups said that at least some teens who submitted the 100 hours had simply forgotten the certificate from the driver training course and had had a parent sign off on the additional training hours. In addition, drivers who completed a driver training course may have performed more than 50 additional hours of practice. The 50 hours of practice is a minimum, not a maximum. It was possible that some of the teens who took a driver training course may have actually performed as much supervised practice as some of the drivers who claimed 100 hours of practice.

Since this requirement was in large part self-reported, no direct measurement could be made of practice time claimed. It is important to remember that the only required verification of practice was a parent's signature. The focus group members said that parents were perceived to be very likely to "sign off" regardless of the actual hours of practice performed. It is therefore highly questionable whether all of the "100 hours teens" had actually practiced driving for the full 100 hours.

Finally, the present study was not intended or designed to be an evaluation of driver training in general, nor the training curricula as delivered by the driving schools approved by ODOT. 
Great caution must be used when interpreting any comparison between these two groups. However, the analysis was conducted to determine if any trends were discernible and, in fact, the proportion of drivers who completed the ODOT-approved training programs might actually be higher than reported; therefore, the effect noted here may have been suppressed due to the limitations.

Conviction, suspension and crash rates were compared between the two training options.

\section{$\underline{\text { Analysis }}$}

Drivers were included in this analysis only if information was available regarding which training option they had chosen. A comparison of drivers for whom this information is available shows that approximately $25 \%$ of 16 -year-olds and $16 \%$ of 17 -year-olds performed the "50 hours + School" option.

Table 15: Characteristics of Drivers Who Chose Driver Education versus Additional Practice

\begin{tabular}{|l|l|l|}
\hline \multirow{2}{*}{ Variables } & \multicolumn{2}{|l|}{ Driver Education and Training Options } \\
\cline { 2 - 3 } & Took Driver's Education & $\begin{array}{l}\text { Claimed Add'1 50 Hours } \\
\text { Practice }\end{array}$ \\
\hline $\mathrm{N}=101,933$ & 21,213 & 80,720 \\
\hline \% Female & $51.5 \%$ & $48.9 \%$ \\
\hline \% Male & $48.5 \%$ & $51.1 \%$ \\
\hline Mean Age at Licensure & 16.45 & 16.55 \\
\hline GDL Drivers Licensed at 16 & 17,662 & 61,713 \\
\hline GDL Drivers Licensed at 17 & 3,551 & 19,007 \\
\hline $\begin{array}{l}\text { Of GDL Drivers Licensed at 16, } \\
\text { Mean Holding Period for } \\
\text { Instructional Permit (days) }\end{array}$ & 354 & 348 \\
\hline $\begin{array}{l}\text { Of GDL Drivers Licensed at 17, } \\
\text { Mean Holding Period for } \\
\text { Instructional Permit (days) }\end{array}$ & 479 & 464 \\
\hline
\end{tabular}

Forty-seven drivers who took Driver's Education and claimed an extra 50 hours of practice were excluded from analysis. Seven hundred fifty-two drivers had missing data for these fields.

Females were more likely to complete a formal driver education course than males $\left(x^{2}=\right.$ $42.99, \underline{p}<.001)$, though the effect size is not large.

Driver Education students obtained their licenses slightly younger than those who claimed additional practice $(\underline{t}=22.9, \underline{p}<.001)$, but held their instructional permits for longer than those who claimed practice. This was true for both 16-year-old licensees (t $=7.3, \underline{\mathrm{p}}<.001)$ and 17-year-old new drivers $(\underline{\mathrm{t}}=3.9$, $\underline{\mathrm{p}}<.001)$. 
The conviction rates, suspension rates, and crash rates were compared between drivers who completed an ODOT-approved driver training course plus claiming 50 hours of supervised practice and drivers who claimed 100 hours of supervised practice. For all ages, during all time periods, the drivers who had certified completing the formal driver education course had fewer convictions and suspensions than those who claimed 100 hours of supervised practice (all z's $>3$, all p's < .01).

When crash rates were compared, most groups showed the same pattern: drivers who completed the formal driver training exhibited lower crash rates (z's > 2.58, p's <.01). The exceptions were the 16-year-old drivers in their second year of driving, and the 17year-olds in months 7-12: these groups' rates were not significantly different.

The " 50 hours + driver training" option tended to be associated with lower crash, conviction, and suspension rates and therefore better performance. Details of conviction, suspension, and crash rate means for the two groups are shown in Appendix D. 


\section{CONCLUSIONS AND SUMMARY DISCUSSION}

\section{CONCLUSIONS}

Fourteen focus groups were conducted. Focus group participants included teenage drivers, parents of teenage drivers, DMV road test administrators, law enforcement personnel, and high school administrators. Two judges were also interviewed. The following conclusions are the result of those discussions.

- Strong support for GDL requirements and restrictions was exhibited across the board, by all groups who participated. Although many of the teenagers disliked the restrictions, even the teens felt the GDL program enhanced their safety.

- The requirements for driver education and/or supervised practice before licensure were well understood.

- The restrictions placed on the first 6 months of licensure were well understood. These included a ban on young, non-family-member passengers and on unsupervised driving between midnight and 5 a.m.

- The restrictions placed on the second 6 months of licensure were not well understood. These included a restriction on the number of young, non-familymembers passengers (no more than 3 ) and no unsupervised driving between midnight and 5 a.m. Parents were often unaware of these restrictions, and law enforcement found it inconvenient to peer at a teen's license date of issue, calculate which restriction period applied, and check the exact restrictions at the time.

- Parents, teens, law enforcement, and driving instructors believed that teens became overconfident after approximately 6 months of licensure. They believed that this overconfidence then translated into less caution, greater risk-taking, and increased danger to the teens. They did not indicate a belief that crash risk drops at 6 months; rather, they believed that crash risk tended to increase at this time. These same groups indicated that parents tended to be "worn down" and relax their own enforcement of the restrictions over time.

- All groups considered parents to be the front line of both implementation and enforcement for the GDL program.

- All groups cited peer pressure as a factor for noncompliance. Strong enforcement was believed to mitigate the influence of peers. 
- The DMV was perceived as weak when enforcing the practice requirements for the GDL program. Most respondents wanted the DMV to require use of the practice log and wanted the DMV to collect it.

- Law enforcement was perceived by others to enforce the restrictions unevenly. There was widespread belief that enforcement differed by geographical area and by local political climate. Law enforcement officers felt that local support for GDL enforcement varied by geographical area and political climate.

- Most parents and teens were unaware that law enforcement officers could not make traffic stops solely for GDL violations. There was strong support for GDL to become subject to primary enforcement.

- The support for primary enforcement was so strong that many respondents advocated a voluntary means for law enforcement to easily identify restricted drivers (e.g., the sticker idea).

- There was strong support for stringent enforcement of the GDL program. Many respondents noted that when a teen was not cited for a GDL violation, word spread quickly and undermined compliance in the community of teens.

- The GDL rules and restrictions were strongly believed to positively affect safety, both for teen drivers and for those they encounter on the road. This seemed to be the major cause of the intense support for the GDL program.

- Parents felt empowered by the GDL program.

- Many of the adult participants saw the GDL program serving a wider purpose of gradually ushering a teen into adult responsibilities. They expected the GDL program's implementation and enforcement to have a long-lasting effect on individuals' broader attitudes toward the law.

Driver performance data; including information on crashes, convictions and suspensions; was analyzed. The following conclusions are the result of those analyses.

- The Oregon GDL program enhances safety.

- Suspension rates for 16- and 17-year-old drivers, when standardized to adult rates, were lower after implementation of Oregon's new GDL program.

- Suspensions of 18- and 19-year-old drivers, when standardized to adult rates, were lower after the GDL law, even though the law does not apply directly to 18and 19-year-olds. 
- Crash rates for 16- and 17-year-old drivers, when standardized to adult rates, were lower after implementation of Oregon's new GDL program.

- Standardized crash rates of 18-year-old drivers were lower in the third post-GDL year. Nineteen-year-old drivers, however, showed increased crashes for two years after GDL implementation.

- After the implementation of the GDL program, a few more Oregon teenagers seemed to wait until they turned 18 to acquire their driver's licenses. Males seemed to be more likely to wait.

- After GDL implementation, conviction and suspension rates were lower for all age groups; however, older novice teens (18- and 19-year-old drivers) had higher conviction and suspension rates than the younger teens, perhaps due to greater exposure.

- Overall, GDL implementation was associated with a pattern of lower crash rates, particularly for 16-year-olds in the first 6 months of licensure. This held true for both males and females, but not for 17-year-old drivers.

- After GDL implementation, 17-year-old licensees showed smaller differences than 16-year-old licensees. Note that drivers exited the GDL program immediately upon turning 18.

- In every age group, in every time period, for either GDL status, males had significantly higher conviction and suspension rates than females.

- Male crash rates were usually higher than the corresponding female crash rates. After GDL implementation, however, males' rates generally dropped to closer to the female crash rates.

- After GDL implementation, males' crash rates overall seemed to be reduced more than females.

- Teen drivers who opted to take an approved ODOT driver education course, in lieu of an additional 50 hours of supervised practice, had fewer crashes, traffic convictions, and suspensions. It is not possible to determine whether these outcomes are associated directly with the ODOT-approved training courses, or if they are an artifact of another variable such as selection bias. It is also important to note that there was no way to verify that the teen drivers who opted for 100 hours of supervised practice actually completed 100 hours of practice. Focus group participants reported that many parents may have simply signed the ODOT form verifying the 100 hours of practice regardless of how many, or how few, hours their teen driver actually completed. 


\section{SUMMARY DISCUSSION}

Focus group participants strongly supported Oregon's GDL requirements and restrictions. The 14 focus groups included teenage drivers, parents of teenage drivers, DMV road test administrators, driving instructors, law enforcement officers, and high school administrators, along with two judges who were interviewed. Participants indicated support for Oregon's GDL program. The GDL program was believed to positively affect safety, both for the teenage drivers and for others on the road.

Support for this GDL program was so prevalent that focus group participants wished to strengthen the standards: many groups wished for more rigorous scrutiny of the requirements by DMV personnel and more stringent, evenhanded enforcement by law enforcement officers.

All of the focus groups considered parents to be the most important component of implementation and enforcement for the GDL program. Peer pressure was seen as a major cause of noncompliance, but enforcement by parents and police was believed to mitigate this effect. Parents acknowledged, however, that their vigilance tended to wane as time passed.

Many of the focus group participants referred to the GDL program as "The 6-Month Rule." This probably indicated the importance placed upon the passenger restriction for the first 6 months of licensure. However, it is interesting to note that "6 months" as a time period recurred in several forms: in the reference to the "6-Month Rule;" in the belief by parents, teens, law enforcement, and driving instructors that young drivers become overconfident after approximately 6 months of licensure; and in the general lack of knowledge found regarding the restrictions still in place after those first 6 months of licensure.

Driver suspension and crash data from Oregon DMV were analyzed in two ways. Outcomes of Teens Relative to Adult Driver Before and After GDL, categorized young driver suspensions and crashes by the age of the driver $(16,17,18,19)$ and by the calendar time period of their occurrence (the year preceding the GDL program and each of the following three years). Outcome ratios were then calculated to express the suspension and crash rates relative to adult (age 25-65) rates during the same time periods.

The other analysis strategy exploited the ability to match specific driver records with outcomes. For any given outcome (conviction, suspension, or crash), it was possible to determine not only the age of the driver, but whether the driver had been licensed under the GDL program, how long the driver had held the license, and what phase of the GDL program (if any) had been applicable to the driver at the time of the outcome. For Outcomes of Teen Drivers As They Gain Experience Before and After GDL, the performance of GDL and non-GDL drivers was examined during the first 6 months of licensure, during the second 6 months of licensure, and the second full year of licensure. This approach allowed conclusions to be drawn about outcomes during specific phases of the GDL program. 
Conviction rates were examined for teens as they gained experience. For all age groups, during each phase of their first 2 years of licensure, teen drivers received fewer convictions after Oregon's GDL program was implemented. Newly-licensed 18- and 19year-old drivers were unrestricted and had not had to fulfill the requirements of the GDL program. In spite of this, these older novices as well as the younger drivers exhibited lower conviction rates after GDL implementation.

It is possible that conviction rates were lower in the general population of Oregon during this time. Because convictions could not be standardized to adult rates in Outcomes of Teen Drivers Before and After GDL, neither this possibility nor other longitudinal factors can be ruled out.

Sixteen-, 17-, 18-, and 19-year-old drivers all received fewer suspensions after GDL implementation. Because adults did not exhibit a similar lowering of suspensions during this time, the teen drivers' reduced suspensions do not merely reflect a decrease in the general population. Both analysis strategies clearly showed lower suspension rates after GDL implementation.

Older novice drivers experienced higher conviction and suspension rates than the 16year-old drivers. The older novices' greater maturity might have been expected to achieve the opposite. It may be that the older teens had more exposure and therefore more opportunity to receive citations and suspensions. Because exposure data was not available, this possibility cannot be assessed.

Examination of crash rates revealed that the greatest improvement occurred in the 16year-old drivers. When 16-year-old drivers' crash rates were standardized to adult crash rates, crash rates were significantly lower in each of the 3 years following GDL implementation. When drivers' records were examined as they gained experience, the lowered crash rates were most clearly demonstrated during the first 6 months of licensure by the 16-year-old novices. Causality cannot be inferred, but the first 6 months is when crash rates are highest, so the lowered crash rate is a key finding.

It is interesting to note that the clearest safety improvements (e.g., 16-year-old drivers in their first 6 months of licensure) occur not only when the restrictions are greatest, but also when parents report the greatest vigilance in supporting the GDL restrictions. In focus groups, parents had reported relaxing their supervision over time, and this parallels the lessening safety improvements as time passes after licensure.

Overall, the gender results seen here were consistent with those seen in the literature: males are at higher risk of infractions and crashes than females. It is extremely promising that after GDL implementation, male crash rates dropped to levels approximating female crash rates. Because young male crash rates are typically higher than female crash rates, a reduction in those crash rates may be an important finding.

Under Oregon's GDL program, teens must claim to have accomplished 50 hours of supervised driving practice. In addition, they must either complete an ODOT-certified 
driver training course, OR claim to have performed an additional 50 hours of supervised practice. The comparison of these two groups is flawed by unavoidable selection bias, cross-contamination of groups, and by lack of direct measurement of the practice claimed. Though the present study was not designed to evaluate driver training options, the two groups of teen drivers were compared. For almost all cells compared, the formally-trained drivers exhibited better outcomes (lower convictions, fewer suspensions, and fewer crashes) than those who claimed additional practice. Further investigation may illuminate this important issue.

The analysis of convictions, suspensions, and crashes offers strong support for Oregon's GDL program. The drivers who showed the most improved safety were those who were most affected by the law, though enhanced safety was seen even in older teens who were not restricted by GDL regulations. Oregon's GDL program is clearly associated with improved safety. 


\section{REFERENCES}

Agent, K. R., Pigman, J. G., Steenbergen, L. C., Pollack, S. H., \& Kidd, C. (2000). Evaluation of Kentucky's Graduated Driver Licensing System. Washington, DC: National Highway Traffic Safety Administration.

Chen, L. H., Baker, S. P., Braver, E. R.., \& Li, G. (2000). Carrying passengers as a risk factor for crashes fatal to 16- and 17-year-old drivers. Journal of the American Medical Association, 283, 1578-1582.

Coombs, W. (2003). Scientific research on graduated licensing verifies reduction to teenage drivers' risk. Retrieved February 18, 2003, from www.scienceblog.com.

Elander, J., West, R., \& French, D. (1993). Behavioral correlates of individual differences in road traffic-crash risk: An examination of methods and findings. Psychological Bulletin, 133, 279-294.

Engstrom, I., Gregersen, N. P., Hernetkoski, K., Keskinen, E., \& Nyberg, A. (2003). Young novice drivers, driver education and training (VTI report 491A).

Swedish National Road and Transport Research Institute.

Ferguson, S. A. (2003). Other high-risk factors for young drivers - How graduated licensing does, doesn't, or could address them. Journal of Safety Research, 34(1), 7178.

Foss, R. D., Feaganes, J. R., \& Rogman, E. A. (2001). Initial effects of graduated licensing on 16-year-old drivers in North Carolina. Journal of the American Medical Association, 286, 1588-1592.

Foss, R. D., \& Goodwin, A. H. (2003). Enhancing the Effectiveness of Graduated Drivers Licensing Legislation. Journal of Safety Research, 34, 79-84.

Mayhew, D. R., Simpson, H. M., \& des Groseilliers, M. (1999). Impact of the Graduated Driver Licensing Program in Nova Scotia. Ottawa, Ontario: Traffic Injury Research Foundation.

McKnight, A. J. (1996). Relationship between experience and learning to drive. In H. M. Simpson (Ed.), New to the Road: Reducing the Risks for Young Motorists. Los Angeles, CA: UCLA.

McKnight, A. J., \& McKnight, A. S. (2003). Young novice drivers: Careless or clueless? Accident Analysis and Prevention, 35, 921-925.

Nissley, J. Z. (2001). Pennsylvania's young driver reforms are saving lives. Directions in Highway Safety, December 14, 4(1), 4. 
Preusser, D. F. (1995). Licensing Practices and Crash Risk in the United States. In H. M. Simpson (Ed.), New to the Road: Reducing the Risks for Young Motorists. Los Angeles, CA: UCLA.

Preusser, D. F., Ferguson, S. A., \& Williams, A. F. (1998). The effect of teenage passengers on the fatal crash risk of teenage drivers. Accident Analysis \& Prevention, 30(2), 217-222.

Shope, J. T. \& Molnar, L. J. (2003). Graduated driver licensing in the United States: evaluation results from the early programs. Journal of Safety Research, 34, 63-69.

Simons-Morton, B. G., \& Hartos, S. L. (2003). How Well Do Parents Manage Young Driver Crash Risks? Journal of Safety Research, 34, 91-97.

Tabachnik, B. G. \& Fidell, L. S. (1996). Using Multivariate Statistics (3rd ed.). New York: HarperCollins College Publishers.

Ulmer, R. G., Preusser, D.F., Williams, A. F., Ferguson, S. A., \& Farmer, C. M. (1999). Effect of Florida's Graduated Licensing Program on the Crashes of Teenage Drivers. Arlington, VA: Insurance Institute for Highway Safety.

Williams, A. F., \& Mayhew, D.R. (2002). Graduated licensing: a blueprint for North America. Retrieved August 2002 from http://www.iihs.org/safety_facts/teens/blueprint.pdf.

Williams, A. F., Nelsen, L. A., \& Leaf, W. A. (2002). Responses of Teenagers and their Parents to California's Graduated Licensing System. Accident Analysis \& Prevention, 34, 834-842.

Williams, A. F. and Preusser, D. F. (1997). Night driving restrictions for youthful drivers: A literature review and commentary. Journal of Public Health Policy, 18(3), 334-345.

Waller, P. F., Olk, M. L., \& Shope, J. T. (2000). Parental Views of and Experience with Michigan's Graduated Licensing Program. Journal of Safety Research, 31, 9-15. 


\title{
APPENDIX A
}

\author{
MODERATOR GUIDE \\ Parents
}

INTRODUCTION

Respondents will introduce themselves by providing:

Name

Occupation

Household composition

Ages and driving status of children

\section{PARENTS' CONCERNS}

What are some of the major fears and concerns you have about your teenagers driving? Why?

Are these concerns anymore or less prevalent for teen drivers than for adult drivers?

Why/Why Not?

What have you done to address these fears and concerns?

What resources do you use to assist in addressing these concerns?

What resources are available?

Where do you turn for assistance?

\section{GRADUATED DRIVER'S LICENSE PROGRAM AWARENESS}

How many of you are familiar with the GDL Program?

How did you become aware of the program?

How many of you feel well versed on the requirements and regulations of the program?

Tell me what you know about the rules and regulations of the program.

(PROBE: How many knew about each rule as they are enumerated)

How many are familiar with the Driver Improvement Program (DIP)?

Tell me what you know about this program.

(PROBE: How many knew about aspects enumerated)

PASS OUT FACT SHEET (With info regarding both GDL and DIP) 
What, if any, information or provisions were you not aware of?

What do you consider to be the objectives of the program?

How do you feel about those objectives?

Do you feel these are what the objectives should be? If not, what should they be?

Do you feel their needs to be any changes to these objectives?

How do you feel about the implementation and enforcement of the program?

To what extent do you feel the regulations are monitored and enforced?

(PROBE: By the police / by the courts / by DMV)

How serious is the system about monitoring and enforcing the rules?

How serious are/were your children about abiding by the rules?

Are there any requirements they take any more or less seriously? Which/Why?

\section{PARENTAL INVOLVEMENT}

How serious are/were you in monitoring and enforcing the regulations?

How important is compliance to you? WHY?

Are there any requirements you take any more or less seriously? Which/Why?

What is your level of involvement in monitoring and enforcing the regulations?

What does your involvement entail?

(PROBE: Monitoring restrictions for $1^{\text {st }}$ versus $2^{\text {nd }} 6$ months)

Are there any other members of the household involved in monitoring or enforcing the regulations?

Are there any other steps you take above and beyond the program to enhance the safety and skills of your teenage driver? (PROBE: Contracts and agreements)

How involved were you, and other household members, in teaching your teenager how to drive?

What transpired during the instructional 6-month period?

Did they take a traffic safety course? Where? How long?

What do you consider to be the pros and cons of the course versus the 50 extra hours? 
How often did they practice? With whom?

How did they keep track of the hours practiced? (PROBE: If as they occurred?)

How accurately were the hours recorded and reported?

After license was received, did you continue to practice with your teen? How often?

For how long after license received, did you practice with your teen?

Did you draw upon any resources to assist you in their training?

(PROBE: Which ones? / From where obtained?)

Did anyone use the Web site? How? For what?

How did you find out about the Web site?

\section{SHOW TUNING UP MANUAL}

Are you familiar with this manual?

Did you use it?

Was it helpful?

\section{SHOW DRIVER EXPERIENCE LOG}

Did anyone use a log like this to record your hours?

How many knew it was available?

Is there any resource you would like to have had? What?/ Why?

\section{PDL PROGRAM IMPACT ASSESSMENT}

Did you or your child ever consider not going through the program? Why?/Why Not?

- What would have been the alternative and its ramifications?

Do you feel the GDL Program has had any impact? Explain?

- Do you feel your teenager would have gotten as much training and experience without the GDL Program?

- Do you feel the requirements/restrictions actually increase safety? (How?) 
How many have older children who got their licenses before GDL implementation?

- Are there any differences in attitudes between your children who went through the program and those who did not?

- Are there any differences in skills between your children?

- Are there any differences in your confidence \& level of comfort with your......?

What do you consider to be the pros and cons of the program?

- Do you think teenagers' risk-taking is influenced by the GDL restrictions?

Is there anything you would change or add to the program to make it more effective?

\section{WRAP-UP}

How likely are you to not report an accident to avoid insurance ramifications?

- Would you be more or less likely for your teenage driver? 


\section{Teenagers}

\section{INTRODUCTION}

Respondents will introduce themselves by providing:

- Name

- Age

- Age when obtained permit

- Household composition

- Ages and driving status of siblings

\section{TEENAGERS' OPINION OF DRIVING}

What factors were barriers / motivations for you to get your driver's license?

What are some of the major issues or challenges for teenage drivers? Why?

Are these concerns any more or less prevalent for teen drivers than for adult drivers? Why/Why Not?

What have you done to address these fears and concerns?

What resources do you use to assist in addressing these concerns?

- What resources are available?

- Where do you turn for assistance?

\section{GRADUATED DRIVER'S LICENSE PROGRAM AWARENESS}

How many of you are familiar with the GDL Program?

- How did you become aware of the program?

How many of you feel well versed on the requirements and regulations of the program?

Tell me what you know about the rules and regulations of the program.

(PROBE: How many knew about each rule as they are enumerated)

How many are familiar with the Driver Improvement Program (DIP)?

- Tell me what you know about this program.

(PROBE: How many knew about aspects enumerated) 
PASS OUT FACT SHEET (With info regarding both GDL \& DIP)

- What, if any, information or provisions were you not aware of?

What do you consider to be the objectives of the program?

- How do you feel about those objectives?

- Do you feel these are what the objectives should be? If not, what should they be?

- Do you feel their needs to be any changes to these objectives?

How do you feel about the implementation and enforcement of the program?

- To what extent do you feel the regulations are monitored and enforced? (PROBE: By the police / by the courts / by DMV)

- How serious is the system about monitoring and enforcing the rules?

How serious are you about abiding by the rules? Why? What is motivation?

- Are there any requirements you take any more or less seriously? Which? / Why?

Do you encourage your friends to abide by the regulations? All? / Which?

Do your friends encourage you to abide by the rules? All? / Which?

\section{PARENTAL INVOLVEMENT}

How serious are your parents in monitoring and enforcing the regulations?

- How important is compliance to them? Why?

- Are there any requirements they take any more or less seriously? Which/Why?

What is their level of involvement in monitoring and enforcing the regulations?

- What does their involvement entail?

Are there any other members of the household involved in monitoring or enforcing the regulations?

Are there any other steps they take above and beyond the program to enhance your safety and skills? (PROBE: Contracts and agreements)

How involved were they, and other household members, in teaching you how to drive? 


\section{EXPERIENCE WITH THE PROGRAM}

How many of you took the traffic safety course during the instructional 6-month period?

- Where did you take it? How long was it?

- What did you think about it?

- Was it interesting? / Worth taking?

$\circ \quad$ What think about the materials used?

- What do you consider to be the pros and cons of the course versus the 50 extra hours?

How often did you practice during the instructional period? With whom?

- How did you keep track of the hours practiced? (PROBE: If as they occurred?)

- How accurately were the hours recorded and reported?

After you received your license, did you continue to practice with a parent? How often?

Did you draw upon any resources to assist you in your training?

(PROBE: Which ones? / From where obtained?)

- Did anyone use the Web site? How? For what?

- How did you find out about the Web site?

\section{SHOW TUNING UP MANUAL}

- How many are familiar with this manual?

- Did you use it?

- Was it helpful?

\section{SHOW DRIVER EXPERIENCE LOG}

- Did anyone use a log like this to record your hours?

- How many knew it was available?

Is there any resource you would like to have had? What / Why?

Did you ever consider not going through the program? Why?/ Why Not?

- What would have been the alternative and its ramifications?

Prior to participating in the program, what had you heard about it? 
Was there any stigma associated with participating in the program?

- Are you considered cool/a loser for participating?

- Would that keep you from participating?

Do you think the program is fair and/or justified?

- Does it discriminate against teenagers?

- Do you think it should be a requirement for all teenagers?

\section{GDL PROGRAM IMPACT ASSESSMENT}

Do you feel the GDL Program has had any impact? Explain?

- Do you feel you would have gotten as much training and experience without the GDL Program?

- Do you feel the requirements/restrictions actually increase safety? (How?)

How has the program influenced your driving?

What do you consider to be the pros and cons of the program?

- Do you think teenagers' risk-taking is influenced by the GDL restrictions?

Is there anything you would change or add to the program to make it more effective?

If the program were voluntary, would you do it?

Would you voluntarily participate in follow-up / continuing programs?

\section{WRAP-UP}




\section{MODERATOR GUIDE}

Driving Instructors

\section{INTRODUCTION}

Respondents will introduce themselves by providing:

- Names

- How long they've been teaching the traffic safety course

- Where they teach

- Household composition

- Ages and driving status of children

\section{CONCERNS AS A PARENT}

What are some of the major fears and concerns you have, or would have, about your teenagers driving? Why?

Are these concerns anymore or less prevalent for teen drivers than for adult drivers? Why/Why Not?

What have you done, or would you do, to address these fears and concerns?

What resources do you, or would you, use to assist in addressing these concerns?

- What resources are available?

- Where does one turn for assistance?

\section{PERCEPTIONS OF TEEN DRIVERS}

What are your impressions of teenage drivers in general?

What do you consider to be their main weaknesses and strengths?

How well prepared are they to assume the responsibility of driving based on your experience with them?

What steps would you suggest be taken to address their weaknesses?

Who should be taking these steps?

GRADUATED DRIVER'S LICENSE PROGRAM AWARENESS

How many of you feel well versed on the requirements and restrictions of the GDL program? 
Tell me what you know about the rules and restrictions of the program?

(PROBE: How many knew about each rule as they are enumerated)

How many of you feel well versed on the requirements and restrictions of the DIP program?

Tell me what you know about the rules and restrictions of the DIP program?

(PROBE: How many knew about each rule as they are enumerated)

PASS OUT FACT SHEET (With info regarding both PDL \& DIP)

What, if any, information or provisions were you not aware of?

How aware are the teenagers and their parents of this information?

What do you consider to be the objectives of the program?

- How do you feel about those objectives?

- Do you feel these are what the objectives should be? If not, what should they be?

- Do you feel their needs to be any changes to these objectives?

How do you feel about the implementation and enforcement of the program?

- To what extent do you feel the regulations are monitored and enforced?

(PROBE: By the police / by the courts / by DMV)

- How serious is the system about monitoring and enforcing the rules?

- Does DMV do all it can to ensure that the practice hours have actually transpired prior to applying for their driver's license?

Have there been any changes to the approaches and practices used by the school since the implementation of the GDL program?

- Are there any changes that should be made?

How serious do you think the parents and the teenagers are about abiding by the rules?

- Are there any requirements they take any more or less seriously? Which? I Why? 
- To what extent do you think parents are involved in teaching and monitoring their teenage drivers?

- What should they be doing?

\section{SHOW DRIVER EXPERIENCE LOG}

- How many of you were aware of the availability of this log? The Web site?

- How many parents and teenagers do you think are aware of this log? The Web site?

- How many parents and teenagers do you think have utilized this log? The Web site?

Do you make them aware of resources like the Web site?

What other resources are you aware of?

What kind of things would you suggest to improve the enforcement of the program?

GRADUATED DRIVERS LICENSE PROGRAM IMPACT ASSESSMENT

Do you feel the GDL Program has had any impact? Explain.

- Do you feel teenagers would have gotten as much training and experience without the GDL Program?

- Do you feel the requirements/restrictions actually increase teenagers' safety?

Comparing the teenagers you instruct today versus those you instructed prior to the implementation of the GDL Program (March 2000):

- Are there any differences in attitudes between the teenagers who went through the program and those who did not?

- Are there any differences in skills between the teenagers ...........?

- What are the pros and cons of taking the course versus doing the extra 50 hours?

What could help instructors like you contribute more to the preparation and safety of these teenage drivers?

- Is there any need to change any of your roles or responsibilities relative to the GDL Program? 
OVERALL, what do you consider to be the pros and cons of the GDL Program?

- Do you think teenagers' risk-taking is influenced by the GDL program?

Is there anything you would change or add to the GDL Program to make it more effective?

\section{WRAP-UP}




\section{MODERATOR GUIDE}

DMV Road Test Administrators

\section{INTRODUCTION}

Respondents will introduce themselves by providing:

- Names

- How long on the job

- Household composition

- Ages and driving status of children

\section{CONCERNS AS A PARENT}

What are some of the major fears and concerns you have, or would have, about your teenagers' driving? Why?

Are these concerns any more or less prevalent for teen drivers than for adult drivers? Why? / Why Not?

What have you done, or would you do, to address these fears and concerns?

What resources do you, or would you, use to assist in addressing these concerns?

- What resources are available?

- Where does one turn for assistance?

\section{PERCEPTIONS OF TEEN DRIVERS}

What are your impressions of teenage drivers in general?

What do you consider to be their main weaknesses and strengths?

How well prepared are they to assume the responsibility of driving based on your experience with them?

What steps would you suggest be taken to address their weaknesses?

Who should be taking these steps? 


\section{GRADUATED DRIVER'S LICENSE PROGRAM AWARENESS}

How many of you are familiar with the GDL Program?

- How did you become aware of the program?

How many of you feel well versed on the requirements and regulations of the program?

\section{PASS OUT FACT SHEET (With info regarding both GDL \& DIP)}

- What, if any, information or provisions were you not aware of?

What do you consider to be the objectives of the program?

- How do you feel about those objectives?

- Do you feel these are what the objectives should be? If not, what should they be?

- Do you feel their needs to be any changes to these objectives?

How do you feel about the implementation and enforcement of the program?

- To what extent do you feel the regulations are monitored and enforced?

- (PROBE: By the police / by the courts / by DMV)

- How serious is the system about monitoring and enforcing the rules?

- Does DMV do all it can to ensure that the practice hours have actually transpired prior to applying for their driver's license?

How serious do you think the parents and the teenagers are about abiding by the rules?

- Are there any requirements they take any more or less seriously? Which? I

Why?

\section{SHOW DRIVER EXPERIENCE LOG}

- How many of you were aware of the availability of this log? The Web site?

- How many of the parents and teenagers do you think are aware of this log?

- How many of the parents and teenagers do you think have utilized this log? 
What kind of things would you suggest to improve the enforcement of the program?

\section{GRADUATED DRIVERS LICENSE PROGRAM IMPACT ASSESSMENT}

Do you feel the GDL Program has had any impact? Explain?

- Do you feel teenagers would have gotten as much training and experience without the GDL Program?

- Do you feel the requirements/restrictions actually increase safety among teenagers?

Comparing the teenagers you test today versus those you tested prior to the implementation of the GDL Program (March 2000):

- Are there any differences in attitudes between the teenagers who went through the program and those who did not?

- Are there any differences in skills between the teenagers ..........?

When the teenagers come to you for testing, is there any way to tell if they took a traffic safety course or did the additional 50 hours?

- Can you notice if there are differences in skills or attitudes between those who took the course versus those who did not?

- What do you feel are the pros and cons of taking the course versus doing the extra 50 hours?

OVERALL, what do you consider to be the pros and cons of the GDL Program?

- Do you think teenagers' risk-taking is influenced by the GDL program?

Is there anything you would change or add to the GDL Program to make it more effective?

\section{WRAP-UP}




\section{MODERATOR GUIDE}

High School Administrators

\section{INTRODUCTION}

Respondents will introduce themselves by providing:

- Names

- How long an educator

- Where employed

- Household composition

- Ages and driving status of children

\section{CONCERNS AS A PARENT}

What are some of the major fears and concerns you have, or would have, about your teenagers' driving? Why?

Are these concerns anymore or less prevalent for teen drivers than for adult drivers? Why? / Why Not?

What have you done, or would you do, to address these fears and concerns?

What resources do you, or would you, use to assist in addressing these concerns?

- What resources are available?

- Where does one turn for assistance?

\section{PERCEPTIONS OF TEEN DRIVERS}

What are your impressions of teenage drivers in general?

What do you consider to be their main weaknesses and strengths?

How well prepared are they to assume the responsibility of driving based on your experience with them?

What steps would you suggest be taken to address their weaknesses?

Who should be taking these steps?

GRADUATED DRIVER'S LICENSE PROGRAM AWARENESS 
How many of you feel well versed on the requirements and regulations of the GDL program?

Tell me what you know about the rules and regulations of the program.

(PROBE: How many knew about each rule as they are enumerated)

PASS OUT FACT SHEET (With info regarding both GDL \& DIP)

- What, if any, information or provisions were you not aware of?

How aware are the teenagers and their parents of this information?

What do you consider to be the objectives of the program?

- How do you feel about those objectives?

- Do you feel these are what the objectives should be? If not, what should they be?

- Do you feel their needs to be any changes to these objectives?

How do you feel about the implementation and enforcement of the program?

- To what extent do you feel the regulations are monitored and enforced? (PROBE: By the police / by the courts / by DMV)

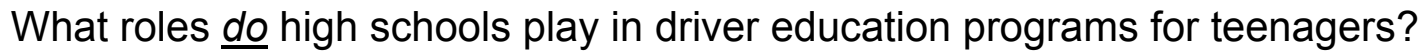

- Do the high schools provide any materials, programs or other resources for the purpose of traffic safety education for teenagers? How effective are they?

What roles should high schools play in traffic safety education programs for teenagers?

Does the school do anything to promote compliance with the GDL regulations?

Have there been any changes to the role of the school in driver education since the implementation of the GDL program?

- Are there any changes that should be made?

\section{SHOW DRIVER EXPERIENCE LOG}

- How many of you were aware of the availability of this log? The Web site?

- How many parents and teenagers do you think are aware of this log? The Web site? 
- How many parents and teenagers do you think have utilized this log? The Web site?

Do you make them aware of resources like the Web site?

What other resources are you aware of?

What kind of things would you suggest to improve the enforcement of the program?

\section{GRADUATED DRIVERS LICENSE PROGRAM IMPACT ASSESSMENT}

Do you feel the GDL Program has had any impact? Explain?

- Do you feel teenagers would have gotten as much training and experience without the GDL Program?

- Do you feel the requirements/restrictions actually increase teenagers' safety?

Comparing the teenagers you instruct today versus those you instructed prior to the implementation of the GDL Program (March 2000):

- $\quad$ Are there any differences in attitudes between the teenagers who went through the program and those who did not?

- $\quad$ Are there any differences in skills between the teenagers ..........?

- What are the pros and cons of taking the traffic safety education course versus doing the extra 50 hours?

What could help educators like you contribute more to the preparation and safety of these teenage drivers?

- Is there any need to change any of your roles or responsibilities relative to the GDL Program?

OVERALL, what do you consider to be the pros and cons of the GDL Program?

- Do you think teenagers' risk-taking is influenced by the GDL program?

Is there anything you would change or add to the GDL Program to make it more effective?

\section{WRAP-UP}




\section{MODERATOR GUIDE \\ Law Enforcement Officers}

\section{INTRODUCTION}

Respondents will introduce themselves by providing:

- Name

- How long been patrolling the streets

- Household composition

- Ages and driving status of children

\section{CONCERNS AS A PARENT}

What are some of the major fears and concerns you have, or would have, about your teenagers driving? Why?

Are these concerns anymore or less prevalent for teen drivers than for adult drivers? Why? / Why Not?

What have you done, or would you do, to address these fears and concerns?

What resources do you, or would you, use to assist in addressing these concerns?

- What resources are available?

- Where does one turn for assistance?

\section{PERCEPTIONS OF TEEN DRIVERS}

What are your impressions of teenage drivers in general?

What do you consider to be their main weaknesses and strengths?

How well prepared are they to assume the responsibility of driving based on your experience with them?

What steps would you suggest be taken to address their weaknesses?

Who should be taking these steps?

\section{GRADUATED DRIVER'S LICENSE PROGRAM AWARENESS}

How many of you feel well versed on the requirements and regulations of the GDL program?

Tell me what you know about the rules and regulations of the program? 
(PROBE: How many knew about each rule as they are enumerated)

PASS OUT FACT SHEET (With info regarding both GDL \& DIP)

- What, if any, information or provisions were you not aware of?

How aware are the teenagers and their parents of this information?

What do you consider to be the objectives of the program?

- How do you feel about those objectives?

- Do you feel these are what the objectives should be? If not, what should they be?

- Do you feel their needs to be any changes to these objectives?

How do you feel about the implementation and enforcement of the program?

- To what extent do you feel the regulations are monitored and enforced? (PROBE: By the police / by the courts / by DMV)

- How serious is the system about monitoring and enforcing the rules?

In the scheme of your priorities, where does looking for GDL offenders fall?

- Do you actually look for offenders, or do you just stumble up on them?

- What percentage of the infractions you encounter do you actually cite?

- What impacts whether or not you cite them?

- Are their any circumstances that alter your priority and make you any more or less vigilante? Why?

- Are there any particular infractions you place a higher priority on? Why?

- How do you feel about enforcing the GDL regulations?

(PROBE: educational versus punitive; doing something for them or to them) 
- Are there any barriers to make it difficult to enforce the GDL Program? What?

- What could be done to minimize the barriers?

What kind of things would you suggest to improve the enforcement of the program?

How serious do you think the parents and the teenagers are about abiding by the rules?

- Are there any requirements they take any more or less seriously? Which? / Why?

To what extent do you think parents are involved in teaching and monitoring their teenage drivers?

- What should they be doing?

\section{GRADUATED DRIVERS LICENSE PROGRAM IMPACT ASSESSMENT}

Do you feel the GDL Program has had any impact? Explain.

- Do you feel teenagers would have gotten as much training and experience without the GDL Program?

- Do you feel the requirements/restrictions actually increase teenagers' safety?

Comparing the teenagers you encounter today versus those you encountered prior to the implementation of the GDL Program (March 2000):

- Are there any differences in attitudes between the teenagers who went through the program and those who did not?

- Are there any differences in skills between the teenagers ..........?

OVERALL, what do you consider to be the pros and cons of the GDL Program?

- Do you think teenagers' risk-taking is influenced by the GDL program?

Is there anything you would change or add to the GDL Program to make it more effective?

\section{WRAP-UP}




\section{MODERATOR GUIDE \\ Judges}

\section{INTRODUCTION}

Respondents will introduce themselves by providing:

- Name

- How long presiding over traffic court / cases

- Household composition

- Ages and driving status of children

Do you encounter many traffic cases involving teenage drivers?

\section{CONCERNS AS A PARENT}

What are some of the major fears and concerns you have, or would have, about your teenagers' driving? Why?

Are these concerns any more or less prevalent for teen drivers than for adult drivers? Why? / Why Not?

What have you done, or would you do, to address these fears and concerns?

What resources do you, or would you, use to assist in addressing these concerns?

- What resources are available?

- Where does one turn for assistance?

\section{PERCEPTIONS OF TEEN DRIVERS}

What are your impressions of teenage drivers in general?

What do you consider to be their main weaknesses and strengths?

How well prepared are they to assume the responsibility of driving based on your experience with them?

What steps would you suggest be taken to address their weaknesses?

Who should be taking these steps? 


\section{GRADUATED DRIVER'S LICENSE PROGRAM AWARENESS}

Is it safe to assume that you are very knowledgeable relative to the GDL program?

Do you feel that most who participate in and/or enforce the program are very knowledgeable? Who? / Where is the shortfall? /

PASS OUT FACT SHEET (With info regarding both GDL \& DIP)

- What, if any, information or provisions were you not aware of? Which provisions?

How aware are the teenagers and their parents of this information?

What do you consider to be the objectives of the program?

- How do you feel about those objectives?

- Do you feel these are what the objectives should be? If not, what should they be?

- Do you feel their needs to be any changes to these objectives?

How do you feel about the implementation and enforcement of the program?

- To what extent do you feel the regulations are monitored and enforced? (PROBE: By the police / by the courts / by DMV)

- How serious is the system about monitoring and enforcing the rules?

- In the scheme of your priorities, where does the adjudication of GDL offenders fall?

- What percentage of the offenders you encounter do you actually penalize to the limit?

- What impacts the level of penalty you inflict?

- Are their any circumstances that alter your priority and make you any more or less vigilante? Why?

- Are there any particular infractions you place a higher priority on? Why?

- How do you feel about enforcing the GDL regulations?

(PROBE: educational versus punitive; doing something for them or to them)

- Are there any barriers to make it difficult to enforce the GDL Program? What?

- What could be done to minimize the barriers?

What kind of things would you suggest to improve the enforcement of the program? 
How serious do you think the parents and the teenagers are about abiding by the rules?

- Are there any requirements they take any more or less seriously? Which? I Why?

To what extent do you think parents are involved in teaching and monitoring their teenage drivers?

- What should they be doing?

GRADUATED DRIVERS LICENSE PROGRAM IMPACT ASSESSMENT

Do you feel the GDL Program has had any impact? Explain?

- Do you feel teenagers would have gotten as much training and experience without the GDL Program?

- Do you feel the requirements/restrictions actually increase teenagers' safety?

Comparing the teenagers you encounter today versus those you encountered prior to the implementation of the GDL Program (March 2000):

- Are there any differences in attitudes between the teenagers who went through the program and those who did not?

- Are there any differences in skills between the teenagers ..........?

OVERALL, what do you consider to be the pros and cons of the GDL Program?

- Do you think teenagers' risk-taking is influenced by the GDL program?

Is there anything you would change or add to the GDL Program to make it more effective?

\section{WRAP-UP}




\section{APPENDIX B}

\section{Oregon Teen Driving Laws}

\section{FACT SHEET}

A brief summary of requirements and restrictions for new drivers under age 18

\section{$\underline{\text { Requirements before receiving license }}$}

Teens must:

- Hold an instruction permit for 6 months

- Certify with parental verification 50 hours of supervised driving experience

- Complete a traffic safety education course

-OR-

Certify an additional 50 hours of supervised driving experience

\section{Restrictions after license is issued}

- For the first 6 months, no passengers under age 20 who are not immediate family members

- For the second 6 months, no more than 3 passengers under age 20 who are not immediate family members

- For the entire first year, no driving between midnight and 5 a.m.

Exceptions: Driving to work or school when there's no other transportation While working When a passenger is a licensed driver over age 25. 


\section{APPENDIX C}

\section{ADVISORY PANEL}

A multi-disciplinary advisory panel was formed to provide support to the project team. The members' expertise included youth driving issues, licensure requirements and policy, and research/analytical techniques. The panel members were kept abreast of the project's activities and provided insight into the challenges of acquiring and using public databases. The panel's primary activity focused on a review the project's data analysis plan. After review, a number of valuable comments regarding analytical techniques, sampling issues, and references to prior research were received and incorporated into the plan. Advisory Panel members reviewed a draft of the paper and provided important comments and suggestions. In addition, the panel was also helpful in facilitating communication with other professionals conducting research in the area of provisional licensing.

The members of the panel were as follows:

\begin{tabular}{|c|c|}
\hline Name & Affiliation \\
\hline Troy Costales & $\begin{array}{l}\text { Administrator } \\
\text { Transportation Safety Division } \\
\text { Oregon Department of Transportation } \\
\text { Salem, Oregon }\end{array}$ \\
\hline Robert D. Foss, Ph.D. & $\begin{array}{l}\text { Senior Research Scientist \& Manager of Alcohol } \\
\text { Studies } \\
\text { Highway Safety Research Center } \\
\text { University of North Carolina }\end{array}$ \\
\hline Mary Garcia & $\begin{array}{l}\text { Driver Licensing Coordinator } \\
\text { Driver Programs Division } \\
\text { Oregon Department of Transportation } \\
\text { Salem, Oregon }\end{array}$ \\
\hline John Harvey & $\begin{array}{l}\text { Driver Education Manager } \\
\text { Transportation Safety Division } \\
\text { Oregon Department of Transportation } \\
\text { Salem, Oregon }\end{array}$ \\
\hline Barnie Jones, Ph.D & $\begin{array}{l}\text { Research Manager } \\
\text { Transportation Development Division } \\
\text { Oregon Department of Transportation } \\
\text { Salem, Oregon }\end{array}$ \\
\hline Iris Key & $\begin{array}{l}\text { Manager, Alcohol \& Other Drugs Division } \\
\text { National Council of Juvenile \& Family Court } \\
\text { Judges } \\
\text { Reno, Nevada }\end{array}$ \\
\hline Dan Mayhew & Senior Vice President \\
\hline
\end{tabular}




\begin{tabular}{|c|c|}
\hline & $\begin{array}{l}\text { Traffic Injury Research Foundation } \\
\text { Ottawa, Ontario }\end{array}$ \\
\hline Rosemary Nye & $\begin{array}{l}\text { Regional Program Manager, Team Leader } \\
\text { Northwest Region } \\
\text { National Highway Traffic Safety Administration } \\
\text { Seattle, Washington }\end{array}$ \\
\hline Susan Riehl & $\begin{array}{l}\text { Youth Program Manager } \\
\text { Transportation Safety Division } \\
\text { Oregon Department of Transportation } \\
\text { Salem, Oregon }\end{array}$ \\
\hline Rodney Rosenkranz & $\begin{array}{l}\text { Driver Programs Manager } \\
\text { DMV Services Division } \\
\text { Oregon Department of Transportation } \\
\text { Salem, Oregon }\end{array}$ \\
\hline Ruth Shults Ph.D., MPH & $\begin{array}{l}\text { Senior Epidemiologist } \\
\text { Injury Center } \\
\text { Centers for Disease Control and Prevention } \\
\text { Atlanta, Georgia }\end{array}$ \\
\hline Patty Ellison-Potter Ph.D. & $\begin{array}{l}\text { Research Psychologist } \\
\text { Office of Research and Technology } \\
\text { National Highway Traffic Safety Administration } \\
\text { Washington, DC }\end{array}$ \\
\hline Linda Cosgrove Ph.D. & $\begin{array}{l}\text { Research Psychologist } \\
\text { Office of Research and Technology } \\
\text { National Highway Traffic Safety Administration } \\
\text { Washington, DC }\end{array}$ \\
\hline James Nichols Ph.D. & $\begin{array}{l}\text { Chair } \\
\text { Nichols and Associates } \\
\text { Vienna, Virginia }\end{array}$ \\
\hline Troy Costales & $\begin{array}{l}\text { Administrator } \\
\text { Transportation Safety Division } \\
\text { Oregon Department of Transportation } \\
\text { Salem, Oregon }\end{array}$ \\
\hline
\end{tabular}




\section{APPENDIX D}

\section{DRIVING PERFORMANCE RELATED TO EDUCATION AND TRAINING OPTIONS}

Conviction, suspension, and crash rates were compared between the two training options.

The conviction rates, suspension rates, and crash rates were compared between two groups:

- Drivers who completed an ODOT-approved driver training course plus claiming 50 hours of supervised practice

- Drivers who claimed 100 hours of supervised practice.

The body of the report cautions readers that interpretation must be cautious, given the many limitations surrounding any comparison of these two groups.

As described in the body of the report, for all ages, during all time periods, the drivers who had certified completing the formal driver education course had fewer convictions and suspensions than those who claimed 100 hours of supervised practice (all z's $>3$, all p's $<.01$ ). When crash rates were compared, most groups showed the same pattern: drivers who completed the formal driver training exhibited lower crash rates (z's $>2.58$, p's < .01). The exceptions were the 16-year-old drivers in their second year of driving, and the 17-year-olds in months 7-12: these groups' crash rates were not significantly different.

Tables 16, 17, and 18, and Figures 16, 17, and 18 show mean rates of convictions, suspensions, and crashes, respectively. 
Table 16: Conviction Rate - Summary of Analyses by Months, Training Option and Comparison Groups

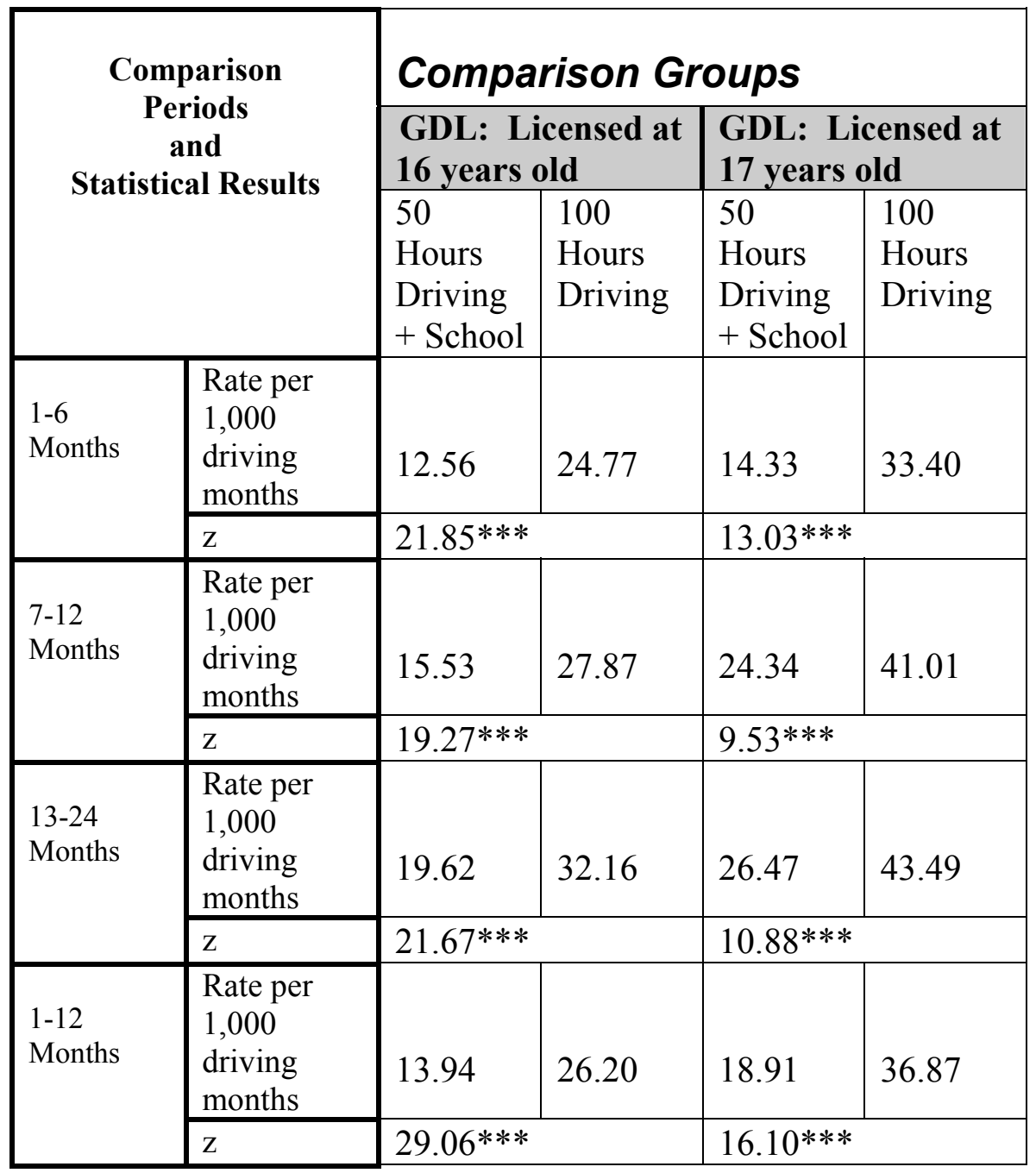

Significance levels: $*=\mathrm{p}<.01 ; * *=\mathrm{p}<.001 ; * * *=\mathrm{p}<.0001$ 
Table 17: Suspension Rate - Summary of Analyses by Months, Training Option, and Comparison Groups

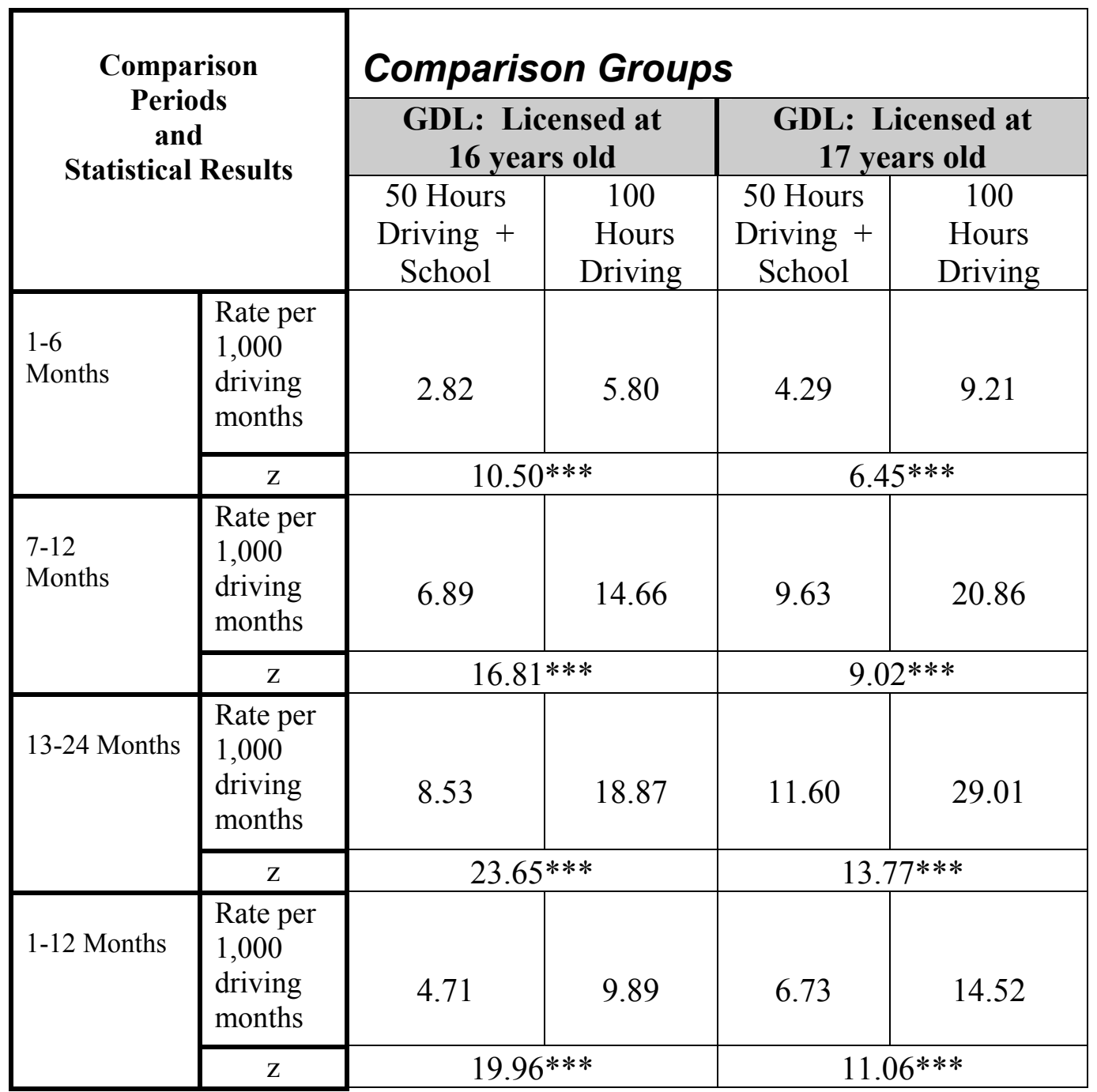

Significance levels: $*=\mathrm{p}<.01 ; * *=\mathrm{p}<.001 ; * * *=\mathrm{p}<.0001$ 
Table 18: Crash Rate - Summary of Analyses by Months, Training Option, and Comparison Groups

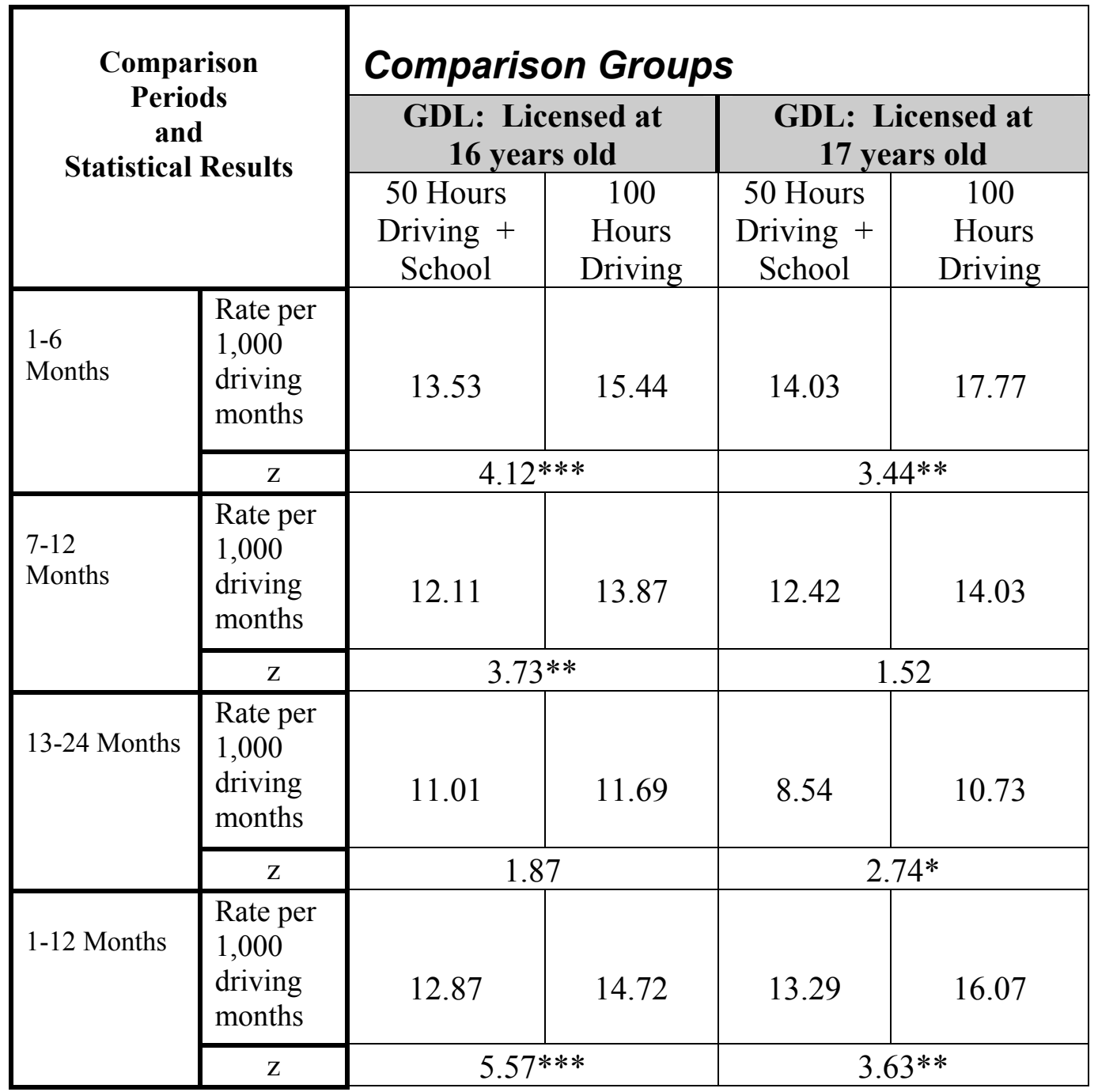

Significance levels: $*=\mathrm{p}<.01 ; * *=\mathrm{p}<.001 ; * * *=\mathrm{p}<.0001$ 
Figure 16: Conviction Rates - 16- and 17-Year-Olds (GDL) by Type of Driver Training

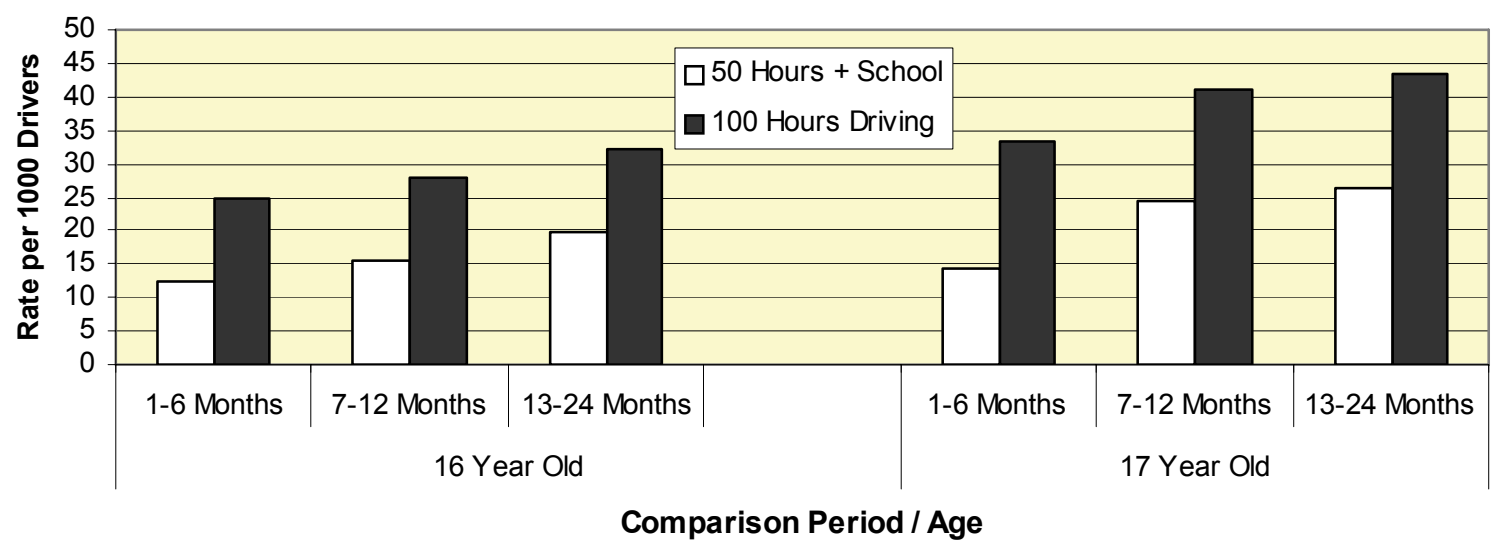

Figure 17: Suspension Rates - 16- and 17-Year-Olds (GDL) by Type of Driver Training and Gender

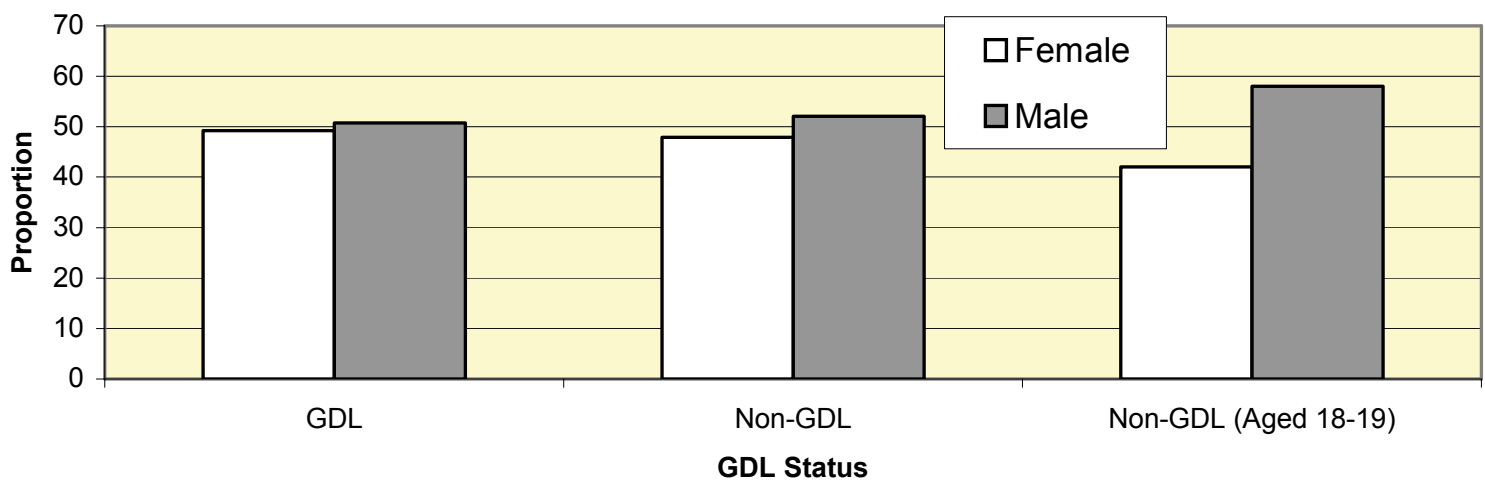

Figure 18: Crash Rates - 16- and 17-Year-Olds (GDL) by Type of Driver Training

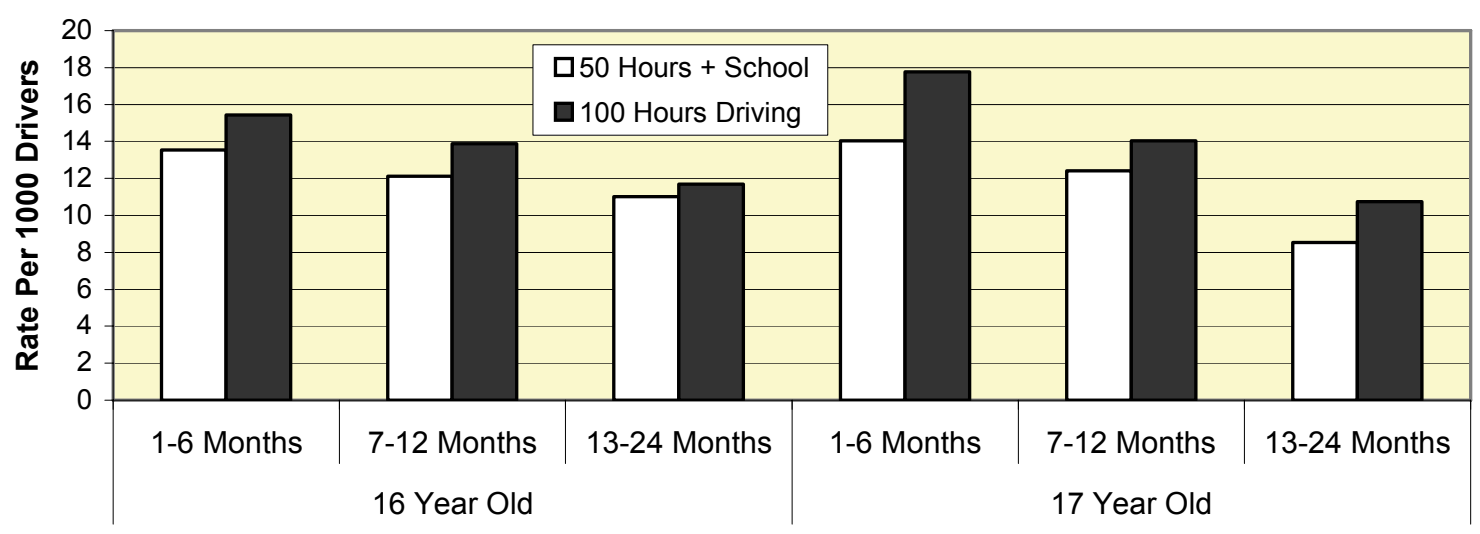

Comparison Period / Age 


\section{APPENDIX E}

\section{DETAILED FOCUS GROUP FINDINGS}

\section{THE PERSPECTIVE OF THE PARENT}

\section{PARTICIPANT DEMOGRAPHICS}

Forty-three parents of Oregon teenage drivers participated in 5 groups held in Portland, Pendleton, Grants Pass, Eugene, and Bend. Nineteen of the parents were male and 24 were female. Twenty of their teenage drivers were male, and 23 were female. Twentysix of the teenage drivers were 16 or 17 years old and 17 of the teenage drivers were 18 or 19 years old.

At the time of the discussion, 16 of the parents' children had received their licenses within the previous year and were thus restricted under Oregon's GDL program. Seven of the parents' teens held learner permits, and 20 had full licenses. Nineteen of these parents also had older children who received their licenses before the GDL program was implemented.

\section{CONCERNS OF THE PARENTS}

\section{A teen's acquisition of a driver's license was a traumatic experience for the parents.}

Parents described the pursuit of their teenagers' driver's licenses as a bittersweet milestone. The parents shared their children's joy and excitement with this rite of passage, as it not only marked a significant point in the lives of their children, but also added a significant amount of convenience and flexibility to the lives of the parents. Carpooling and chauffeuring duties were significantly reduced, if not totally eliminated.

However, these benefits were at the cost of great apprehensions. The most prevalent concerns of the parents were death and injury of their child. In addition, they feared for the lives and injury of others, and the property their children could destroy.

Another major apprehension of many of the parents was the reduction in the amount of control they could maintain over their children after they got their driver's licenses. Given access to an automotive vehicle, their children had the ability to go almost anyplace they wanted, be with whomever they wanted, and do what they wanted; all without parental knowledge or consent. The driver's license gave their teenagers more freedom and independence than they had ever had before in their lives.

"You immediately lose some control over their lives."

“...fear of doing things they shouldn't be doing. You want to keep them home where they are safe, but if you can't do that..."

In return for this newfound independence, it was extremely important to most parents that their teenagers accepted responsibility and operated within the rules. 


\section{Lack of experience, immaturity, and insurance costs were the major factors driving the fears of the parents.}

Even after their teenagers had mastered the basic skills to operate an automotive vehicle, lack of experience and immaturity continued to be the parents' greatest concern. The parents believed that any driver was probably at most risk when inexperienced.

In addition to inexperience, parents felt that new teenage drivers had other disadvantages working against them as a result of their immaturity (e.g., distractions in the car). Many of the parents felt their teenagers were easily distracted, and had not completely developed the skills of multitasking. Parents said that attempting to drive, adjust the radio, and talk to friends might be typical for an experienced adult, but would be a problem for an inexperienced teenage driver.

"Teens don't have the experience."

"Kids aren't as good at multitasking or thinking ahead..."

"The majority of them (teens) drive too fast for the conditions, too close, and they don't anticipate things. They don't pay attention and they don't leave any room for a margin of error."

Parents felt the teens suffered from a sense of invincibility. Teens did not expect bad things to happen to them. Thus, they were not cautious enough. Further, they had a tendency to show off for their peers. They were more likely to do dangerous things when with friends than if they were alone. Thus, their peers were not only a distraction, but also a liability because of the influence they had on each other.

Parents indicated that in addition to being a menace to themselves, teen drivers were also exposed to the foolishness of other drivers.

"Sometimes, it's not really my kid I worry about. It's the other drivers on the road."

"Other drivers have no mercy...on young drivers."

"I worry about my son's friends' driving more so than my son's driving."

The cost of auto insurance was a major consideration for both the parents and their children. Many of the parents passed this cost on to their teenagers not only to defray the expense, but also to heighten the teens' awareness of the responsibility and exposure. Parents indicated that the attempt to reduce the insurance costs was a major motivation for the teens to pursue driver safety training. 


\section{AWARENESS OF THE GDL PROGRAM}

\section{The parents in the smaller cities appeared to be more aware of the GDL}

restrictions than those in the larger cities.

The parents in Portland and Eugene did not appear to be as well versed on the GDL regulations as the parents in the smaller cities (Pendleton, Grants Pass, and Bend). Generally, few if any of the parents referred to the program as the "Graduated Drivers License" or "GDL" program. Most called it the "6-Month Rule," which indicated the importance they placed on the restrictions during the first 6 months. Some referred to the program as the "Provisionals," a term that had also been applied to Oregon's previous laws regarding novice drivers.

Few parents were aware of the consequences of violating the provisions of the GDL program.

\section{Most parents were more aware of the requirements to get the license than of the later restrictions.}

Parents showed more knowledge of licensing requirements than of restrictions placed on new drivers. They felt this was probably because the teens knew more about the regulations than their parents, and the teens were more concerned about informing their parents about the requirements to obtain the license than telling their parents about the restrictions that kept them from doing what they wanted.

"I knew about most of the provisions before they obtained their licenses, but I wasn't too familiar with the ones after."

"Most of this stuff you have to find out on your own. Your kids aren't going to tell you about this stuff."

Although there was some confusion about the age of allowable passengers (many of the parents felt the 20-year-old stipulation seemed less logical than 21 years, and somewhat confusing), most of the parents were very aware of a restriction on passengers for the first 6 months. However, many were not aware of the restrictions on driving between midnight and 5 a.m., a stipulation for both the first and second 6 months. Many of the parents were more aware of the adolescent curfews of their respective municipalities, many of which were more restrictive than those of GDL.

"I was not familiar with the no driving between midnight and 5 a.m."

The parents were generally much less aware of the restrictions during the second 6 months than of the restrictions during the first 6 months. The parents in Portland were the least knowledgeable of the first 6 months' restrictions.

\section{Available resources were not widely utilized.}

Most of the parents were unfamiliar with the Tuning Up manual, a pre-licensing guide intended by ODOT for distribution to parents and teens when the learning permit is obtained. The Tuning Up manual offers suggestions on teaching and learning to drive. 
In fact, it appeared that the manuals were actually not being distributed at some DMV facilities in Portland. Of the parents who had obtained and used the manual, most considered it to be useful. However, many of the parents appeared to have been intimidated by the amount of information presented.

For information about the GDL program, most parents wished for a single fact sheet that summarized the major GDL requirements and restrictions. They felt they could have posted something like this on their refrigerators as a reminder.

The parents were even less aware of the DMV Website than the manual. Those who had used it found it to be beneficial. Parents felt empowered by the knowledge and documentation.

"We actually went to the Web site and looked up stuff. We printed out a sheet and showed them, 'Yes, you can do that. No, you can't do that."'

\section{PERCEPTIONS OF THE GDL PROGRAM}

\section{The parents felt the GDL program empowered them to enhance the safety of their teenage drivers.}

Many of the parents felt they would have imposed many of the same regulations had the GDL program not existed, especially those for the first 6 months of having their driver's licenses. However, without the GDL program, the parents felt they would have had much more difficulty trying to enforce them. The law made it much easier to restrict their children's driving.

"It (GDL) also helps us as parents when your kids are like, 'Well, everyone else is doing it.' 'Actually no, no they can't!'”

Parents felt that compliance with these regulations had a positive impact in many ways. Parents said the program achieved the following (1) Ensured that teenage drivers had been given sufficient, supervised training and experience prior to obtaining their licenses; (2) Sheltered teen drivers from the distractions and pressures of their peers; and (3) Limited the number of teenagers exposed to potential danger in the event of crashes.

The parents recognized and appreciated the need for the GDL program. They felt the objectives of the program were consistent with their personal objectives.

"The objectives of the program are to give the kids experience such that they can learn how to be safe drivers under a formalized instruction period..."

"Kids need boundaries. They need to know they can only do this, this, and this for a certain time."

"They are trying to limit the negative impact of peer pressure." 
"Many of the concerns we have are not being solved, but are definitely being addressed by these laws."

\section{Many parents did not consider the requirements to be tough enough.}

Many of the parents, especially the fathers, were leery about the level of maturity and responsibility of teenagers relative to driving. Some felt the existing GDL restrictions were giving the teenagers too much, too fast. Some of the parents felt the age at which one could get a driver's license was too young. They felt a teenager should not be allowed to get a license until they were 18 years old. Others thought the age of eligibility should be linked to grades in, and references from, school and/or other sources regarding maturity and responsibility. Some thought the restrictions should last until age 18, regardless of how long the license had been held. Most of these suggestions represented the perceived need to ensure teenagers were mature and responsible enough to drive safely.

"The restrictions are good, but they are not strict enough."

"I think there is a huge difference in 16-year-olds and 17- or 18-year-olds getting their licenses. That year makes a big difference."

"They should include references in terms of getting a license from teachers, employers, etc."

"I think kids should see the consequences. I take them [his kids] to the morgue."

However, there were parents who felt the GDL restrictions were sufficient. Although they felt there were some teenagers who were not mature and responsible enough to drive at any age, most, including theirs, were.

"I think it's more of an issue of maturity rather than age, so I don't think it should be tougher. Like we said before, it varies from person to person."

"I think what's tough to me is that it's a maturational thing, and how do you judge that by an age?"

“....and that's why I wouldn't want to see it tougher, because it varies from person to person..."

These parents felt it was the responsibility of the parents to determine if their teenager was responsible and mature enough to manage what could become a dangerous weapon.

Caravanning and an incentive for dishonesty were perceived to be the two major cons of the GDL program.

Often, because of the restrictions on passengers, individual teens drove separately in caravans. Many of the parents felt this caused more exposure to danger than having 
them ride together. On occasions like these, some wished there were more flexibility with the restrictions.

"It's funny to see these caravans that form. You have these three kids that come to your house and then there your kid goes and the four of them go off."

"It just doesn't make sense that all the kids have to drive. Now all of them have the potential to get in accidents, as opposed to one."

Some parents felt awkward because they expected their children to break the rules with respect to the passenger restriction and lie to maintain the driving privilege.

\section{PERCEPTIONS OF IMPLEMENTATION AND ENFORCEMENT}

\section{Enforcement of the GDL regulations was very important to the parents.}

Enforcement of the rules and regulations of the GDL program was very important to most of the parents for several reasons. The most obvious was that these rules were perceived to be effective in saving the lives of teenage drivers. In addition, many of the parents, especially those in the smaller cities, felt these rules should have been enforced if for no other reason than that they were the law.

"If the State of Oregon has made these laws, they should enforce them. If not, do not have the law. Also, word gets around...."

"If you have a set of rules like these, you should do something to enforce them...."

Parents said that the driver's license was one of the most important responsibilities bestowed on a teenager. Many of the parents felt it was very important that their teenagers learned that with responsibility came accountability. They wanted their teenagers to recognize that this rite of passage not only bestowed the benefits of driving, but also represented their passage into the real world of adult responsibilities, rules, and regulations. These parents wanted to make sure this experience reinforced their teenagers' respect for, and adherence to, the law. They wanted these laws to prepare the teenagers for life as an adult. Thus, many of the parents felt the enforcement of these rules set a precedent not only for attitudes about driving, but also for other important issues of adulthood.

Many of the parents were disappointed by the implementation and enforcement of the requlations.

Many of the parents felt the regulations were not monitored and enforced seriously enough. Several indicated that even before the driver's license was issued, they felt that the program was not being diligently enforced. For example, several of the parents were very disappointed that the DMV had not required documentation to substantiate the supervised driving experience. Some parents had meticulously recorded their practice hours and felt that the DMV not requiring it may have sent the wrong message to teenage drivers, trivializing the requirement. It also implied that the parents were not 
being held responsible and/or accountable, and that it was easy for parents to simply "sign off" on the practice hours, regardless of actual practice.

"I kept a careful log of my son's hours, and nobody asked for it. If they had asked for it, had parents certify it, then that would have made the parent show that they did do their job..."

"I filled out the log. I did exactly what they told me to do and they didn't even ask for it."

Many of the parents also felt that the DMV needed to be more effective in communicating the consequences of violating the regulations.

"No one... knows what the consequences are besides some greenbacks and a fine."

Parents wanted penalties behind the regulations, and they wanted those penalties to be visible. Further, many of the respondents did not feel they were effectively informed of all of the regulations and their responsibilities. They wanted a brief summary like the focus group Fact Sheet (see Appendix B) that could have been posted in their homes. Parents mentioned no awareness that this information was available on the DMV Web site. Though teens at the time of licensure were supposed to receive a wallet card listing GDL requirements and restrictions, parents showed no awareness of this card.

Parents also wanted the DMV personnel to be more diligent about making sure the parents knew what the rules and consequences were.

"I don't feel as though I was informed well enough, and I know there are many parents out there like me."

Many of the parents were very critical of and frustrated with the lack of enforcement provided by police officers. They felt the law enforcement officers were not aggressive enough in monitoring for and stopping violators.

"I see a lot of kids around here driving Suburbans around, driving techno cars around packed with kids under 18 and I know they shouldn't be, and the police go right by them and don't say anything."

Many of these parents were not aware that GDL violations were not subject to primary enforcement. They did not realize that a traffic stop could not be made solely for a GDL violation.

However, many of the parents felt justified in their complaint that they felt the police officers were not diligent in citing GDL violations even when the teenagers were pulled over for other violations. They said that officers often pulled teenagers over for other violations, and did not cite them for the GDL regulations they were also violating. They felt this not only sent the message that the authorities were not serious about enforcing the regulations, and that the teenagers did not have to worry about the consequences, but it also wasted an opportunity to have a positive impact on teen safety. The parents 
said the perceived lack of enforcement had a strong impact. They felt that vigorous enforcement would increase teens' caution.

"My daughter got pulled over twice, but I appreciated the fact that they did and gave her a warning because it made her a more cautious driver."

The parents said that if the laws were not vigorously enforced, their teenagers would not fear being caught, would not feel the need to comply, and would not benefit from the regulations. The parents knew that if the teenagers felt the chances of being caught and cited were very slim, the teens would have never expected that they would be the ones who would actually be penalized.

\section{The parents wanted stricter enforcement.}

The parents recognized that the existing GDL regulations were hard to enforce, and that if police were as diligent as possible at seeking out violators, their efforts could border on harassment.

"It's very hard to enforce. If you have cops out there enforcing these laws and stopping every kid they see with passengers in the car, you start getting into harassment issues. The idea is good, but I just don't see it being enforced in a way that would be effective."

"I think if police too strictly enforce this rule, you are going to get kids to hate cops, which is a bad thing, and we don't need that as a society."

However, many of the parents wanted primary enforcement of GDL violations. They wanted some of these regulations enforced as rigorously as possible, and by almost any means possible.

"I think it would help enforcement if there were some random stops like after school or after football games. I'm not saying go after them and stop everybody. I'm just saying stop a few at random and say, 'Hey you didn't do anything wrong. We're just stopping to check.' Say, 'Good job, great.' I think it helps the kids to know someone is watching, and that's the message that kids need to get."

"It might be better if the police stopped kids more often, just to let them know..."

These parents wanted enforcement made easier for the police officers. They would have liked to have had a means of making it easier for police officers to identify teenage drivers with restrictions. One well-received suggestion made by one respondent was that there should be some type of identifying sticker that could be placed on vehicles driven by restricted teenage drivers. Parents who wanted police to closely monitor their teenage drivers could use the sticker. Those who did not want closer monitoring, or thought closer monitoring was no longer necessary, could refrain from using the sticker. 
PARENTAL INVOLVEMENT

\section{Parents recognized that they were the foundation of the program.}

Most parents, when made fully aware of how the GDL regulations were written, recognized that they were the focal point for the implementation and enforcement of the program.

"I think it's personal. If you as a parent don't enforce it, then nobody else will."

"I think they are just not getting caught. There is no enforcement. I think the enforcement should be by the parents, because the police cannot enforce it. They aren't in every home and every car, and on the rare occasion that they do get pulled over, then they can enforce it."

"I think it starts with the parental authority, but it's backed by the law."

"I was serious about these laws before these laws were even laws."

However, to be effective catalysts for this program, the parents said they must be well armed with knowledge regarding how the program works and steps they could take to effectively promote and monitor compliance. Many of the parents felt unsure of their role with respect to GDL and their teen drivers.

Parents were very involved in teaching their teenagers during the instructional period.

Most of the parents indicated they drove with their teenagers very frequently during the instructional period, some almost every day. This was especially true in the less urban areas. Their concerns were more related to making sure their children learned to drive than about the fulfillment of the supervised driving requirement. The parents did not want their teenagers driving until they felt comfortable about the teens' skills.

"I had to be confident that my kids had the confidence and experience to drive while I was in the car in order to let them get their license and drive alone."

Most felt they spent far more than the required hours of supervised driving experience. However, very few of them kept an accurate accounting of the time. Further, some who did admitted that the accounting was not accurate.

"We were rounding up, especially towards the end. We needed to get those 100 hours!"

Once parents felt comfortable with their teenagers' abilities, they were ready to allow the teens to take the test for their driver's license. 


\section{Parents were very committed to compliance during the first 6 months of restrictions.}

Most parents reported they were initially very diligent about trying to monitor and enforce the restrictions during the first 6 months, especially the passenger limitation. This was the rule parents considered to be the most important. It was also the rule they perceived to be the most difficult to monitor and most likely to be violated. However, many of the parents said they became less diligent as time passed. Some became less concerned about compliance because they felt more comfortable with their teenagers' driving skills, but most did so simply because they got worn down.

"I do not enforce these laws because my daughter has gained my trust; therefore I don't feel the need to rigorously enforce these laws."

"It's hard after a while. I just rolled over."

The parents in the smaller cities appeared to have an advantage over those in the larger cities. The families knew and looked out for each other. A parent did not have to catch his or her teenager to know if the teen was violating the rules, because their neighbors would tell them. Communities wanted to help each other monitor and manage the affairs and safety of their children. There was more of this sense of community in the smaller towns.

"Living in a small town, you rely on other people in the community to tell you how well your teen drives."

"It's very difficult as a parent if the other parents aren't enforcing the law as you would."

"It's good to know people in the area. Lets parents know when your kids are doing wrong."

Because of a lack of awareness of the restrictions, most parents did very little to enforce the second 6 months' regulations.

\section{Parents often added their own rules and restrictions.}

Many of the more responsible parents, in addition to close monitoring and enforcing the GDL regulations, had taken steps above and beyond the program. Some of the parents had their teenagers sign contracts or statements of understanding of expectations, regulations and consequences.

"I rigorously enforce these laws, but I have imposed a set of rules far and above these laws..."

"I knew the laws, but I kind of changed the laws myself. I imposed one passenger instead of three. I think three is way too many." 
"For first six months, he couldn't drive at night or in inclement weather."

"No answering cell phones in the car."

\section{Parents perceived the traffic safety training courses as beneficial.}

The most popular benefits of the traffic training courses were that they reduced the insurance rate and the number of hours of supervised driving experience for the teenage drivers.

Most of the parents firmly believed that having a trained professional teach their teenagers how to drive resulted in safer drivers. They felt the professional instructor was current with techniques, procedures and had access to teaching aids, including a curriculum. For example, some parents learned to drive before airbags were popular and felt the hand positioning they were taught was not correct for today's vehicle equipped with airbags. Further, they felt that an instructor who did not instruct on a regular basis (e.g., a parent or a history teacher) could easily have forgotten lots of important information.

"What if I am teaching my child how to drive and I'm forgetting some key piece... or, the way l'm teaching them is not sinking in, so I want to have that from someone else who has been trained."

Some parents preferred the driver education courses in lieu of the 100 hours of supervised driving.

"Who's to say if you don't take the class that the 100 hours are being completed? The driving ed class is more thorough. I know myself there are a lot of things I forgot, so the course covers that."

Many parents felt the trained professional was not only better prepared from the technical aspects, but also had a psychological advantage. Their teenagers were more receptive to the constructive criticism from almost anyone than from their parents, and especially from a professional trainer.

"The best part about it is they are driving with Bruce, 'cause you know how they like to listen to mom and dad."

"I figured I would just give someone else the gray hairs, plus I figured they could offer so much more than I could."

Many of the parents felt the benefits of the traffic safety training were worthwhile and wished professionally-taught courses were mandatory for everyone. This would have made them feel that all drivers had been properly trained, and that the roads were safer.

"For my peace of mind, it would be nice if the driver education course was mandatory. It would let me know that some other parent didn't just sign a form and let their kid go." 
"The driver education program is effective and thorough. It should be a mandatory requirement. However, if they are going to make it mandatory, they need to make it free."

Most of the parents preferred to have the public school system provide the traffic safety training for their teenagers. They expected it to cost less, be more convenient and more thorough than that provided by commercial schools.

\section{PERCEIVED IMPACT OF GDL PROGRAM}

Parents perceived the program to be effective in saving lives of teenage drivers.

Some of the parents had heard statistics indicating that deaths among teenage drivers had decreased since the implementation of the GDL Program. However, even the parents who had not heard such statistics felt that it saved lives.

\section{Parents felt empowered by the GDL program.}

GDL reinforced the power of parents to enforce the type of rules many parents needed to make them feel comfortable about the safety of their teenage drivers. It also informed those parents who might not have recognized the need for such provisions.

"As a parent, I appreciate any help that I can get in support of trying to do things to raise a kid. It's not just me saying this..."

"It's the law. It gives us a stopping point. You don't have to argue it."

\section{Parents said that the GDL program mandated experience.}

The law dictated that teenage drivers under age 18 be given at least a minimum amount of supervised driver training and experience before they were qualified to pursue a driver license. Parents said GDL not only provided experience, but also reinforced the attitude that driving was a serious responsibility, and provided an opportunity to thoroughly evaluate the teenagers' readiness.

"It used to be teens would get their license and just be off. Now, with this program, it's like you have 6 months to show parents and family members that you can drive."

\section{Parents said that GDL made them more involved in their teens' licensure.}

The GDL program created the need for the parents to get involved in their children's learning and licensing process, and defined the minimum level of involvement needed.

\section{Parents felt that the GDL passenger restrictions reduced distractions and} temptation for foolishness.

Parents perceived the limitations on passengers to be the most important and effective aspect of the GDL program. The passenger limitations were perceived to not only 
reduce distractions, but also shelter the teenage drivers from peer pressure to do things they would not do if driving alone.

“...minimizes peer pressure while you are an inexperienced driver.”

The passenger restrictions were also perceived to protect the passengers in the event of a crash. This perception was prevalent among focus group participants, who referred to a well-publicized crash in which several teenagers had been killed while in violation of the GDL regulations.

\section{Parents said that the GDL program made teenagers drive more safely.}

Parents held that even when teenagers violated the regulations, GDL promoted safer driving. Several parents felt that when their teenagers were in violation of GDL, they were less likely to violate other rules, because they were leery of being cited for both violations.

"It's good because even when you aren't following the law, you are a more safe driver because you don't want to get caught with three passengers in the car."

"This small chance that my son might be pulled over because he is 16 , even though he might think it is unfair, he drives more cautiously, and that prevents about ten other things."

\section{THE PERSPECTIVE OF THE TEENAGER}

Forty-nine Oregon teenage drivers participated in 5 focus groups held in Portland, Pendleton, Grants Pass, Eugene, and Bend. Twenty-five were male and 24 were female. Thirty-one were 16 or 17 years old and 18 of them were 18 or 19.

At the time of the discussion, all of the teenage participants were licensed drivers. Twenty-eight of the teenagers had held their licenses for less than a year and were thus in the provisional period, and 21 were out of the provisional period.

\section{CONCERNS OF THE TEENAGE DRIVERS}

\section{The driver's license was one of the most exciting milestones in a teenager's young life.}

The teenage drivers in Oregon said they placed a high priority on the privilege of driving. For these teenagers, the driver license was a rite of passage. The privilege was a means of freedom, flexibility, independence, it was new and exciting, and it enhanced their social status. They no longer had to wait until it was convenient for someone else to take them places. They could do things on their own and stay out later. They felt independent of their parents. They could get out on their own, free at last.

"I just hate having to rely on my parents to go anywhere." 
"Not having to rely on my parents."

The driver's license also allowed the teenager to be more flexible relative to finding and holding jobs.

\section{Some of the major concerns of the teenagers included liability and costs.}

The teenagers recognized that the driver's license was a big responsibility. Many of the teenagers indicated that they were initially very fearful of hitting people when driving. They also worried about the safety of their passengers.

"I was really scared the first time I drove. I was scared of killing someone. I could potentially make a mistake."

The costs of driving were also major concerns for the teenagers. These costs included insurance, gasoline, and in some instances, the costs of buying and maintaining a vehicle. Insurance costs were one of the greatest concerns.

However, the biggest concern of all was the "6-month rule," which restricts carrying unrelated passengers for the first 6 months of licensure. Much of the anticipation and excitement of getting their driver's license was perceived to be severely dampened by this rule.

"I thought the 6-month rule created a situation where more of my friends lied to their parents."

The teens said they were under extreme pressure to break the GDL restrictions. All of their friends were going to want rides, and encouraged them to break the rules and lie to their parents.

"[We] go everywhere in groups. If you don't go in one car, you have a caravan of ten."

\section{Many of the teenagers indicated that overconfidence became a problem.}

After driving for several months, many of the teenagers felt their fear and caution faded into a dangerous overconfidence. They began to feel they were much better drivers than they actually were. They became more careless and took greater risks. In many cases, it was not until they had a crash, had been cited for a violation, or their parents reined them back that they reassessed their skills, responsibility, and consequences.

"Another thing about driving for a while, you start to get careless. You just get way too comfortable."

"I think it's just all about experience. For me, it's like before you get in that first wreck, you think you are invincible. After I got in my first accident, reality kind of hit me. Until you really have to deal with something serious on your own, you really don't think about it." 


\section{AWARENESS OF GDL PROGRAM}

\section{Most teens were very well versed on the "6-month rule."}

The teens were not familiar with the program as the "Graduated Driver License" or "GDL" program. Like almost all participants, they referred to it as the "6-month rule" or the "Provisionals". The teens were much more aware of the provisions of the program than the parents. They were most familiar with the restrictions for the first 6 months, and, much more so than the parents, very aware of the fact that violations were a secondary offense.

"If you are breaking the 6-month rules and are speeding, just don't get caught."

A few of the teens were even aware of the Driver Improvement Program, something about which none of the parents were aware.

Although some of the teens recalled hearing about the GDL program through the media when it was introduced, most of the teens became aware of it through their friends, the DMV, or driver education courses.

Most of the teens were much less aware of the second 6 months' restrictions. In fact, a few were not even aware that there were restrictions for the second 6 months.

"I thought there were only restrictions for the first 6 months."

Most of the teens were also unaware of the DMV Web site. The few who had used it found it to be useful, especially for the practice tests. It was felt that the Web site could be a valuable resource if it provided information and training tools in an interesting and interactive manner.

"If I had known about the Web site, I would have used it. I wish they had told me at the DMV or something."

Most of the teens who received the Tuning Up manual did not use it.

\section{PERCEPTIONS OF THE GDL PROGRAM}

\section{Most teens recognized the objectives of GDL.}

Although they were reluctant to admit it, most of the teens said that GDL was implemented to enhance their safety and to save their lives, and they recognized that most of these regulations were helpful for their initial level of driving experience and skills. 
"They figure we're distracted easily. So during our first couple of months driving, they try to restrict the experience."

"The younger you are, the more immature you are. So kids after curfew are probably out with nothing to do."

"It's all pretty logical to me. They graduate with responsibility in that when you first start out, you are by yourself during the daylight hours, then it progresses to other situations. It makes sense that as you gain expertise, you gain responsibility."

However, there were some teens who were skeptical of the motivations for GDL. They thought it was discriminating against teenagers and/or just a way to make money. They felt there was no good reason to establish a threshold of age 18 for the restrictions. They felt the restrictions should apply to all new drivers, not just teenage drivers. A few also felt that recent changes to the mandatory fines were an indication that money was a prime motivation.

"I just don't like the way they treat us. 'Oh, because you're a teenager, you don't know how to drive."'

"It's easier (for cops to target teens). Yeah, we want to go faster to get places and it's more fun. And it's not like you can sit outside of some business and know there is going to be 3,000 people going there. If you go to a school, it just kind of makes sense. But it doesn't really bother me because they got to make money somehow. "Why else would speeding tickets be so high? Why would they be passing laws so judges couldn't reduce tickets?"

However, these suspicions were not widespread and were primarily limited to teens in Portland. Most of the respondents felt that teens were more susceptible to the risks addressed by GDL than were adults.

"I think it should only apply to teens. Teenagers are stupid. We're immature and we do stupid things. And, collectively, they do 'stupider' things, and that's why we have these rules. Twenty-five year olds don't race and pile people in the car and crash."

"Good driving has to do with maturity and it's kind of hard to judge that and at what age it is."

"I was really a bad driver when I first started driving. I never thought about the 6-month rule because I never had anybody in my car. But if I did when I first started, there would have been some broken legs or something, because I do fool around a lot when I'm with people in the car."

Although participants felt there were some teens who did not need the extent of the restrictions, there were also some who did, and that protection for those who did require the restrictions was more important than the freedom of the teen drivers who did not require such restrictions. 
"There is a first time for everything and the first time could be crashing into a park filled with kids. I think there are a lot of responsible teenagers, but there are also a lot of irresponsible teenagers. And because you can't pick out all the bad, you just go ahead and educate them all. Sure some people have to do an extra bit of work, but it's all worth it."

"Driving alone is better than not driving at all."

Although most of the teens recognized the need for most of the restrictions applying to the first 6 months, most felt the second 6 months' restrictions were not justifiable. They felt that by that time, they would have gained the experience, skills, and maturity to not need the restrictions any more.

"I don't think the second 6 months should apply, because by the second 6 months, you're a good driver."

This attitude was an interesting counterpoint to the teens' own description of their overconfidence.

\section{Teens said that GDL empowered their parents.}

Even though most of the teens recognized the objectives of the GDL restrictions, they did not think their parents could have enforced them if they were not the law. They felt that without the law, some parents would not have recognized the need, and those who did would eventually cave in as their teens would wear them down.

"If my parents made this up, it would be like, 'No way!' But if it's something that the State came up with... it would be like, 'Yeah, I need to do that'..."

"I think mine (my parents) could encourage it, but I don't know how much power they would have over me."

"I think the rules actually give the parents a reason...'Oh! You're not allowed to legally, so no friends in the car for you for the first 6 months.' It's easier to enforce rules that exist."

\section{Much of the consternation toward GDL was because it was new.}

Some of the teenagers felt the GDL laws were unfair because many of their friends and family did not have to abide by such restrictions. Being the first, they felt like they were being picked on. Had the laws been in place longer, they would have expected and been more receptive to them. Most felt the restrictions will be easier to swallow in the future by other teenagers for whom the restrictions will have become the norm.

"You've waited 16 years to get your license, and then when you get there, it's sort of a letdown." 
"If we were younger and we knew about the 6-month rule, I think we would go along with it more when it came to that time."

\section{PERCEPTIONS OF IMPLEMENTATION AND ENFORCEMENT}

\section{Enforcement of GDL requirements was seen as lax.}

When teens went to get their licenses, the fact that the experience log was not checked or collected was an indication to some that the DMV was not taking enforcement of the GDL seriously. Compliance with the supervised practice was perceived to be low, and this requirement, overall, was not taken seriously.

"I think they should have this stuff required, mandatory. If you had to have this (the driver experience log) signed, confirmed. They just have this little check box that your parents had to do about your hours and stuff. They ought to make sure that it's enforced."

\section{Enforcement of GDL restrictions was perceived as weak and inconsistent.}

Although some municipalities were perceived to be more serious about enforcing GDL restrictions than others, the general perception was that the restrictions were not seriously enforced. Many of the teens indicated that even before they got their driver license, they did not expect serious enforcement by the police. Many of their friends had had encounters with police officers while in violation of GDL and were not cited. Some had even been told, by persons they considered to be knowledgeable authority figures, that the GDL restrictions were not seriously enforced.

"I was taking driver's education and they told me in driver's education, but they were like 'don't worry, they won't enforce it."'

Many of the teens had their own firsthand experience in which they had been stopped for primary violations and had not been cited for their violations of GDL. This reinforced the perception of lackadaisical enforcement, not only with the individual involved, but also with their friends as information like this spread rapidly among the teenagers.

The courts were also perceived to be soft on the enforcement. Teens who had been before the court for traffic violations bragged about how lenient the adjudication was in general and specifically how they were not punished at all for the GDL violations. They indicated that this not only dilutes the anticipated consequences for those involved, but also for the many friends to whom they brag.

"I've been to court three times, and they reduce the fine every time."

"I went to court. He just gave me a ticket for speeding. It was like 300 bucks. I went to court and just paid the fine. That was it. So he was pretty nice." 
"Everyone likes to think the cops in Beaverton are bigger [expletive deleted] than in Portland, but the courts are pretty laid back."

\section{Teens said that strict enforcement of GDL would result in better} compliance.

As a result of the perceived lack of enforcement, many teenage drivers did not feel they would be caught, be cited, or suffer consequences by law enforcement entities for the violation of GDL. However, the teenage drivers indicated their belief that more consistent and stricter enforcement of GDL by police would enhance their compliance. If they knew what the consequences were and that there was a good likelihood of being both caught and punished, they would abide by the laws.

"I'm sure if it were enforced, we would take it more seriously. In Pendleton, it is not really enforced that much, so no one really thinks about it."

"I think once I got pulled over, I drove more cautiously. It improved my driving a ton."

"We definitely talk about it a lot. So if I get pulled over and say they didn't do anything, then it makes my friends and younger people not have respect for the program. But if I did get a ticket, it would have more impact and at least scare people a little."

"I think it would be a lot more fair if everyone got a ticket. Because if I get pulled over and my buddy doesn't get a ticket and I do, I would be really [angry]."

"There needs to be a clear set of consequences."

Most of the teenagers said their compliance would be higher if there were consistent enforcement and zero tolerance.

\section{Parents were central to GDL enforcement.}

Most of the teenage respondents were more concerned about their parents catching them breaking the GDL laws than the law enforcement officers. For many, this was because they knew the consequences were guaranteed and would be severe.

"My parents really enforce it. That will get me in more trouble than the police."

"If they catch me, they take my car."

"People are more scared of their parents than the cops. It's more about hiding from your parents." 
The teens whose parents were most conscientious about enforcement and monitoring were those who were most likely to comply. There were some parents who were strict right from the beginning.

"I know a couple of people who don't have their licenses yet because their parents haven't signed the thing because they actually haven't driven the 50 hours yet."

\section{Pressure and practicality wore down compliance.}

Most of the parents and teens said they were much more conscientious about compliance in the beginning. However, as time passed and teens gained experience, both the parents and the teens tended to be less concerned about compliance. As the parents and teens felt more confident about the teens' capabilities, external pressures more easily wore both down. Both became more likely to trade off compliance for practicality and convenience. For example, the parents thought it was more practical and safer to carpool than caravan, especially when they thought their child had sufficient experience and/or "it just made sense." The teens said their parents got tired.

"My parents try to be strict about it, but after a while they just didn't care."

"They're getting much easier because I have to give my friend a ride to school..."

"My parents don't really enforce it. They did at first, because they didn't want me out there recklessly driving. After that, they didn't really enforce it. But, they don't want a bunch of people in my car..."

The teenagers were constantly pressured by peers to give them rides. As they gained confidence and realized they probably would not get caught, they gave in to the pressure and broke the rule that was the most difficult for them to uphold, the passenger restrictions.

"I try my hardest to keep them (the rules), but if somebody really needs a ride, I do it."

"Some of my friends were like, 'Why aren't you giving me a ride. It's right down the road. It's not like you are going to get caught.' Then after hearing that for a while you're like hey... alright."

\section{Driver Education was perceived to be useful, but could be more effective in making teenagers safer, more experienced drivers.}

Most of the teenagers took the course to lower their insurance costs and to reduce the number of hours of supervised instruction. As anticipated, most found driver education to be boring and "remedial," but felt there were direct benefits. In addition to the benefits enumerated earlier by the parents, the teens appreciated an objective third party perspective rather than "having mom or dad telling me what to do." They also felt they benefited from the hours on the road, the informational and sometimes graphic videos, and guest speakers such as police officers. 
"It was easier learning from a stranger, because I personally have a hard time driving with my parents."

"It obviously increases young drivers' awareness about the road and the rules and everything you need to know."

"The only reason I took driver's education was to pass the exam and to decrease my insurance."

"I didn't realize how much I had learned [from driver education] until I got on the road."

The administration of driver education had a big impact on its effectiveness. Lengthy, continuous classroom sessions appeared to be ineffective. Teenagers felt the need for more hours on the road to increase their driving experience. They felt shorter and more interactive classroom sessions would be more effective.

Some of the teens, especially in Pendleton and Grants Pass, disagreed about Driver Education being boring. Some indicated they not only learned a lot, but also actually had fun.

"It wasn't boring. I had fun in there, but I didn't learn so much until I got on the road."

Although some teens were aware of additional driving programs, only one teen had actually taken one, which simulated driving in poor weather conditions. He said he greatly benefited from it in terms of experience and a decrease in insurance.

\section{IMPACT OF GDL}

\section{Teens perceived GDL to have had a very positive impact on their safety.}

The teens felt GDL has been effective in enhancing their traffic safety in many of the ways indicated by the parents. Specifically, the teens believed that GDL (1) increased their awareness of and concern for traffic safety overall; (2) increased the amount of supervised training; (3) increased the involvement of parents in the instructional and monitoring process; (4) empowered the parents to maintain some level of control; (5) reduced distractions by limiting passengers, and thereby eliminating peer pressure to do "stupid things;" and (6) provided a reason for failing to give peers a ride.

Most of the teens admitted that even when they violated the GDL restrictions, the program made them drive more safely because they did not want to be stopped for a primary violation and also be cited for a GDL violation. The primary violation could be unintentional. However, with the GDL violations, one could not tell their parents they were unintentional. A GDL violation was not a mistake; it was disobedience. 
"I think people are a lot more aware of how they're driving and the rules that they need to be going by, even if they aren't."

"If you have kids in the car and you're breaking the law, you are going to be more careful."

Most teens felt GDL could have been even more effective if it were more consistently enforced by both law enforcement and parents, and if GDL, along with the consequences for GDL violations, had been aggressively publicized.

"I think it has impact, but not enough. For something to have a good impact, you need to have something happen if you break it. Like here, it's like a little slap on the hand, where in Henderson, it's probably a lot more well-known than here."

\section{THE PERSPECTIVE OF LAW ENFORCEMENT OFFICERS}

All six of the law enforcement officers who participated in the focus groups were male. Four were officers working for the Eugene Traffic Enforcement Department, and two were State troopers. All of the officers had tenures of between 6 and 27 years, ensuring that all had been enforcing traffic laws since before the GDL program began. The average tenure was approximately 16 years. Five of the officers were Caucasian, and one was African American.

\section{PERCEPTIONS OF TEENAGE DRIVERS BY LAW ENFORCEMENT}

\section{$\underline{\text { Teenager overconfidence was a major concern to law enforcement. }}$}

Law enforcement officers, like the parents, were concerned about the lack of experience of new teenage drivers. The officers said that inexperience was initially somewhat tempered by their fear of making mistakes. The teens tended to be very cautious in the beginning.

The police officers observed that after about 6 months to a year, teenage drivers tend to feel more comfortable and confident about their capabilities and skills. It was at that point many of the police officers thought the teens were vulnerable as they began to take more risks.

"After 6 months of driving there is a certain amount of confidence that teens acquire of this new skill and sometimes it's an inflated sense of confidence."

"That first year they are very cautious. Then after that they get comfortable and careless."

"Most of the drivers are well behaved, but it is just those few, and I think those that make mistakes really just don't know. It's that overconfidence, like following too close, exceeding the speed limit. A lot of them I can actually tell really that they don't think they are doing anything wrong. It's lack of experience and training." 


\section{The Eugene area was perceived to have lower compliance.}

The police officers considered Eugene to be different from the rest of Oregon. They felt the parents in Eugene were more likely to place a higher priority on personal freedom than compliance with GDL restrictions. Thus, they expected the teens in Eugene to push the envelope more than teens in other cities in Oregon, and they did not expect as much support from the parents.

"I think the parents here want their kids to have too much freedom."

"I think in other parts of the country, there is more of a fear of punishment. Here in Oregon (especially Eugene), young drivers question authority just to see what they can get away with."

The officers felt many of the teenagers were not properly prepared to drive.

The law enforcement officers felt that the level of driver training provided to teenagers was inconsistent and inadequate. They thought, however, that driver education courses should be mandatory because parents were not qualified to adequately teach their kids how to drive. They felt in some cases, the parents did not know how to drive themselves, much less how to teach. Further, they felt DMV testing was so basic that the inadequacies of the teenager would go undetected. Thus, some of the officers felt that many teenagers who passed the DMV test were grossly unprepared to drive in real world situations.

"In a lot of cases, you have parents teaching kids to drive, when they never learned to drive themselves. Driver's education should be mandatory and reinforced [the courses updated] every 3 years or so."

"They [DMV] test people on frivolous stuff. They need to start testing on real world, everyday, common sense stuff for driving and handling a vehicle."

They felt teens needed to be better prepared to recognize danger signs and anticipate potential problems, and how to react to problems.

\section{AWARENESS AND PERCEPTIONS OF GDL BY LAW ENFORCEMENT}

\section{The officers considered GDL to be a good law that had impact.}

The officers felt GDL has the potential to save the lives of teenage drivers by eliminating distractions and peer pressure, and gradually increasing freedom and responsibility. Many of the police officers said that the statistics showed that GDL was working.

"I think it's a good law and has the potential to save lives." 


\section{Many of the officers felt GDL laws were more complicated than necessary.}

The officers felt "semi-well-versed" on the GDL laws. However, as a result of there being one set of restrictions for the first 6 months, and another set for the second 6 months, the officers had to calculate one time frame for one set, and another timeframe for the other. To make sure they did not get confused, many of the officers felt the need to keep a copy of the restrictions with them to ensure accurate execution of the laws.

"I got a copy of it in my ticket book. When I stop them, I check it."

\section{Police officers said they were very serious about enforcement of GDL.}

Although there appeared to be a slight difference in tolerance of GDL violations, most of the officers indicated they cut very little slack. They insisted that they ticketed almost everyone they encountered who was in violation of the GDL laws. The slight distinction was that the traffic officers stated they granted zero tolerance, while the State troopers ticketed about $90 \%$ of the violators.

"I'm strict down to the board. I feel like if I pull over a car full of kids, give them a $\$ 240$ ticket, make the other kids walk, that gets around. Perhaps that might stop some other kids from doing it."

"Every now and then you get a kid in the gray area. So, I use it as a P.R. thing. I educate them and let them go. ...Kids are brought up to think we are cops all the time (bad), and that shows them that we do care. Parents use us as disciplinarians. We are not. The parents are."

These officers said they did not enforce this law with enthusiasm just because it was the law. They were strict with this law because they felt they were doing something for the kids, not to them. They were not out to punish the kids. They felt they were saving their lives. These officers wished the GDL violations were subject to primary enforcement, which would have made enforcement easier.

\section{Law enforcement officers said that teens did not appear to be aware of the consequences of GDL violations.}

The officers felt GDL compliance would be higher if the teens were more aware of the consequences. Most of the teens they encountered were very unaware of the consequences of the GDL violations they committed.

"Most times they are surprised at the consequences. The reality doesn't hit them until it actually happens to them. They have this mentality, 'Oh, it won't happen to me."

This appeared to be consistent with what the teenagers had said about the positive impact getting busted had on their concern for safety and compliance. 


\section{Law enforcement officers perceived the judiciary to be weak relative to GDL.}

Many of the police officers felt the courts sent the wrong messages to teenage drivers by reducing the consequences of violating the GDL restrictions. Some also felt the actions of the courts frustrated law enforcement officers. It gave them the perception that the courts were undermining the police officers.

"When I pull over kids in violation of GDL, they are so honest I don't know if they are that dumb or if DMV is not getting it (the information) to them. There should be more strict punishment. I give them a ticket for $\$ 235$, well $\$ 240$ now, and then they go to court, get it reduced, and they go right back out again."

"We are teaching our kids that there are no concrete consequences. There is always a loophole. If you can get to the right person, you can get away with it...too worried about rights, not responsibility."

Even though police officers felt the impact of reducing the consequences was counterproductive, some officers felt that all was not lost.

"I don't think even having the ticket reduced is that bad, because now you have gotten the parent in there. They go to court. They talk about this $\$ 240$ ticket. Insurance goes up. They now know the consequences."

\section{Officers said that curfew and passenger restrictions were most frequently violated.}

The restrictions most frequently violated were the passenger restrictions and the curfew during the first 6 months. Most of the officers felt that even the parents with the best of intentions got worn down by their teens. This observation was consistent with those of the parents and the teenagers.

\section{Officers were very receptive to "the sticker idea".}

The police officers were very supportive of a suggestion to place a highly visible sticker on vehicles driven by teenage drivers restricted by GDL. These stickers would not only highlight that there was a high probability that a teenager driving this vehicle was restricted, but also indicate that the owner/parent encouraged the monitoring and enforcement of the restrictions. Thus, if a police officer saw a car with the sticker driven by a teenager in violation of the restrictions, he knew he had the blessings of the owner/parent to encounter this vehicle.

"If they had a bright orange sticker on their car saying '6-month driver', that would be great!"

The officers also thought it would be a good idea to extend the 6-month passenger restriction to a year. This might help counter some of the risk resulting from the overconfidence they believe teens experience between 6 months to a year. 


\section{THE PERSPECTIVE OF DMV DRIVING TEST ADMINISTRATORS}

Ten DMV driving test administrators participated in the focus group. Four of these participants were male and 6 were female. Their tenure ranged from 6 to 28 years, with an average tenure of slightly over 10 years. This ensured that all participants were familiar with teen drivers both before and after enactment of the GDL program. Seven of these respondents were Caucasian, two were Hispanic, and one was AfricanAmerican.

Except where noted, the opinions and perceptions of these DMV employees were very similar to that of the other respondents in this research. Following are additional insights from the perspective of employees who test the teenage drivers:

\section{The DMV road test examiners highly recommended Driver Education courses.}

DMV driving test administrators indicated they could immediately tell which candidates had been taught by professionals versus by parents. They said that those taught by professionals had better mechanics, independently made better decisions, paid attention to details, had fewer bad habits, and were generally much better prepared to be safe drivers. The candidates trained by their parents learned the bad habits of their parents. They were less likely to be taught details like checking the brakes, mirrors, and blind spots.

\footnotetext{
"As soon as they get in the car and go to the end of the driveway, I can tell you who has had schooling and who has not."
}

"Those who have not had driver's ed pick up bad habits of parents and don't pay attention to detail."

"They will ask for instruction because they are used to asking their parents. Like making a right or left turn, they will say, 'Should I get over?' because they are used to asking their parents."

Although the DMV employees indicated that they could immediately detect which candidates had or had not been taught professionally, they could not tell which schools had trained them. They had not detected any noticeable differences between the schools.

Many felt the cutback on driver education in the public school systems had forced parents to teach their kids how to drive. They felt that the difference in the preparedness of the candidates was noticeable.

\section{Driving test examiners said the 6-month instruction permit had a very positive} impact.

Of all of the benefits of GDL, the most obvious to these DMV employees were those resulting from the requirement that the candidate had their instructional permit for at least 6 months. They felt the candidates, whether they were parent or professionally trained, appeared to have had more on-the-road experience and were better prepared 
to take the driving test. They were also more aware of aspects of safe driving. They felt this was a major benefit.

"The 6-month rule of having a permit has been a very effective rule because prior to that, you could only have it for a day prior, have no experience driving, and then get your license."

\section{Road test examiners wished for more emphasis on the driver experience} logs.

Maintaining the driver experience log was important even if the candidates inflated the time recorded. If nothing else, it made them more aware of how much time was actually expected to be invested toward becoming a safe driver.

"It would really show them that to accumulate experience behind the wheel, it takes a lot more time than they think."

\section{Examiners indicated that the DMV did not appear to be taking advantage of the available resources.}

In some instances, the DMV personnel did not appear to be aware of resources available to assist teenage drivers. Specific examples include their Web site and the Tuning Up manual. Only one of the $10 \mathrm{DMV}$ employees in the focus group was aware of the organization's Web site. Thus, they were not aware of the availability of the practice test, driver experience logs, and other resources they could have recommended to candidates.

Some of the road test examiners said that some DMV sites were not handing out the Tuning Up manual to candidates because of alleged shortages. Others said that there were manuals available, but they were not easily accessible to employees.

\section{Some personnel felt DMV needs to be more stringent.}

Some examiners felt DMV officials were too concerned about keeping the public happy and not making waves, and not serious enough about maintaining higher safety standards. To some extent, the examiners felt undermined by a system that they felt placed too much emphasis on customer service and conflict avoidance.

"My biggest complaint is when my integrity is being challenged. When a kid doesn't pass the exam and the parents come to complain to a supervisor as to why his kid doesn't have his license, they are basically saying I can't do my job. And now you have this thing again where the parent is justifying the child's behavior."

"With DMV, there is always a loophole, because we are customer friendly." 
Many felt the DMV was too quick to compromise and shelter the teens from consequences.

\section{Some examiners felt the enforcement of GDL was inconsistent if not selective.}

Some examiners felt the enforcement of GDL was not consistent even within the area of Portland. Some DMV employees hinted that although there may be some justification for the varying degree of enforcement, it might be another example of enforcement being compromised to avoid conflict.

\section{Examiners believed that parents were not carrying their load relative to GDL.}

DMV personnel probably had more interaction with the parents of teenage drivers than most of the other respondents interviewed other than the teens themselves. They observed that most parents did not know the details of GDL, and thus, were not prepared to enforce the laws. Further, they believed that the parents were not inclined to enforce the laws because they were too concerned with appeasing their teens.

They said that because the GDL restrictions were subject only to secondary enforcement, law enforcement was at a disadvantage. As a result, DMV personnel felt the parents were the most important entity affecting the enforcement and impact of the GDL program.

\section{DMV examiners said the GDL program should be simplified.}

DMV personnel suggested that the "6-Month" rule be changed such that no teens under age 18 be allowed to have passengers under age 20 who are not immediate family members. This would not only simplify the law for enforcement purposes, but also enhance safety by increasing the level of maturity at which they will be exposed to increased peer pressure and distractions.

"Make the law a blanket law for the 6-month rule. No passengers between the ages of 16 and 17 . That would make it easier for law enforcement to do their jobs."

DMV personnel also suggested making GDL violations primary to make enforcement more effective. 


\section{THE PERSPECTIVE OF DRIVING INSTRUCTORS}

Ten driving instructors participated in the focus group. Eight were male and two were female. Four worked for the public school system, and six worked for private companies. Their tenure ranged from 6 to 36 years, with an average of almost 17 years.

Except where noted, the opinions and perceptions of the driving instructors of teenage drivers; their parental involvement; and the implementation, enforcement, and impact of the GDL program were very similar to that of the other respondents in this research. Following are additional insights from the perspective of professional instructors who teach the teenage drivers:

The GDL program was very highly regarded by the driving instructors.

Although the instructors felt GDL has the potential to have even greater impact, they were very pleased with what has been achieved to date. They felt stricter enforcement by DMV, parents, and police could obtain even better results.

The instructors perceived there to be a discrepancy between their goals and the goals of DMV. The instructors felt that they wanted to instill higher standards than DMV was willing to require. Congruent with the comments of the DMV employees, the instructors said that DMV was more customer service oriented than safety oriented.

\section{Driving instructors said that the requirements for traffic safety courses were} inadequate.

The traffic safety instructors felt their industry was not sufficiently regulated. They felt there was a big difference between the instruction received at the different schools; there should be some level of standardization. They also felt there should be a rigorous certification process to qualify the schools and/or instructors.

\section{The instructors suggested that the submission of the driving experience log be required.}

The driving instructors strongly supported the practice requirement of the GDL program. However, the DMV does not require the submission of the driving experience log for licensure. All the driving instructors felt that the submission of the log should be a requirement.

Some of the instructors felt so strongly that the log, and the practice it represented, should be taken more seriously, that they lied to their students and told them that the log will be collected and checked by the DMV.

"I tell my students to keep the log. I lie to them and say that the DMV will check the log." 


\section{The instructors endorsed the "sticker suggestion."}

One of the instructors, originally from Europe, suggested that Oregon could benefit from using an approach similar to that used in parts of Europe to identify "rookie" drivers. There they placed a big "R" sticker on vehicles driven by new drivers to let the public beware and maybe cut them some slack. His suggestion was that a similar approach might make it easier for police officers to recognize restricted drivers and better enforce the GDL restrictions. The suggestion was very well received by this group of instructors and by most respondents in other groups.

\section{THE PERSPECTIVE OF HIGH SCHOOL ADMINISTRATORS}

Five respondents participated in the focus group composed of high school administrators. Three of the respondents were female and two were male. Their tenure as high school administrators ranged from 3 to 22 years. Four participants were counselors, and one was a driving instructor.

Except where noted, the opinions and perceptions of these high school administrators of teenage drivers, parental involvement, and the implementation, enforcement, and impact of the GDL Program were very similar to that of the other respondents in this research. Following are additional insights from the perspective of these high school administrators:

The high school administrators were no more knowledgeable than the general public regarding GDL.

With the exception of the driving instructor, these respondents were probably the least knowledgeable relative to GDL. Most of these respondents had children, but did not have experience with the GDL program, as their children were old enough to have been licensed prior to the program's implementation.

\section{High school administrators supported strong enforcement of the GDL program.}

Like many participants in other groups, the high school administrators were unaware that GDL violations were not primary offenses. They expressed frustration with the enforcement of GDL provisions. They felt that if the police were serious about enforcing GDL, they would stake out the high schools at lunch time to discourage teens piling into cars to go off-site for lunch. The high school administrators strongly supported primary enforcement of the GDL program.

The administrators felt budget cuts to driver education have hurt teenage driver safety.

The administrators felt the budget cuts have reduced the ability of the schools to provide driver education to its students. They felt this has the most impact on lower income families who can not afford to pay the rates of commercial programs.

"Less advantaged teens don't have the parental or monetary resources to get the training they need to be better drivers." 
The high school administrators felt that driver education programs were very important for teen driver safety, and that lower income teens were particularly endangered by the lack of formal classes.

\section{Some felt high schools should have more impact on granting teenagers their driver's license.}

Some of the respondents felt that there was a correlation between good grades, good behavior, responsibility, maturity, and safe driving. They felt this was why some insurance companies extended discount rates to teenagers with good grades. Assuming this correlation does exist, the respondents felt the high school administrators could be a good source of information regarding a teenager's readiness to drive. Some felt the high schools should have more input and impact on the issuance of a driver's license to teenagers.

"Good grades get a higher discount because of the attitude associated with it. They figure if the kids show responsibility by getting good grades, it's more of a factor than driver's education."

"(the high schools should be) able to call DMV and put a hold on their permit if behavioral issues are being seen."

The high school administrators felt that conduct in school was a good predictor of driver safety, and felt that the DMV should take that into account when issuing licenses.

\section{THE PERSPECTIVE OF JUDGES}

Two judges who routinely worked with traffic cases agreed to an interview. Except where noted, the judges' opinions and perceptions regarding teenage drivers were very similar to that of the other respondents in this research. The two judges seemed to have different levels of interest in Oregon's GDL program. Judge A presided in urban Portland, and Judge B presided in the more suburban Eugene, Oregon. Following are additional insights from the perspective of judges who adjudicate violations committed by the teenage drivers:

\section{The judges disagreed on the level of GDL compliance.}

Judge $A$ indicated that because he does not adjudicate very many cases of teenagers who violated the GDL restrictions, this indicated to him that teens were complying with the restrictions.

Judge B said that the incidence of violations of GDL was not as high as it should be because the Sheriff's officers do not cite many of the violations they encounter. This judge indicated that police officers were stopping teenagers for other violations and only citing those violations and not the GDL laws which were also being violated.

"My experience with it is, it (the level of enforcement) is not enough. They cite the teens for one violation and not the other...They should be cited for both."

"They need to acknowledge that a rule has been violated." 
Although enforcement of the GDL restrictions were somewhat stifled by being a secondary offense, Judge $B$ felt the Sheriff's officers were not enforcing the GDL restrictions to the extent that was feasible. In contrast, Judge A thought there was a high level of enforcement.

The judges disagreed on the value of strict enforcement among teenage drivers.

The recent legislation in Oregon restricting the power of the judges to reduce fines was a defining point of difference between the two judges. Judge A thought the legislation was implemented for the express purpose of raising revenue, and that it was at the expense of flexibility to order alternative remedies for teenage offenders. He felt some of the alternative remedies, corrective driving classes and programs, were more beneficial than dealing out the prescribed consequence.

"The legislature killed them (the alternative remedies). In the last session, in the effort to raise more money, they took away from the judges the discretion to reduce fines for any reason. The trade-off was when we sent kids (to corrective driving and other programs)..."

However, Judge B saw the legislation in a different light. Judge B felt the legislation was necessary because judges were being too lenient with traffic adjudications. Judge $B$ did not believe the corrective driving programs were as effective as making the perpetrator face the consequences.

“...I don't send them to those classes (corrective driving). Due to my experience, they are ineffective. You need to learn from your mistakes, otherwise, you will repeat them."

Judge $B$ thought there were too many judges who were too lenient on traffic violations among teenagers in general, and specifically with GDL violations. This judge felt neither the police officers nor the judges were adequately enforcing the GDL laws in the jurisdiction of this judge.

\section{One judge felt that enforcement of GDL was very important.}

The enforcement of GDL was important to Judge B not only for safety reasons, but also because of the potentially wider-ranging impact. Judge $B$ felt that it was important that the teens learn they had a responsibility to follow the rules, especially when the rules had an impact on the greater society. They must learn that they had to face the consequences of their actions. Judge B felt that GDL violations represented the most likely opportunity to teach this lesson to teens who are on the borderline.

Judge $B$ said that GDL violations frequently represented the first time that otherwise law-abiding teens were brought before a judge. Judge $B$ felt it was important that these kids were made to realize that the law was the law and that if broken, consequences would be forthcoming. Judge $B$ felt that failing to deal immediately with disrespect for the law was doing an injustice to both the individual and to society. 
"A deal is a deal and a contract is a contract... when you say you are going to do something, you have to go through with that...that's a maturity aspect that a lot of adults don't get."

\section{Peer pressure was an important factor for teenagers.}

Judge $B$ indicated that most of the time when teenagers were caught violating laws, they were with other teenagers.

"All of the trouble teens get into is when they are around other teens...I very seldom see someone who is violating the provisional driving restrictions other than going out to watch speed racing with buddies, or picking up their buddies to go somewhere where someone is providing them alcohol...Companions with teenagers seem to be the problem with teenage driving."

"The fatalities we have had in [our] county have been multiple, two teenagers, three teenagers, in the car. We have kids jumping gullies and it's never just one teen in the car."

Experience in dealing with teenage drivers from the bench made Judge $B$ very sensitive to the benefits of the "6-month rule" restricting passengers. Judge B considered it to be one of the most important aspects of GDL. Judge B said that from professional experience, teenagers were more prone to show-off and experiment with their buddies than adults would be, and that immaturity justified the need to protect the teens from themselves.

"Teens are more prone to do things experimentally than adults would do. Like you wouldn't see an adult doing donuts in a parking lot."

\section{Parents were a major cause of compliance.}

As important as Judge $B$ thought judges and law enforcement officers were to the implementation and enforcement of GDL, the judge acknowledged the importance and responsibility of the parent. The judge felt the parents who were conscientious about raising their kids were also conscientious about enforcing GDL; compliance was a reflection and function of the parenting.

"I think some parents do (conscientiously try to enforce GDL), and some parents don't. I think the ones that don't, also don't know who their kids are hanging out with or what time their kids are getting in."

\section{More education was necessary among the ranks.}

Judge B was extremely passionate about the importance of GDL and the importance of implementing and enforcing it to the maximum. The judge felt it was extremely important to stress the importance of enforcing this law (not only for traffic purposes but also to encourage a law-abiding population) more at conferences and meetings of judges and law enforcement officers. 


\section{APPENDIX F}

\section{Oregon Statutes Related to Youth Driver Licensing (as of 2005)}

807.065 Additional eligibility requirements for persons under 18 years of age; provisional driver license. (1) The Department of Transportation may not issue a driver license to a person who is under 18 years of age unless the person:

(a) Complies with the requirements of ORS 807.040 and 807.066;

(b) Passes an examination designed to test the person's knowledge and understanding of safe driving practices, in addition to any examination required under ORS 807.070;

(c) Has had, for at least six months prior to application for the license, an instruction driver permit issued under ORS 807.280 or the equivalent of an instruction driver permit issued by another state of the United States or by the District of Columbia;

(d) Certifies to the department that the person has had at least 50 hours of driving experience during which the person was supervised by a person at least 21 years of age who has had a valid driver license for at least three years; and

(e) Completes a traffic safety education course that meets standards developed by the department under ORS 802.345. In lieu of completion of a traffic safety education course, a person may certify to the department that the person has had at least 50 hours of driving experience during which the person was supervised by a person at least 21 years of age who has had a valid driver license for at least three years, in addition to the 50 hours required by paragraph (d) of this subsection.

(2) A person under 18 years of age need not comply with the requirements of subsection (1)(c), (d) and (e) of this section if the person has been issued a driver license by another state and surrenders that license in order to get an Oregon license.

(3) If the person takes but does not pass a test that consists of an actual demonstration of driving ability under ORS 807.070, the department may not allow the person to perform the demonstration again until the person has had an instruction permit issued pursuant to ORS 807.280 for a period of not less than one month.

(4) A driver license issued pursuant to this section shall be a provisional driver license.

(5) The department shall prominently identify each driver license issued pursuant to this section as a provisional driver license. [1989 c.715 §2; 1993 c.751 §37; 1999 c.328 §1; 1999 c.789 §5; 2001 c. $176 \S 4 ; 2003$ c. $92 \S 1]$

807.066 School requirements for persons under 18 years of age. The Department of Transportation shall not issue driving privileges to a person who is under 18 years of age unless the person:

(1) Has graduated from high school and provides the department with proof of graduation satisfactory to the department;

(2) Has received a General Educational Development (GED) certificate from a community college and provides the department with proof of the certificate satisfactory to the department;

(3) Provides the department with a form provided by the department and signed by the principal, or the designee of the principal, of the secondary school attended by the person that declares that the person is enrolled in a secondary school of this state or any other state;

(4) Provides the department with a form provided by the department and signed by the authorized representative of the community college attended by the person that declares that the person is making satisfactory progress toward a General Educational Development (GED) certificate;

(5) Provides the department with a form provided by the department and signed by the 
authorized representative of the community college attended by the person that declares that the person is making satisfactory progress toward a high school diploma;

(6) Provides the department with a form provided by the department and signed by the authorized representative of the education service district or school district having jurisdiction over the area of the person's residence that declares that the person is being taught by a private teacher or parent in compliance with ORS 339.035;

(7) Provides the department with documentation satisfactory to the department that indicates that the person is exempted from school attendance requirements due to circumstances beyond the control of the person; or

(8) Provides the department with documentation satisfactory to the department that the person is exempt under ORS 339.030 (2) from the requirement to attend school. [1999 c.789 §2]

807.122 Restrictions on operation with provisional driver license. (1) The Department of Transportation shall place the following restrictions on a provisional driver license issued under ORS 807.065:

(a) Except as provided in subsections (2) and (3) of this section, for the first six months after issuance of the license, the holder of the license may not operate a motor vehicle that is carrying a passenger under 20 years of age who is not a member of the holder's immediate family. For the second six months, the holder of the license may not operate a motor vehicle that is carrying more than three passengers who are under 20 years of age and who are not members of the holder's immediate family.

(b) For the first year after issuance of the license, the holder of the license may not operate a motor vehicle between the hours of 12 midnight and 5 a.m. except when:

(A) The holder is driving between the holder's home and place of employment;

(B) The holder is driving between the holder's home and a school event for which no other transportation is available;

(C) The holder is driving for employment purposes; or

(D) The holder is accompanied by a licensed driver who is at least 25 years of age.

(2) Subsection (1)(a) of this section does not apply to the holder of a provisional driver license who:

(a) Is employed by a farmer, rancher or orchardist;

(b) Is operating, solely for employment purposes, a motor vehicle that is owned by the employer and for which financial responsibility requirements of ORS 806.060 have been met;

(c) Is transporting passengers who are employed by the same employer as the driver and who are being transported solely for employment purposes;

(d) Is not transporting more passengers than the number of available seat belts; and

(e) Has in the vehicle a written statement signed by the employer certifying that the driver is employed by the employer and that there is no other option for transporting the employees.

(3) Subsection (1)(a) of this section does not apply to the holder of a provisional driver license who is 16 or 17 years of age and who is operating a motor vehicle with:

(a) An instructor in the vehicle as part of a certified traffic safety education course; or

(b) A person in the vehicle who has valid driving privileges and who is the parent or stepparent of the holder of the license. 1999 c.328 §3; 2001 c.410 §6; 2001 c.608 §1; 2003 c.14 $\S 475 ; 2003$ c. $767 \S 1]$ 
809.260 Denial of driving privileges for convicted juvenile. (1) Whenever a person who is 17 years of age or younger, but not younger than 13 years of age, is convicted of any offense described in this subsection or determined by a juvenile court to have committed one of the described offenses, the court in which the person is convicted shall prepare and send to the Department of Transportation, within 24 hours of the conviction or determination, an order of denial of driving privileges for the person so convicted. This section applies to ORS 166.370 and to any offense involving the delivery, manufacture or possession of controlled substances or the possession, use or abuse of alcohol.

(2) If a court has issued an order of denial of driving privileges under this section, the court, upon petition of the person, may review the order and may withdraw the order at any time the court deems appropriate except as provided in the following:

(a) A court may not withdraw an order for a period of 90 days following the issuance of the order if it is the first such order issued with respect to the person.

(b) A court may not withdraw an order for a period of one year following the issuance of the order if it is the second or subsequent such order issued with respect to the person.

(c) Notwithstanding paragraph (a) of this subsection, a court may not withdraw an order for a period of six months if the order is based on a determination or conviction involving controlled substances.

(3) Upon receipt of an order under this section, the department shall take action as directed under ORS 809.280. [1985 c.16 §206; 1991 c.835 §3; 1993 c.625 §6; 1999 c.1051 §88]

809.480 Driver improvement programs; rules; purpose; suspension; fee. (1) The Department of Transportation may establish, by administrative rule, programs for the improvement of the driving behavior of persons who drive in this state. The programs shall have as their goal the reduction of traffic convictions and especially accidents. The programs may include, but need not be limited to, letters, interviews and classroom instruction.

(2) The department may establish programs for persons who are under 18 years of age that are different from programs for adults. Differences may include, but need not be limited to, differences in criteria for entry into a program and differences in content.

(3) The department, under a program authorized by this section, may suspend driving privileges based on any of the following:

(a) A person's record of convictions or accidents.

(b) A person's failure or refusal to complete or comply with a requirement of a program established by the department under this section.

(4) The department may charge a reasonable fee to participants in a driver improvement program to cover costs of administration.

(5) Any suspension that the department stays under a driver improvement program in this section shall continue for the full term of the suspension if a person fails to complete the program. For purposes of reinstating driving privileges, the stay of a suspension under this section may not be used to determine the length of time a person's driving privileges have been suspended if the person does not successfully complete the program.

(6) A person is entitled to administrative review of a suspension imposed under this section if based on a conviction. [1983 c.338 §368; 1985 c.16 §190; 1991 c.702 §12; 2001 c.176 §2; 2003 c. $402 \S 34]$ 


\section{This is the relevant administrative rule: $735-072-0023$}

\section{Provisional Driver Improvement Program}

(1) Drivers who have reached 14 years of age but who have not yet reached 18 years of age are subject to the Provisional Driver Improvement Program. The Provisional Driver Improvement Program is designed to have a quick and immediate impact on young drivers who are convicted of traffic offenses or involved in preventable accidents. This rule applies to driver improvement violations and preventable accidents that occur when the driver is 14, 15, 16 or 17 years of age, and whose record review date occurs before the person has reached 18 years of age.

(2) On the record review date, DMV will review the person's driving record and restrict the driving privileges of any provisional driver who has:

(a) Two driver improvement violations; or

(b) Two preventable accidents; or

(c) A combination of one driver improvement violation and one preventable accident.

(3) The following apply to provisional restrictions:

(a) DMV will restrict the license or instruction permit of a provisional driver to drive only to and from or for employment, with no passengers except their parent, stepparent or guardian;

(b) DMV will impose the restriction for a period of 90 days regardless of whether the driver becomes 18 years of age during the restriction period. DMV will notify the provisional driver by letter that the restriction will begin five days from the date of the letter. During the 90-day restriction period, the provisional driver must carry the restriction letter at all times while the person is driving a motor vehicle;

(c) A person who violates the Provisional Driver Improvement Program restriction, can be cited under ORS 807.010, operating in violation of license restrictions, which is a Class B traffic violation; and

(d) DMV will delay imposition of a restriction to driving privileges and place a pending restriction code on the person's driving record of any provisional driver:

(A) Whose driving privileges are cancelled, suspended or revoked until DMV grants driving privileges or fully reinstates driving privileges; or

(B) Who has not been granted driving privileges until DMV grants driving privileges in the form of a provisional driver license or instruction permit;

(C) Unless that provisional driver gets another driver improvement violation or preventable accident while under the age of 18. In that case, DMV will suspend the driving privileges or right to apply for driving privileges as set forth in subsection (6) of this rule. This suspension will supercede the pending restriction and the pending restriction code will be removed from the person's driving record. 
(4) DMV may offer an interview with a DMV employee to a provisional driver whose driving privileges are restricted. The purpose of the interview is to re-evaluate the person's driving privilege based on a review of performance since the date of the incident that caused the restriction. Actions DMV may take after re-evaluating the person's performance include but are not limited to:

(a) Lessening or increasing the severity or duration of the restriction;

(b) Requiring the completion, within 90 days of the interview, of a driver improvement course;

(c) Requiring the person to complete and pass all or some of DMV's driver license examinations (knowledge test, vision test and drive test) within 60 days from the date of the interview directing the person to complete the examination and to notify DMV of the completion. If the person fails any licensing examination, DMV will suspend the person's driving privileges or right to apply for driving privileges under ORS 809.419.

(5) DMV will suspend driving privileges or the right to apply for driving privileges if a provisional driver has an interview with a DMV employee and does not comply with any requirement imposed by DMV. If the requirement is to complete and pass all or some of DMV's driver license examinations, the suspension will continue until the provisional driver completes and passes all required examinations. For all other requirements imposed by DMV, the suspension will continue until the provisional driver fully complies with the requirement or for five years from the effective date of the suspension, whichever is earlier.

(6) DMV will suspend for six months the driving privileges or right to apply for driving privileges of any provisional driver who has:

(a) Three driver improvement violations;

(b) Three preventable accidents; or

(c) A combination of driver improvement violations and preventable accidents that total three.

(7) For each subsequent driver improvement violation or preventable accident, DMV will suspend for six months the driving privileges or right to apply for driving privileges of a provisional driver, regardless of a previous or current Driver Improvement Program suspension(s), who has:

(a) Four or more driver improvement violations;

(b) Four or more preventable accidents; or

(c) A combination of driver improvement violations and preventable accidents that total four or more.

(8) DMV will suspend for one year the driving privileges or the right to apply for driving privileges of a provisional driver convicted of any offense listed in ORS 809.600(1). This suspension is for Provisional Driver Improvement Program purposes and is in addition to any suspension or revocation imposed because of the specific conviction. 
(9) The suspension period for those suspensions imposed under sections (6), (7) and (8) of this rule will be imposed for the full suspension period, regardless of whether the provisional driver becomes 18 years of age during the suspension period. A suspension of driving privileges or the right to apply for driving privileges under this rule shall run concurrently with any other suspension, revocation, or cancellation in effect at the time the suspension begins. This section is applicable to suspensions imposed on or after June 30, 2002.

Stat. Auth.: ORS 184.616, 184.619 \& 809.480

Stats. Implemented: ORS 809.480

Hist.: DMV 29-2001(Temp), f. 12-14-01 cert. ef. 1-1-02 thru 6-29-02; DMV 12-2002, f. 6-2402, cert. ef. 6-30-02; DMV 7-2003(Temp), f. 5-14-03, cert. ef. 5-15-03 thru 11-10-03; DMV 132003, f. \& cert. ef. 9-22-03; DMV 1

\section{This is the statute that limits the authority of a police officer to enforce nighttime and passenger restrictions detailed in ORS 807.122:}

810.410 Arrest and citation. (1) A police officer may arrest or issue a citation to a person for a traffic crime at any place within or outside the jurisdictional authority of the governmental unit by which the police officer is authorized to act as provided by ORS 133.235 and 133.310.

(2) A police officer may issue a citation to a person for a traffic violation at any place within or outside the jurisdictional authority of the governmental unit by which the police officer is authorized to act:

(a) When the traffic violation is committed in the police officer's presence; or

(b) When the police officer has probable cause to believe an offense has occurred based on a description of the vehicle or other information received from a police officer who observed the traffic violation.

(3) A police officer:

(a) Shall not arrest a person for a traffic violation.

(b) May stop and detain a person for a traffic violation for the purposes of investigation reasonably related to the traffic violation, identification and issuance of citation.

(c) May make an inquiry into circumstances arising during the course of a detention and investigation under paragraph (b) of this subsection that give rise to a reasonable suspicion of criminal activity.

(d) May make an inquiry to ensure the safety of the officer, the person stopped or other persons present, including an inquiry regarding the presence of weapons.

(e) May request consent to search in relation to the circumstances referred to in paragraph (c) of this subsection or to search for items of evidence otherwise subject to search or seizure under ORS 133.535.

(f) May use the degree of force reasonably necessary to make the stop and ensure the safety of the peace officer, the person stopped or other persons present.

(g) May make an arrest of a person as authorized by ORS 133.310 (2) if the person is stopped and detained pursuant to the authority of this section.

(4) When a police officer at the scene of a traffic accident has reasonable grounds, based upon the police officer's personal investigation, to believe that a person involved in the accident has committed a traffic offense in connection with the accident, the police officer may issue to the person a citation for that offense. The authority under this subsection is in addition to any other authority to issue a citation for a traffic offense. $[1983$ c.338 $\$ 400 ; 1985$ c. $16 \S 212 ; 1991$ c.720 §1; 1995 c.308 §1; 1997 c.682 §1; 1997 c.866 §\$4,5; 1999 c. $1051 \S 89]$ 


DOT HS 810830

September 2007

2

U.S. Department of Transportation

National Highway Traffic Safety

Administration 